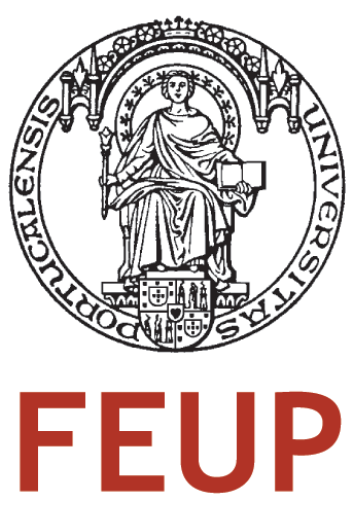

\title{
ANT+ Medical Health Kit for Older Adults
}

\author{
Ricardo Belchior Teles Lagido
}

Master in Informatics and Computing Engineering

Supervisor: António Miguel Pontes Pimenta Monteiro (Ph.D)

Second Supervisor: Diogo Dias Júnior (M.Sc)

$18^{\text {th }}$ June, 2012 



\title{
ANT+ Medical Health Kit for Older Adults
}

\author{
Ricardo Belchior Teles Lagido
}

Master in Informatics and Computing Engineering

Approved in oral examination by the committee:

Chair: Rui Carlos Camacho de Sousa Ferreira da Silva (Ph.D)

External Examiner: José Manuel Matos Moreira (Ph.D)

Supervisor: António Miguel Pontes Pimenta Monteiro (Ph.D)

$16^{\text {th }}$ July, 2012 



\section{Abstract}

Rising life expectancy and declining birth rates are ageing the population of most developed countries all over the world. As a result, in a few years there will be a large portion of senior citizens in our society, therefore, it is more important than ever to figure out ways to improve their well-being and quality of life. Unfortunately, older adults require health care services more than other adults, meaning they need to be monitored more often by their doctor. Most of the time, the measurement of a couple values is enough, but the patient is forced to make long trips to the hospital or to pay expensive medical appointments, which in the end, compels the elderly to not have the appropriate treatment. Besides, if a problem is not detected in time, serious problems can arise, resulting in a longer and more difficult treatment.

Recent improvements in sensor technology, have allowed the creation of small, light weight and wireless devices that are practical and easy to use by almost everyone; more specifically, the ANT+, whose main advantage is to work more than one year, only on a small battery. This technology can be compared with Bluetooth 4.0, being designed for the collection and transfer of sensor data. It can be used with several devices - heart rate monitors, speed sensors, blood pressure monitors, foot pods, among others - , but their standalone use is quite limited. However, combining those sensors with a smart-phone, creates an independent solution that without any more requirements has an enormous potential. The advanced computing power and connectivity features available on a standard smart-phone, allow an almost endless number of possibilities, whereas current applications are only scratching the surface.

This thesis describes the research made on current mobile health monitoring systems, targeting the elderly and the development of an elderly-oriented solution, serving as a proof-of-concept of the research done. It provides a scientific contribution, by specifying a system whose components and characteristics were never combined before, when applied to the health monitoring of older adults; also, by developing a prototype for that system and evaluating its success with end users, the elderly.

The proof of concept solution allows the patient to measure himself with ANT+ sensors connected to his Android smart-phone. The measured data is stored on the mobile device for later reading and sent through the network, to a medical entity. This entity can, whenever desired, analyse that information and give an appropriate feedback to the patient through a web application. 


\section{Resumo}

O aumento da esperança média de vida e a diminuição da taxa de natalidade estão a causar o envelhecimento da população dos países mais desenvolvidos em todo o mundo. Como resultado, em poucos anos haverá um grande número de idosos na nossa sociedade e portanto, é cada vez mais importante descobrir formas de melhorar o seu bem-estar e qualidade de vida. Infelizmente, os idosos necessitam de mais cuidados de saúde do que o resto da população, o que significa que precisam de ser seguidos com mais frequência pelo seu médico. Na maioria das vezes, a medição de um pequeno número de indicadores é suficiente para monitorizar o seu estado de saúde, mas o paciente é obrigado a fazer longas viagens para o hospital ou a pagar consultas médicas bastante dispendiosas. Estes motivos acabam por levar os idosos a não ir regularmente ao médico e não ter o tratamento adequado. Além disso, se um problema não é detetado a tempo, graves problemas podem surgir, resultando num tratamento mais longo, mais difícil e mais caro.

As recentes inovações tecnológicas no campo dos sensores sem fio, têm permitido a criação de dispositivos bastante leves e pequenos; mais especificamente em $A N T+$, cuja principal vantagem é aguentar mais de um ano apenas com uma pequena bateria. Esta tecnologia é comparada ao Bluetooth 4.0, tem como objetivo a transferência de dados entre sensores e pode ser utilizada com vários dispositivos - leitores de frequência cardíaca, sensores de movimento, leitores de pressão arterial, pedómetros, entre outros. Porém, enquanto que a sua utilização por si só é bastante limitada, a combinação desses sensores com um smart-phone, cria uma solução independente, que sem mais nenhum requisito, tem um grande potencial. O elevado poder computacional dos smart-phones hoje em dia, assim como as várias possibilidades de conectividade dos mesmos, permite um número quase infinito de possibilidades.

Esta tese descreve a pesquisa efetuada sobre sistemas móveis de monitorização de saúde, direcionados para idosos e o desenvolvimento de uma solução, servindo como prova de conceito da pesquisa efetuada. Esta tese vem trazer uma contribuição científica, ao especificar um sistema cujas características nunca foram combinadas em estudos anteriores, quando aplicados à monitorização de saúde de idosos; e também, através do desenvolvimento de um protótipo do sistema e consequente avaliação do mesmo com os utilizadores finais - os idosos.

A prova de conceito permite ao paciente medir-se a si próprio, com os dispositivos $A N T+$ ligados sem fios ao seu smart-phone. Os dados da medição são armazenados no mesmo para leitura posterior e enviados através da rede, a uma entidade médica. Esta pode, sempre que achar oportuno, analisar esses valores e dar uma resposta adequada ao paciente através de uma aplicação web. 


\section{Acknowledgements}

This dissertation would not have been possible without all the support given from my mother, father and sister, not only during this thesis but also throughout the years, making every effort they possibly can to watch me succeed and do well in life.

I am truly thankful to my supervisor at Fraunhofer Portugal, Diogo Dias Júnior, whose help throughout this thesis was key to its success. I would also like to thank Prof. Miguel Monteiro, who supervised the thesis at FEUP.

To all family, friends and co-workers not mentioned here, who helped me during this thesis, it is a great pleasure to thank you all for your kindness and attention.

Ricardo Belchior Teles Lagido 


\section{Contents}

1 Introduction 1

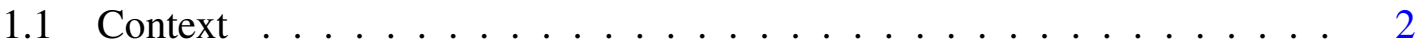

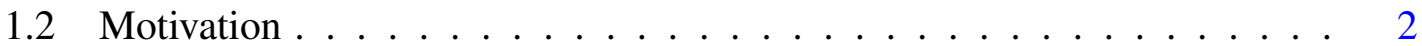

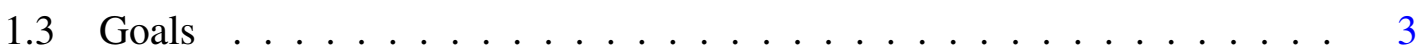

1.4 Document structure . . . . . . . . . . . . . . . . 4

2 State of the Art $\quad 7$

2.1 Related Projects . . . . . . . . . . . . . . . . . 7

2.1 .1 UAHealth . . . . . . . . . . . . . . . . . 7

2.1.2 Heart Monitoring Using Smart Phones . . . . . . . . . . . . . 7

2.1 .3 eCAALYX ..................... 8

2.1.4 Perceptions and Experiences of Mobile Phone-Based Telemonitoring ......................... 9

2.1.5 Main Problems of the Elderly _. . . . . . . . . . . . . 10

2.1.6 Secure Mobile Health Systems . . . . . . . . . . . . . . . . . . . . . . . 11

2.2 Automatic Anomaly Detection . . . . . . . . . . . . . . . . 12

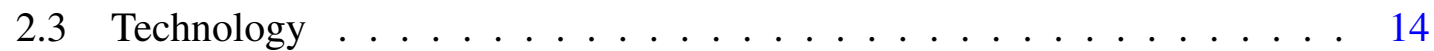

$2.3 .1 \quad$ ANT $+\ldots \ldots \ldots \ldots \ldots \ldots$

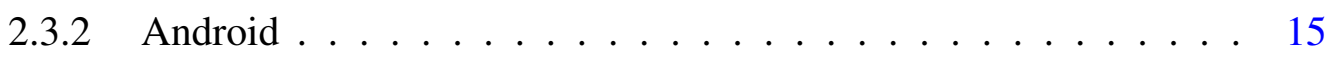

2.3 .3 Ruby On Rails . . . . . . . . . . . . . . . . . . . . . 17

2.4 Conclusions . . . . . . . . . . . . . . . . . 20

3 System Requirements and Architecture 2

3.1 System Requirements . . . . . . . . . . . . . . . . . . . . . . . 23

3.1.1 Requirements Elicitation . . . . . . . . . . . . . . 23

3.1 .2 Context Description . . . . . . . . . . . . . . . . . 26

3.1 .3 Actors . . . . . . . . . . . . . . 26

3.1 .4 Use Cases . . . . . . . . . . . . . . . . . . . . . 27

3.1.5 Non-functional Requirements . . . . . . . . . . . . . . . . . . . 35

3.1 .6 Assumptions and Dependencies . . . . . . . . . . . . 36

3.2 System Architecture . . . . . . . . . . . . . . . . . . . . . . . 36

3.2 .1 Domain Model . . . . . . . . . . . . . . . . . . . . . . . . . . . . . 36

3.2 .2 Physical Model . . . . . . . . . . . . . . . . . . . 38

3.2.3 Technological Model . . . . . . . . . . . . . . . 39 
4 Implementation $\quad \mathbf{4 1}$

$4.1 \quad$ ANT+Protocol . . . . . . . . . . . . . . . . . . . 41

4.1 .1 Weight Scale . . . . . . . . . . . . . . . 41

4.1.2 Blood Pressure Monitor . . . . . . . . . . . . . . . . 44

4.1.3 ANT+ with Android . . . . . . . . . . . . . . . . . . 49

4.2 Mobile Application . . . . . . . . . . . . . . . . . . . . 50

$4.2 .1 \quad \mathrm{ANT}+\ldots \ldots \ldots \ldots \ldots \ldots$

4.2.2 Main Activities . . . . . . . . . . . . . . . . . . 52

4.2 .3 Web Adapter . . . . . . . . . . . . . . . . . . 55 55

4.2 .4 Alarms ......................... 58

4.3 Web Application . . . . . . . . . . . . . . . . 58

4.3.1 Authentication . . . . . . . . . . . . . 66 61

4.3.2 Manage Patient . . . . . . . . . . . . . . . 62

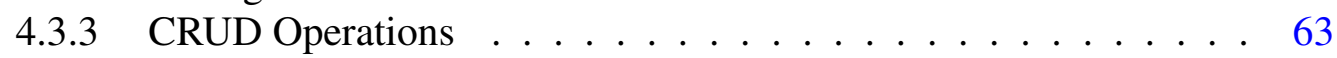

4.3 .4 Patient Features . . . . . . . . . . . . . . . . . . . 64

4.3.5 Internationalization . . . . . . . . . . . . . . . 64

4.3 .6 Mobile API . . . . . . . . . . . . . . . 65

5 Tests and Results $\quad 67$

5.1 Usability Testing . . . . . . . . . . . . . . . . . 67

5.1 .1 Sample ......................... 68

5.1 .2 Method ....................... 68

5.1 .3 Results ...................... 69

5.2 Prototype Testing . . . . . . . . . . . . . . . . 72

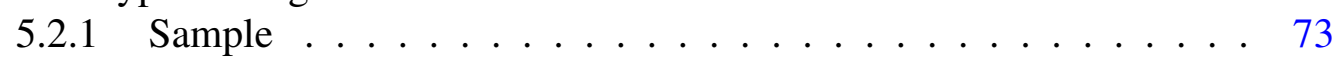

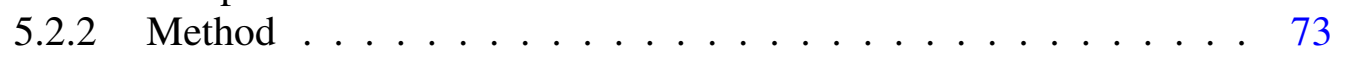

5.2 .3 Results ..................... 76

6 Conclusions and Future Work $\quad 79$

6.1 Thesis Summary . . . . . . . . . . . . . . . . . . . . . . 79

6.2 Main Results . . . . . . . . . . . . . . . . . . . . . 80

6.3 Conclusions . . . . . . . . . . . . . . . . . 81

6.4 Future Work . . . . . . . . . . . . . . . . . . . 81

$\begin{array}{ll}\text { References } & 83\end{array}$

$\begin{array}{lll}\text { A Clinicians Interviews } & 87\end{array}$

B Usability Test Script $\quad 89$

C Usability Test Results $\quad 91$

$\begin{array}{ll}\text { D Prototype Test Script } & 101\end{array}$

$\begin{array}{lll}\text { E Prototype Test Results } & 103\end{array}$ 


\section{List of Figures}

1.1 System architecture . . . . . . . . . . . . . . . . 4

2.1 OSI Model . . . . . . . . . . . . . . . . . . . . . . . . . 14

2.3 Current Distribution . . . . . . . . . . . . . . . . . 17

2.4 Ruby On Rails framework components . . . . . . . . . . . . . . . . . . 19

3.1 Use Case Model . . . . . . . . . . . . . . . . . . . . . . . . . . . . . 28

3.2 Mobile Application . . . . . . . . . . . . . . . . . . . . . 29

3.3 Connect to ANT $\ldots \ldots \ldots \ldots$. . . . . . . . . . . . . 30

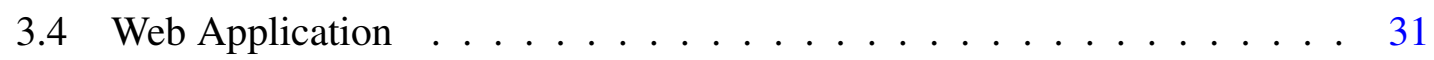

3.5 Manage Patient . . . . . . . . . . . . . . . . . . 32

3.6 Patient Views . . . . . . . . . . . . . . . . . . . . . . . 34

3.7 Domain Model . . . . . . . . . . . . . . . . . . . . . . 37

3.8 Physical Model . . . . . . . . . . . . . . . . . . . . . . . . . . . . . . . 38

3.9 Technological Model . . . . . . . . . . . . . . . . . . 39

4.1 Weight Scale Use Case . . . . . . . . . . . . . . . . . . . . . . . 42

4.2 Blood Pressure Monitor Use Case . . . . . . . . . . . . . . . . 45

4.3 Link Layer Sequence Diagram . . . . . . . . . . . . . . . . . . . . . . 46

4.4 Pairing Request Message Flow . . . . . . . . . . . . . . . . . . . . . . . . . . . . . . . . . 47

4.5 Passkey Authentication Message Flow . . . . . . . . . . . . . . . . 48

4.6 Download Message Flow . . . . . . . . . . . . . . . . . . . . . . 49

4.7 Mobile Application Architecture . . . . . . . . . . . . . . . . 51

4.8 Weighing Operation . . . . . . . . . . . . . . . . 54

4.9 Blood Pressure Measurement Operation . . . . . . . . . . . . . . . 55

4.10 Web Application Models . . . . . . . . . . . . . . . . . . . 59

4.11 Web Application Controllers . . . . . . . . . . . . . . . . . . . 60

4.12 Physician Home Page . . . . . . . . . . . . . . . . . . . 62

4.13 Patient Profile Page . . . . . . . . . . . . . . . . . . . . . . . . . . 63

4.14 Sensors Settings Page . . . . . . . . . . . . . . . . . 64

5.1 Naming Questions Number 1 and 2 . . . . . . . . . . . . . . 70

5.2 Naming Question Number $2 \ldots \ldots \ldots 70$

5.3 Duration of Measure on Usability Tests . . . . . . . . . . . . 71

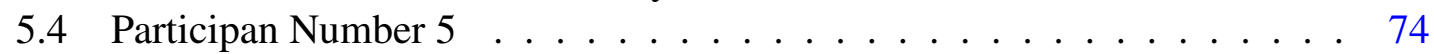

5.5 Participan Number $1 \ldots \ldots \ldots \ldots 75$

5.6 Duration of Measure on Prototype Tests . . . . . . . . . . . 76 


\section{LIST OF FIGURES}

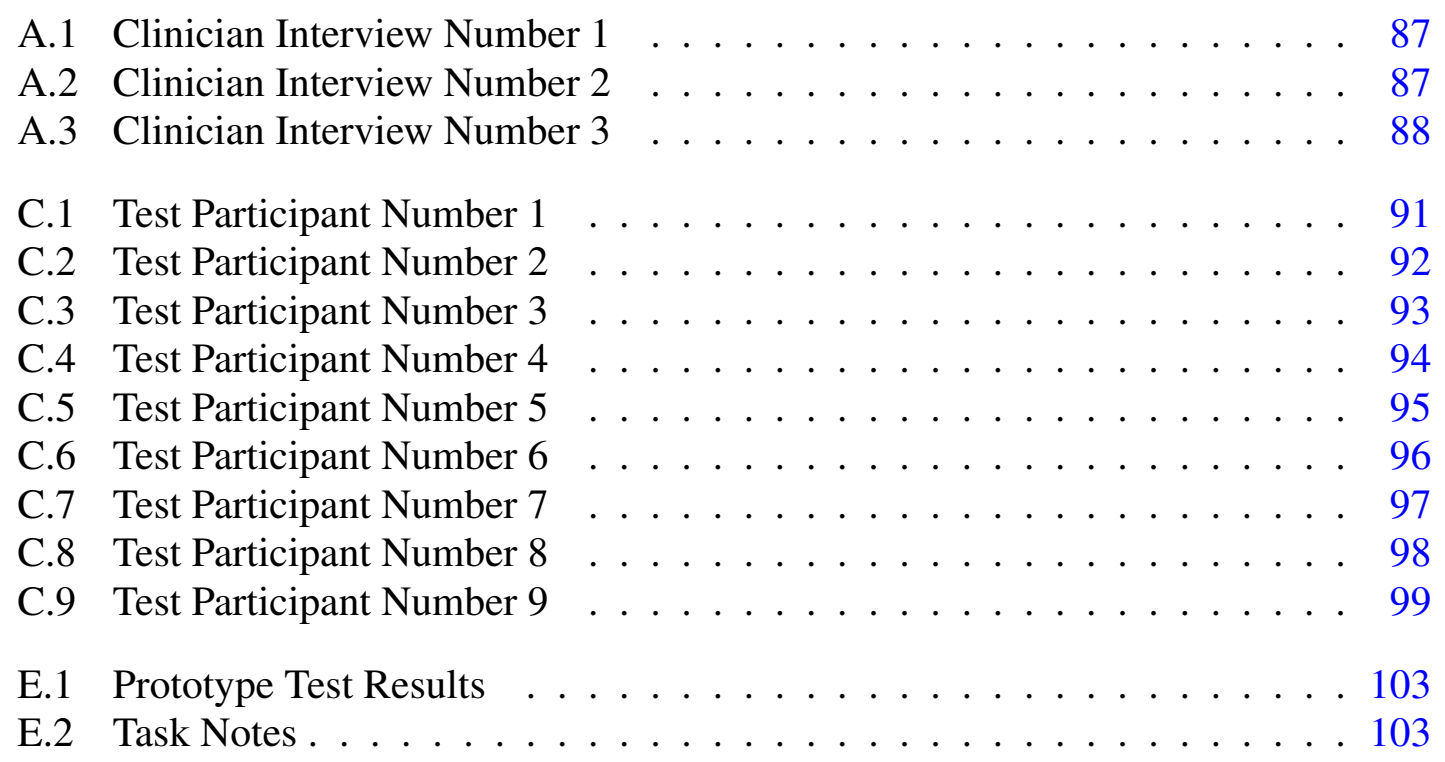




\section{List of Tables}

1.1 Demographics of the most developed regions . . . . . . . . . . . 1

2.1 Classification of blood pressure for adults . . . . . . . . . . . . . 13

2.2 Resting heart rate normal values . . . . . . . . . . . . . . . . . 13

2.3 General Body-fat Percentage Categories . . . . . . . . . . . . . . . . 13

2.4 Worldwide Smartphone Sales to End Users by Operating System in 2Q11 (Thousands of Units) . . . . . . . . . . . . . . . . . 18

2.5 State Of The Art - Overview . . . . . . . . . . . . . 20 
LIST OF TABLES 


\section{Abbreviations}

\begin{tabular}{ll} 
2D & 2 Dimension \\
2Q10 & Second quarter of 2010 \\
2Q11 & Second quarter of 2011 \\
3D & 3 Dimension \\
API & Application Programming Interface \\
BAN & Body Area Network \\
CAALYX & Complete Ambient Assisted Living Experiment \\
CRUD & Create, Read, Update, Delete \\
DBP & Diastolic Blood Pressure \\
DRY & Don't Repeat Yourself \\
eCAALYX & Enhanced Complete Ambient Assisted Living Experiment \\
ECG & Electrocardiogram \\
EPR & Electronic patient record \\
EU & European Union \\
FhP & Fraunhofer Portugal AICOS \\
HTML & HyperText Markup Language \\
JSON & JavaScript Object Notation \\
mmHg & Millimetre of mercury \\
MVC & Model View Controller \\
RHTML & Rails HyperText Markup Language \\
RoR & Ruby On Rails \\
RXML & Rails Extensible Markup Language \\
SBP & Systolic Blood Pressure \\
SQL & Structured Query Language \\
URI & Uniform Resource Identifier \\
URL & Uniform Resource Locator \\
UI & User Interface \\
VM & Virtual machine \\
XML & Extensible Markup Language \\
& \\
\hline
\end{tabular}


ABBREVIATIONS 


\section{Chapter 1}

\section{Introduction}

Nowadays in most of the industrialized countries, it is a known fact that there are more and more older people. This ageing of population has began a couple decades ago and it is mainly because of the rising life expectancy and the low birth rate in those countries. Table 1.1 shows some numbers concerning the more developed regions - Europe, Northern America, Australia/New Zealand and Japan [otDoEotUNS11].

Table 1.1: Demographics of the most developed regions

\begin{tabular}{lcc} 
Period & Number of births & Life Expectancy at Birth \\
\hline $1955-1960$ & 94680 & 68.0 \\
$1965-1970$ & 84330 & 70.3 \\
$1975-1980$ & 79233 & 71.2 \\
$1985-1990$ & 78469 & 72.9 \\
$1995-2000$ & 65835 & 73.1 \\
$2005-2010$ & 69785 & 75.4
\end{tabular}

Due to this factor, it is more important than ever, to look for ways to improve the quality of life of senior citizens. And obviously, health, plays a major role when speaking of quality of life. Unfortunately, the elderly are more likely to suffer from certain types of diseases, when compared to younger people and if a problem is not detected in time, serious problems can arise, resulting in a longer and more difficult treatment. Which means they need to be monitored more often in order to detect changes in their condition as early as possible [SAL06].

Long trips to the hospital, expensive medical appointments or the lack of specialized doctors in remote areas, are all motives that constantly lead an older person not to have proper health cares [CRP08]. In addition, if the patient eventually gets worse, he will probably have to pay for several medications and different treatments. Treatments that, usually, also have costs for the hospital; several studies have shown that the health care 
expenditures increase significantly for the elderly [May00]. Eventually, if the patient needs to be hospitalized, these numbers will obviously rise and the simple fact of being in the hospital can bring more problems to his health condition [Mor93]. Summing up, the lack of proper monitoring might end up bringing costs to both patient and health system.

Recent improvements in sensor technology have allowed the creation of small, light weight and wireless devices that are practical and easy to use by almost everyone. The result is that much of the process of clinical examination, once done in uncomfortable and harsh environments, can now be done at the patient's place of comfort. Combining this technology with the computing power of a smart-phone and its connectivity to the Internet, there is a large number of possibilities to try to reduce some of the problems regarding the elderly. Renowned entities are already embracing these trends, as the Medical Technology Policy Committee of the IEEE USA refers: "Appropriate adoption of existing and emerging technology can improve the efficiency and quality of health care delivery, restrain cost increases and, perhaps most importantly, improve the quality of life for our ageing population" [Com09].

\subsection{Context}

This is a dissertation project, that focus on mobile health systems, with special attention to the usability needs from the elderly. It was developed at the Fraunhofer Portugal Research Center for Assistive Information and Communication Solutions (FhP AICOS), which is a non-profit private association founded by Fraunhofer-Gesellschaft, the largest organization for applied research in Europe.

Lately, the FhP AICOS has been working on several wireless technologies and is targeting their efforts on the area of telemedicine. This dissertation is one of those projects, making use of information technologies to provide clinical health care at distance.

\subsection{Motivation}

The motivation of this work was to apply the growing use of communication technologies, namely the smart-phones and the Internet, in order to:

- Prevent health problems - As it was referred earlier in this chapter, frequent monitoring of the elderly can avoid severe health problems. This monitoring often consists of checking a few easily read parameters, like the heart rate, the blood pressure, the weight, among others. Most of these values can be read with wireless sensors and then sent to a common smart-phone. A possible scenario, is one in which a patient has one blood pressure monitor at home, does a couple readings and that data is sent to the patient's smart-phone. The mobile device is then able to 
detect if the read values are normal or not. At the same time, the mobile device can send that information to the patient's doctor that can, at a later moment, give a more accurate feedback to the patient;

- Enhance the doctor-patient communication - Nowadays with the Internet, it is pretty easy to send big quantities of information in a fast and cheap way (raw data, emails, chats, calls or video-calls). As a result, information that was once only available through direct contact with the patient, can now be easily sent with a smart-phone;

- Reduce costs - Both smart-phones and the Internet are becoming more and more accessible to the general population, in terms of costs and availability, making the solution being presented here, a feasible and useful product to the patients and also to the health system. A study the Boston Consulting Group states that with mobile healthcare, costs related to data collection can be reduced by $24 \%$ and costs in elderly care can be reduced by $25 \%$ [The12].

All of these reasons combined together, have, as a common purpose, to improve the quality of life of the senior citizens.

As a glimpse to the future, it is not hard to imagine, in a couple decades, a regular person having at home his own set of sensors, capable of analysing entire parts of his body, detecting potential problems and taking the right measures to that specific person. At the same time a doctor would be receiving that same information and only supervise the decisions taken by the machine. The goals of this thesis research, are precisely towards turning such idea closer to reality.

\subsection{Goals}

The goal of this dissertation was to create a system with the interactions presented on Figure 1.1. A certain patient would have his sensor, that would capture one of several values, including heart rate, blood pressure, weight, body fat, among others. The sensor would then receive the data from the patient and send it to the smart-phone, allowing him to immediately read the collected data. At the same time, that data would be sent through the Internet to a medical entity, who could analyse it thoroughly and contact the patient again, if necessary. The same information could be registered in a remote server, in charge of the medical entity, so that the doctor would be able to review the historical data from any patient, at any time.

The work can be roughly divided into three main parts. The first one includes the communication between each sensor and the patient's smart-phone. The smart-phone should be able to seamlessly obtain the measurements from each sensor, requiring minimum interaction with the end-user. This communication will be integrated into the mobile 


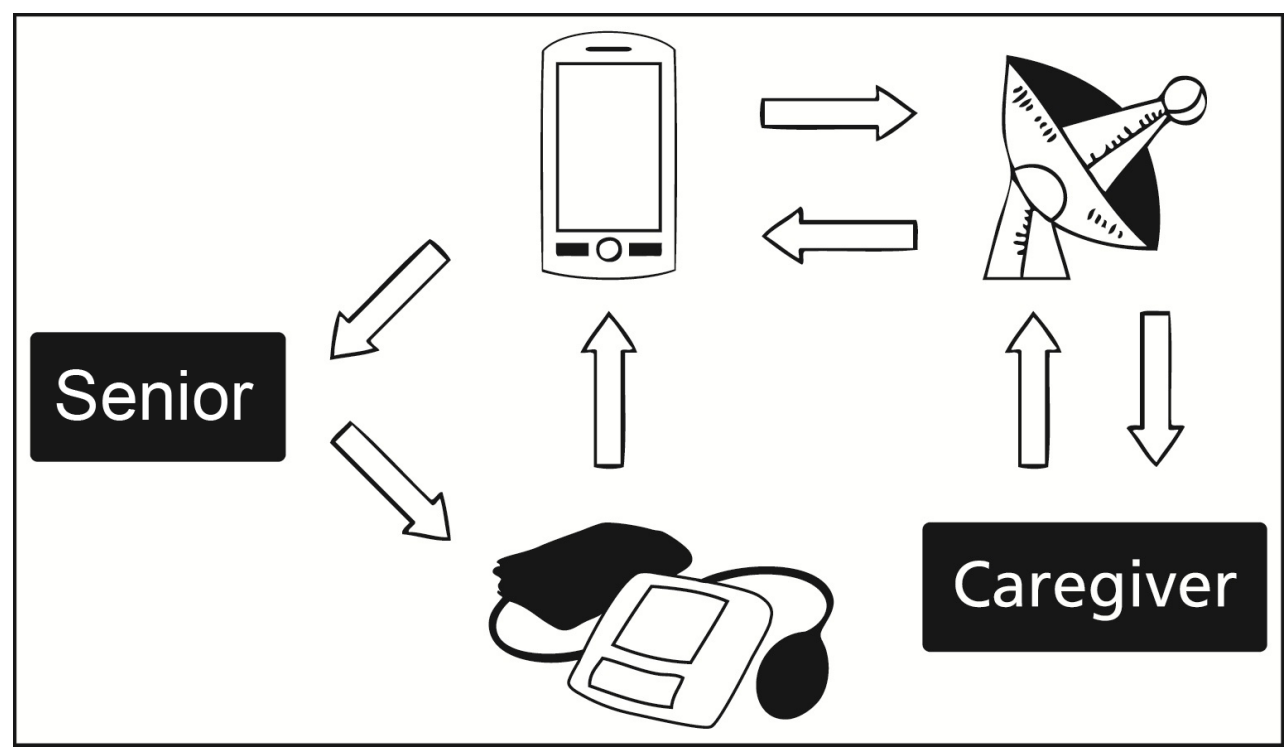

Figure 1.1: System architecture

application, whose goal is to retrieve, store and present the sensor's data to the patient. The second one is targeted to the clinicians, so they are able to manage their patients and the historical data of each one. More specifically, it is a web application allowing physicians to access the patient's measurements anytime, anywhere. The third part, responsible for an automatic detection of anomalies, will immediately warn the patient's clinician if something wrong is detected in the information obtained from the wireless sensors. It will check the collected data on the mobile application against a set of rules, designed to assure the values are within normal.

As this thesis name says, it is targeted for the elderly, which basically means that special attention should be paid to usability issues. This is a thesis goal that was kept in mind during all phases of work, looking to simplify and clarify as much has possible the interface presented to the end-user. Given the fact that the system will be dealing with sensitive information travelling wirelessly and through the Internet, the security issue must not be forgotten. Therefore, the security of the information sent between the patient's devices and the medical entity, was taken into consideration.

\subsection{Document structure}

In addition to the introduction, this document has five more chapters. In chapter 2, it is described the state of the art on mobile health systems and all the technologies involved within this thesis. Chapter 3 presents the elicitation requirements process and the system's requirements and architecture. On chapter 4 , the implementation of the working prototype is described in its three main parts: the ANT+ communication protocol, the mobile and 


\section{Introduction}

web application. Then, chapter 5 presents the two usability tests conducted during this thesis, including its sample, method and results evaluation. At last, chapter 6 makes an overview of the work done on this thesis, its main results, conclusions and future work. 
Introduction 


\section{Chapter 2}

\section{State of the Art}

\subsection{Related Projects}

The goal of this section is to present work whose domain intersects with this dissertation. Several research was done on systems where mobile phones are used to improve the health service provided to their users, regardless of the technology in use. An overview of those systems is presented below.

\subsubsection{UAHealth}

In this project [MSJ11], Milosevic et al. describe the development of UAHealth, an iPhone application for health monitoring and management, designed to monitor physical activity, weight and heart activity. The author refers that until this application, most of the systems available in the market would only monitor a single parameter. This system has the iPhone communicating with a set of wireless sensors to collect information about the user's physiological signals. For the communication protocol, ANT+ wireless standard is used. All the relevant collected data is uploaded to a remote server, which can be accessed by the user or any other entity approved by him. As most of their users not always connect to the sensors near an Internet connection, the authors contemplate the problems of intermittent connection. The system is capable of working both online and offline, by monitoring Internet connectivity to determine the right moment to upload health related information. For this motive, the application includes both a local and remote database.

\subsubsection{Heart Monitoring Using Smart Phones}

Another similar project, is the one presented by Gay et al. [GL07], developing a personalized heart monitoring system using smart phones. Their target are patients with high risk of cardiac issues, so they designed a system capable a analysing ECG data in realtime. The smart phone can automatically alert a pre assigned entity and also give advice 
or reassure the patient, based on the sensors data. The heart is monitored using different types of sensors - ECG, accelerometer, oximeter, weight scale or blood pressure monitor. Each of these sensors can be customized by the patient's doctor by selecting one or more sensors to be used for a particular patient and configure threshold levels for each of the sensors. The prototype built within this project is said to be fully functional, being able to detect life threatening arrhythmias locally on the smart phone.

Since the patients will have high risk of cardiac issues, the heart monitoring was a crucial component of their architecture. The authors focused on two life threatening arrhythmias (Ventricular Fibrillation and Ventricular Tachycardia), using an open source heart beat detector and classifier, based on the algorithms developed by Pan and Tompkins [PT85]. Other components of this project included the detection of falls and the patient's location, personalization of the sensor's and an emergency procedure. Although some problems were referred regarding the low battery life of the used devices, the authors are confident that this project was a success.

\subsection{3 eCAALYX}

eCAALYX is a EU funded project (Enhanced Complete Ambient Assisted Living Experiment, built up on the strengths of the infrastructure and functionality developed in the original CAALYX project $\left[\mathrm{BRM}^{+} 07\right]$. It aims at building a remote monitoring system targeting the elderly with multiple chronic diseases. One of the main goals of this project is to act as a seamless intermediary between the health sensors used by the older person and the health professionals. This is done by reporting to the medical entity, alerts and measurements obtained from sensors and the geographic location of the user. It also is capable of identifying easily detectable anomalies such as tachycardia and signs of respiratory infections, based on established medical knowledge. An user interface is also available, allowing the patient to view his most recent medical details obtained from sensors, perform new measurements and communicate with his doctor.

In the paper [BWTJ11], the major challenges of this project are presented, being usability the first discussed issue. Since users in this target group, usually do not have any familiarity with technology, sometimes worsened by physical or cognitive disabilities, it is key to this project that the mobile application is totally transparent to the user and its interface as accessible as possible. The authors present some used guidelines regarding the physical handling, the maintenance of the mobile phone and the practical solutions adopted during the development phase.

Another interesting discussion addressed, was to try to figure out if people with chronic diseases go online and can smart phones with Internet access, make a difference. There is no definite answer for such a question, but the authors start by analysing a Fox and Purcell [FP10] report, stating that only $62 \%$ of adults living with one or more chronic disease 
go online, comparing to $81 \%$ of adults without any chronic disease that go online. And although several interventions promoting the use of mobile phones have been made, no significant result was seen. Besides, despite already existing hundreds of health oriented applications, few of them are designed thinking about the patient in the first place.

At a more technical point-of-view, Boulos et al. [BWTJ11] also warn for the limitations of a smart phone. It is true that the computational power is advancing at a rapid pace, but the small internal storage capacity, processing power and screen size of the device often require applications to be in a reduced format [KCW10]. The authors also remind not to forget the security issue. The possibility of sensitive information being exchanged, allied to the fact that mobile devices are often used in public spaces (with inherent issues regarding wireless Internet vulnerability) should reinforce the importance given to security. Nevertheless, this has been a concern for a while and research has already been done on this issue [LV04, BHHS07].

\subsubsection{Perceptions and Experiences of Mobile Phone-Based Telemonitoring}

A group of researchers conducted a study whose goal was to provide insights into the impact of telemonitoring on self-care and clinical management and to determine the main features contributing to a successful heart failure telemonitoring system. A total of 50 patients were recruited to use their system for six months. During that time, patients had to take daily weight and blood pressure readings, weekly ECGs and to answer daily symptom questions on a mobile phone. Those readings were sent via Bluetooth to a BlackBerry mobile phone, installed with a custom application used to display, store and transmit the information to the data repository at the hospital. After those six months, interviews were conducted with both patients and clinicians leading to quantitative and qualitative results, presented on this paper $\left[\mathrm{SLC}^{+} 12\right]$.

On the essential features for the success of similar telemonitoring systems, the authors claim it should provide immediate self-care and clinical feedback, it should be easy to use and the perceived benefits of using the system should be clear to everyone involved. By immediate self-care feedback they mean that, during the usage of the system, as the patient modifies his own lifestyle behaviours, clinicians should be available to hear and guide the patient in order for him to make appropriate self-care decisions. This is an important issue, as they say, heart failure self-care has been found to improve health outcomes, reduce healthcare costs and it has also been stressed as an important component of heart failure management in international clinical guidelines. Regarding the immediate clinical feedback, this telemonitoring system sent alerts to the clinicians, remembering them to contact their patients for various motives. This feature, from the patient's pointof-view, besides improving health outcomes also reduced their anxiety. Now they knew 
that someone was keeping an eye over them and, as a result, it motivated them to improve self-care.

The fact that the system was quick, easy to use and required minimum understanding of technology was a decisive factor to the adherence of the system. The authors refer some trials of heart failure telemonitoring proving that when patients find the system hard to learn and interact with, their willingness to use it is poor. The last feature stated as requirement for a successful telemonitoring system is related with the perceived benefits of the user by both patients and clinicians. The authors are confident that patients must believe that sending daily information to their doctors will benefit them in tangible ways, otherwise eventually, they will stop doing so. On the clinicians perspective, although there were some concerns of implementing the system, they supported the use of telemonitoring because they believed it was a useful tool to help the management of their patient's conditions, to increase the patient's self-care and to ultimately improve their patient's health outcomes.

\subsubsection{Main Problems of the Elderly}

When developing applications for the elderly, a different approach is necessary. Vision impairment, poor hearing, motor difficulties and reduced perception are all physical difficulties very common in aged people. Combining this difficulties with bad usability designs, makes it very hard for the elderly to adopt these kind of technologies [OLZ11]. Holzinger et al. [HSN07] review the major problems of the elderly using mobile phones, as a way to understand what developers can change to create applications capable of reaching their needs. The design of new mobile applications should be a reflection of this understanding, instead of the creation of more psychological barriers between the mobile device and the end-user.

The problems are categorized into cognitive, motivational, physical and perceptive. Starting with the cognitive problems, the author states that since the cognitive performance slows down with age, lowering the complexity of applications could be a key for design and development of mobile applications. The authors show, by referring several studies, that the benefit of lower complexity was much larger than it was theoretically predicted. In an experiment, it was seen that although the elderly had a lower navigation performance comparing to younger users, their performance matched the younger users when the tested mobile applications had low complexity.

Motivational issues may include preconceived beliefs, attitudes, fear, acceptability, among others. In this issue, the authors found studies indicating that a large percentage of older adults are actually motivated to use mobile applications, when they actually recognize the benefits of their use. This fact could mean that the lack of interest in mobile phones is due to the poor understanding of their benefits and also some hesitation to learn 
a technique that they feel that requires a highly specialized expertise or knowledge that they do not have.

Regarding physical impairments of the elderly, although it is not possible to quantify the exact physical effects of ageing, studies show that there are common illnesses that can be classified as age-related and with them, common symptoms. Holzinger et al. state that it is the combination of partial loss of vision, hearing, memory and mobility that contribute to a loss of confidence, which leads to difficulty in the retention of information [HSN07]. However, the perception issues are the most obvious barrier to which the elderly are subject.

\subsubsection{Secure Mobile Health Systems}

Adesina et al. $\left[\mathrm{AAF}^{+} 11\right]$ analyse the security problems inherent to a mobile health system and examine several ways of implementing data security measures. Importance is given to the topics of sending patient data over the Internet and keeping the database where it is stored and secure. The authors reviews the concepts of a patient record and EPR (electronic patient record), where a patient record is defined as "any relevant record made by a health-care practitioner at the time of or subsequent to a consultation and or examination or the application of health management"[dKA93]. EPR are basically a conversion from the current paper-based patient record to a digital format, so they are available in an electronic form and can be used in a distributed way. Although EPR's can have many advantages, the question of security is a main concern - the fact that they are being transmitted over the Internet makes them vulnerable to unauthorized access or use. This is totally opposite to the classic model, where patients need to go to the hospital to be monitored or to view their medical records, only accessed by a limited number of personnel. These are motives to strengthen the data security and the integrity of the EPR's.

The topics of encryption, digital watermarking, steganography are reviewed and their use in mobile health systems, analysed. The authors believe that medical data can be secured within the database server and during transmission by applying the following measures:

- Defining clear attributes for role-based access as the systems are put into place;

- Developing policies to protect the patient's right to privacy with regard to their medical data;

- Defining the extent of medical data transmitted via the Internet from patient's home to the central monitoring station, and whether patients have partial or full control of their data;

- Specifying who has the right to analyse the data. As EPR's are becoming widespread, more health organizations will have databases that store patient information in a 
common electronic format, allowing the sharing of data over the network; hence the administration of particular part of data in circulation has to be secured or restricted.

This paper concludes by referring the importance and difficulty of applying an effective digital watermark to the EPR. Therefore, it should be complemented with data encryption mechanisms to improve the assurance and integrity of the data stored, retrieved or transmitted across electronic devices. Patients and health-care workers should not lose confidence in the privacy and integrity of their sensitive data.

Another interesting paper regarding the security issue was written by Saponas et. al $\left[\mathrm{SLH}^{+} 07\right]$ where they find and technically explore scenarios where the Nike+iPod Sport Kit's design can lead to a leak of personal privacy and safety. This kit is composed of two modules, a sensor to put on the user's shoe and another one, the receiver, to be used with the user's iPod. The researchers implemented a prototype surveillance system, able to track people wearing these sensors, plotting their location and sending real-time surveillance data to an attacker. It tracks individuals when they are working out and when they are casually walking without their iPods. Besides, they also developed the means for an attacker to obtain surveillance data on his/her wrist watch. This is relevant work when dealing with sensors transferring data in public spaces and, as the authors say, suggests a greater need for rigorously evaluating the privacy of new technologies before deployment.

\subsection{Automatic Anomaly Detection}

Regarding the automatic anomaly detection, it has to be analysed depending on the desired values to measure - blood pressure, heart rate or body fat values, among others, must be detected and classified independently. It is also important referring the purpose of this feature in the project; it is not envisioned as a real-time monitoring system, whose sensors seek to alert health failures in emergency situations. Although it can be possible to adapt to such system, it is designed to give a feedback of the patient's condition over time, by making scheduled measurements of this values, with their frequency assigned by the medical entity.

Having said that, in order to make those detections a research has been done, looking for pre-established tables for classifying each of the values. The health community designates this as "Clinical Practice Guidelines" and research on improving clinical guidelines has been done since 1980 [ACIS ${ }^{+}$10]. The U.S. National Heart Lung and Blood Institute [Nat12] states that the purpose of the Clinical Practice Guidelines is to help clinicians and patients make appropriate decisions about health care by:

- Describing a range of generally accepted approaches for the diagnosis, management, or prevention of specific diseases or conditions. 
- Defining practices that meet the needs of most patients in most circumstances.

The recommendations are not fixed protocols that must be followed. Usually, these guidelines depend on several factors like the age, gender or height of the patient. Also, previous health problems should be considered. All these conditions require that some input information is provided by the patient or the health-care specialist himself, in order to make small adjustments to the guidelines and develop individual treatment plans tailored to the specific needs of the patient [Nat12].

Therefore, the system will have the detection system based on the default guidelines, allowing, at the same time, for the health-care specialist in charge to specify the threshold values for each sensor. Starting with the blood pressure field, based on a report on "Prevention, Evaluation and Treatment of High Blood Pressure" [Nat04], Table 2.1 states the proposed threshold values of blood pressure for adults over 18 years old.

Table 2.1: Classification of blood pressure for adults

\begin{tabular}{lcc} 
Blood Pressure Classification & SBP $(\mathbf{m m H g})$ & DBP $(\mathbf{m m H g})$ \\
\hline Normal & $<120$ & and $<80$ \\
Pre-hypertension & $120-139$ & or $80-89$ \\
Stage 1 - Hypertension & $140-159$ & or $90-99$ \\
Stage 2 - Hypertension & $\geq 160$ & or $\geq 100$
\end{tabular}

Regarding the heart rate of a patient, Kliegman et al. [KN07] define as a normal heart rate if, when at rest - the patient must have been resting for at least 10 minutes — the values are within the ones described on Table 2.2.

Table 2.2: Resting heart rate normal values

\begin{tabular}{lc} 
Ages & Heart beats per minute \\
\hline Newborns (0-30 days old) & $70-190$ \\
Infants (1-11 months old) & $80-120$ \\
Children (1 to 10 years old) & $70-130$ \\
Children over 10 and adults (including seniors) & $60-100$ \\
Well-trained athletes & $40-60$
\end{tabular}

Another relevant chart is the one presented by the American Council on Exercise [Mut09], about ideal the percentages of body fat. Table 2.3 presents those data.

Table 2.3: General Body-fat Percentage Categories

\begin{tabular}{lcc} 
Classification & Women (\% fat) & Men $(\%$ fat $)$ \\
\hline Essential fat & $10-13 \%$ & $2-5 \%$ \\
Athletes & $14-20 \%$ & $6-13 \%$ \\
Fitness & $21-24 \%$ & $14-17 \%$ \\
Average & $25-31 \%$ & $18-24 \%$ \\
Obese & $32 \%$ and higher & $25 \%$ and higher
\end{tabular}




\subsection{Technology}

This section will present the technologies used during this thesis, by making a brief description of their purpose and main features. I will describe their main advantages and disadvantages, as well as the main reasons leading to their choice.

\subsubsection{ANT+}

ANT + is a wireless sensor network technology, designed to enable communications between self powered devices in an extensible network environment, easing the collection, automatic transfer and tracking of sensor data for monitoring of all personal wellness information. This ability to transfer data between sensors is a feature built on top of the base ANT protocol, a proprietary technology. Rod Morris, director of ANT Wireless states at the ANT+ website [Mor], that ANT is the lightest protocol available that still has the ability to scale into complex network topologies and communication methods, achieving lower costs and power. It is capable of being powered by a coin cell battery, operating on it for up to several years. ANT+ is said to be compact, with a small stack size; scalable, supporting complex network topologies; flexible, supporting ad hoc network reconfiguration; focused, by not being a standard development organization; and proven, because of the millions of nodes delivered around the world.

Figure 2.1 represents in which OSI layers, the ANT protocol is developed.

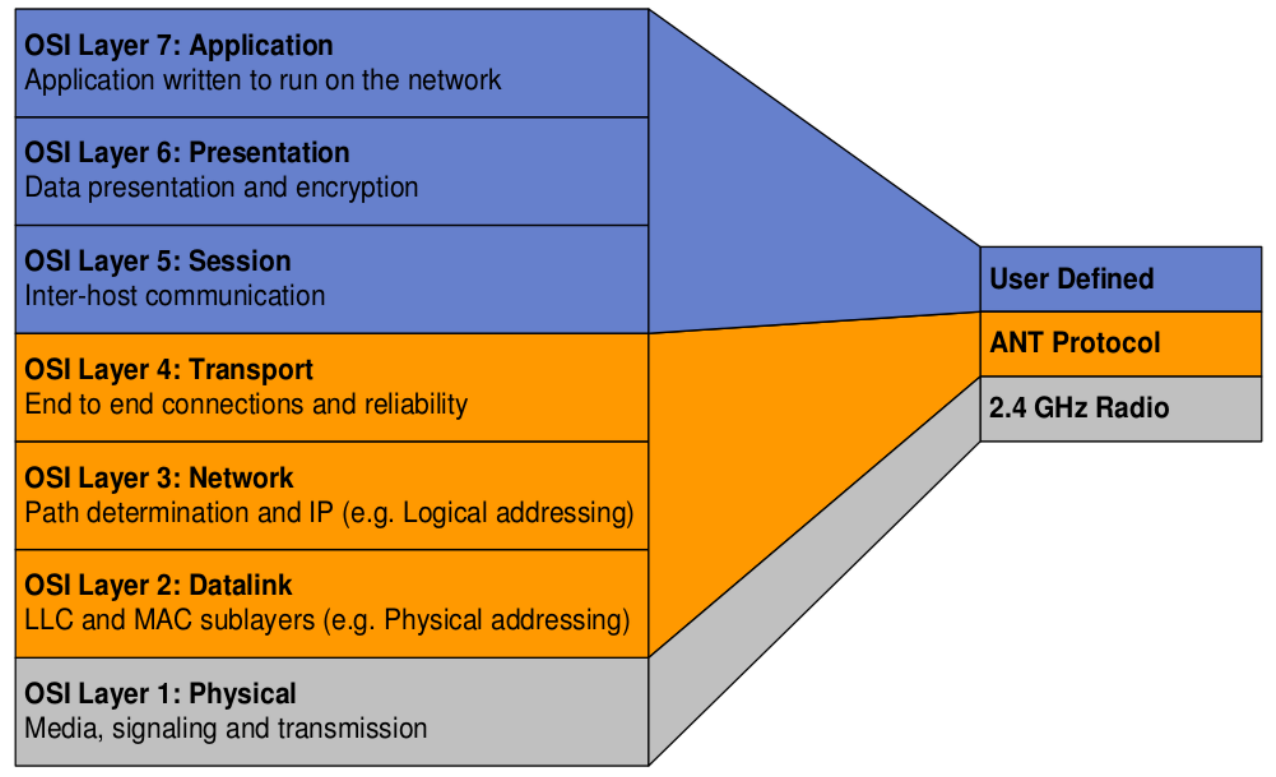

Figure 2.1: OSI Model

The user is able to define the top three layers: session, presentation and application. The session layer allows the definition of the network topology. The presentation layer 
serves as a data translation layer, allowing the formatting and delivery of data to the application layer; encryption and decryption operations are also done here. The application layer, usually contains all the methods specifying the communication between two, or more end-points.

Ant+ has several device profiles defining the network parameters and the structure of data, so that different products are able to communicate seamlessly. Current ANT+ profiles are currently available for the following devices: Heart Rate Monitor, footpod, Bicycle Speed and Cadence, Bicycle Power, Weight Scale, Multi-Sport Speed and Distance (Radar, GPS).

It is a quite recent technology and not much research has been done using it. Besides, most of the products available on the market focus on sports and fitness, instead of health and well being. One of the innovative points of this dissertation is exactly to take advantage of this technology and apply it to health services.

\subsubsection{Android}

Android is an open-source, Linux-based operating system built for mobile devices. Although its main use are smart-phones and tablets, it was designed to run on all sorts of physical devices, making no restrictions on the screen size, resolution, chipset and other characteristics of the equipment [KMH11]. It started at the start-up company Android Inc. acquired by Google in 2005. Then in 2007 a group of industry leaders, including Motorola, Samsung, Vodafone, Intel and others, formed the Open Handset Alliance in order to support the Android platform. According to their website (http://www.openhandsetalliance.com/) there are already 84 partners.

\section{Design Architecture}

The Android operating system is structured in several layers, as shown in Figure 2.2. Android relies on the Linux kernel version 2.6, acting as an abstraction layer between the hardware and the software. This layer provides the core system services, such as security, memory and process management, network stack and driver model.

The Android Runtime layer includes the Dalvik virtual machine and a set of libraries providing most of the features of the Java programming language. Each Android application executes on a single process, each of them on top of Dalvik VM. Dalvik runs on top of the Linux kernel and was designed so that it is able to run several virtual machines at the same time, efficiently. The Libraries layer contain a set of $\mathrm{C}$ and $\mathrm{C}++$ features used by several components of the Android system - including both 2D and 3D graphics engine, a database engine, media libraries, among others. These capabilities are then used by

\footnotetext{
${ }^{1}$ http://developer.android.com/guide/index.html
} 


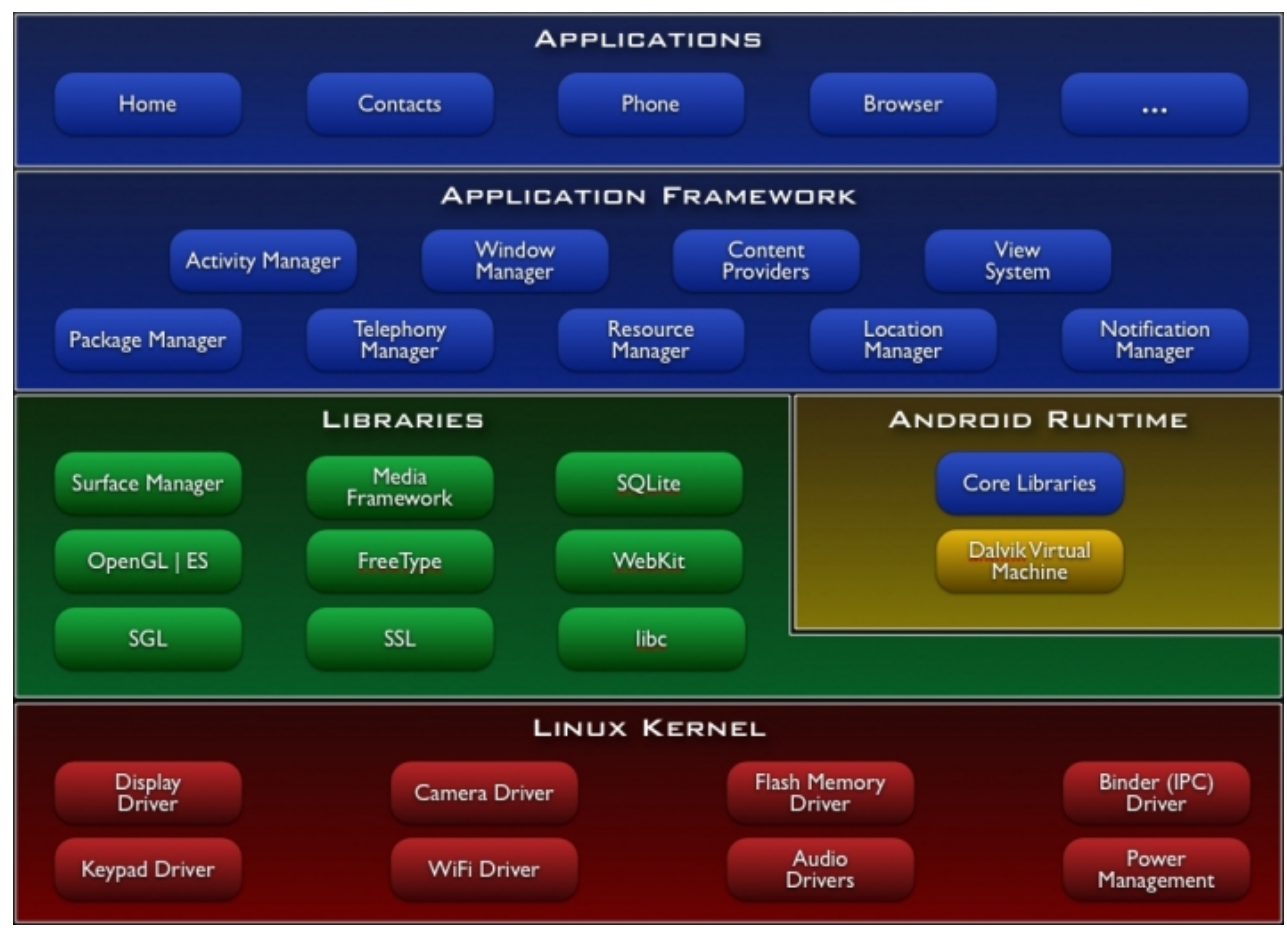

Figure 2.2: Android Architecture ${ }^{1}$

developers through the Application Framework. This Application Framework layer simplifies the use and reuse of components, by giving the developer full access to the same framework APIs used by the core applications. This layer is the basis for building the rich applications available to the end-user, such as the browser, the contacts, the phone or every installable application.

Several versions have been released since the beginning of the Android project, the latest being Android 4.0.3. It is important to know the distribution of the active devices running a given Android platform before the development phase. Developing an application for the most recent platform could restrict it to devices owned by just a small share of the market, therefore it is helpful to understand this, in order to develop an application that can be used by most of the users of the Android market. Figure 2.3

\section{Market Share}

The Android platform has been increasing its popularity since its appearance. According to a report by Gartner Inc. $\left[\mathrm{CZM}^{+} 11\right]$ on the market share of mobile communication devices, Android is the leader. Table 2.4 shows the worldwide smart-phone sales to end users by Operating System in the first quarter of 2012. 


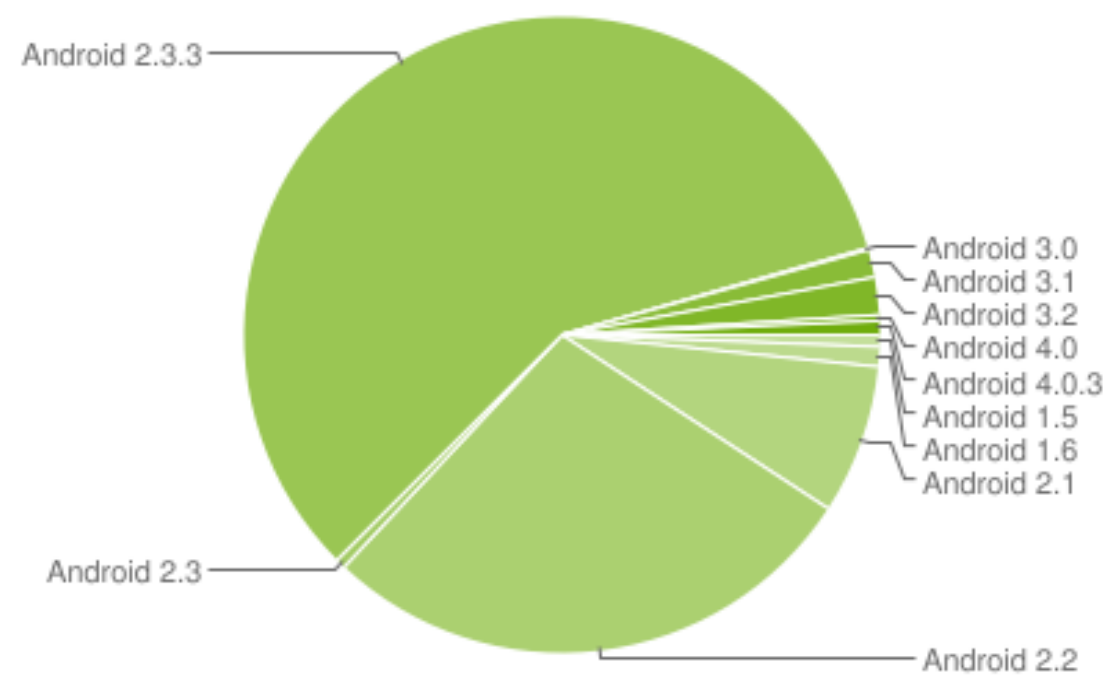

Figure 2.3: Current Distribution

\subsubsection{Ruby On Rails}

In order to send the sensor's data to the medical entity and store all the patient's information, it is required to develop a web server. Its purpose it to serve as an interface between the patient and the health-care specialist. For this end, I decided to use the open-source web application framework Ruby On Rails. Although it is not the most used framework in the Internet, it has been growing at a fast pace and several acclaimed personalities in the software industry have shown their interest on it ${ }^{2}$. A quote by Tim O'Reilly is presented below:

"Ruby on Rails is a breakthrough in lowering the barriers of entry to programming. Powerful web applications that formerly might have taken weeks or months to develop can be produced in a matter of days."

This ability to develop rich applications in a short period of time was probably the main reason to have chosen this technology over other server-side scripting languages, such as PHP, ASP, Java, among others.

Bachle et al. [BK07] take a look at the Ruby On Rails underlying principals and main components. The following words on Rails are a brief overview of those concepts.

\section{RoR Principals}

Although Ruby On Rails provides the tools for developing complex and state of the art websites, the basic objectives are simplicity, reusability, expandability, testability, productivity and maintainability. In order to accomplish these goals, the following principals:

\footnotetext{
${ }^{2}$ http://rubyonrails.org/quotes
} 
Table 2.4: Worldwide Smartphone Sales to End Users by Operating System in 2Q11 (Thousands of Units)

\begin{tabular}{lcccc} 
OS & $\mathbf{1 Q 1 2}$ & $\mathbf{1 Q 1 2}(\boldsymbol{\%})$ & $\mathbf{1 Q 1 1}$ & $\mathbf{1 Q 1 1}(\boldsymbol{\%})$ \\
\hline Android & $81,067.4$ & 56,1 & $36,350.1$ & 36.4 \\
iOS & $33,120.5$ & 22.9 & $16,883.2$ & 16.9 \\
Symbian & $12,466.9$ & 8.6 & $27,598.5$ & 27.7 \\
Research In Motion & $9,939.3$ & 6.9 & $13,004.0$ & 13.0 \\
Bada & $3,842.2$ & 2.7 & $1,862.2$ & 1.9 \\
Microsoft & $2,712.5$ & 1.9 & $2,582.1$ & 2.6 \\
Others & $1,242.9$ & 0.9 & $1,495.0$ & 1.5
\end{tabular}

- MVC architecture - A model-view-controller architecture clearly separates the code depending on its purpose. The corresponding frameworks in Rails for this model are the Active Record, Action View and Action Controller.

- Convention over configuration - Ruby On Rails attempts to save some of the developer's time by using several commonly used approaches in the design of web applications. Very little configuration is needed for each project and the RoR framework is able to firmly integrate each components to cooperate even without configuration. However, it is still possible to overwrite conventions so that specific adjustments can be made.

- Don't Repeat Yourself - The DRY approach helps developers repeat themselves seldom or never. It is designed to make singular declarations and reuse as easy as possible.

- Scaffolding - This is a command line command, letting RoR create a basic skeleton of controllers and view templates that already include CRUD operations. It also allows for automatic generation of some recurring elements, such as the login form, saving precious time and letting the developer immediately start work on core functionalities.

- Immediate feedback - RoR does not require projects to compile first and then execute. It allows developers to get an updated status of their program by reloading the browser.

- Ruby - Ruby On Rails, as it says, is based on the dynamically typed, objectoriented Ruby programming language, introduced in 1995 by Yukihiro Matsumoto. In relatively little code, developers can cover a lot of features in their application.

\section{RoR Components}

A description of the interaction between RoR framework components in shown on Figure 2.4 and their purpose is then presented. 


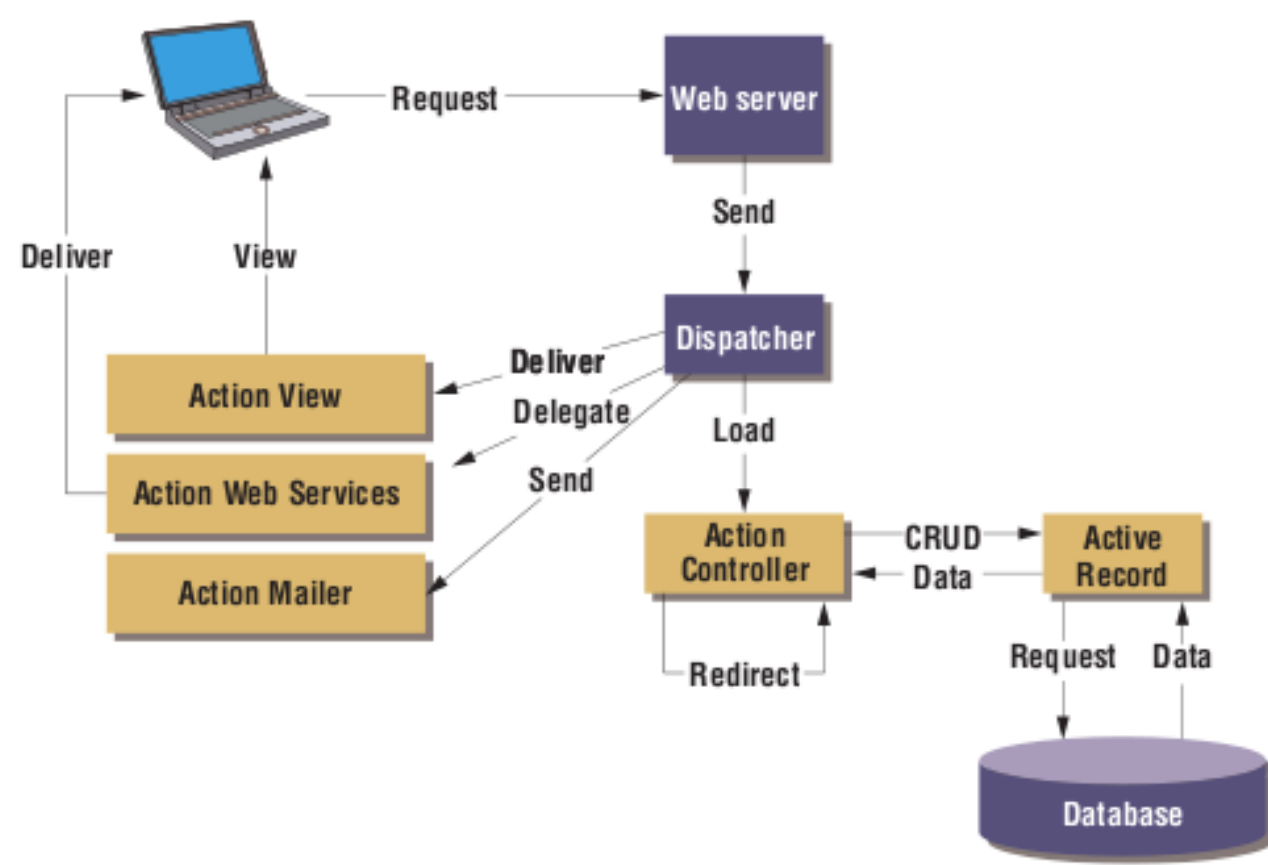

Figure 2.4: Ruby On Rails framework components

- Active Record - This component establishes the connection between the domain objects and the database, transforming the CRUD functions that come from the Action Controller into SQL commands. Sends the requests to the database and returns the received results to the Action Controller.

- Action Controller - Through the Action Controller, developers define actions determining how the controller will react to HTTP requests. A typical procedure involves this module to receive a request from a URL, process it as an action or object and then send the correct view back to the browser. It also establishes the connection to an Active Record and supplies data from the database Action View, Web Services and Mailer.

- Action View - Action View has the purpose of presenting data, typically, in the HTML format. Rails has templates to separate the presentation layer from the rest of the application. Although it has several template forms, the most relevant are RHTML and RXML. RHTML templates mix Ruby code with HTML and during runtime, templates are filled with content obtained from Ruby. To create XML files, RoR has its own builder library, transferring Ruby commands into XML tags.

- Action Web Services - Using this component, RoR supports XML-RPC-based and SOPA-based Web services, easing the publishing of features and the inclusion of external services. 


\subsection{Conclusions}

Looking back section 2.1, several projects were found going in similar directions as the ones pretended with this dissertation. Table 2.5 shows a brief overview of their characteristics. It can be seen that although they might use one or two of the features pretended in this thesis, none of them completely gathers them. This finding comes to strengthen the fact that there is still room for research improvements, when it comes to sensor technology applied to the health monitoring and well-being of the elderly.

Table 2.5: State Of The Art - Overview

\begin{tabular}{lcccc} 
Project & Device OS & Sensor technology & Anomaly Detection & Target \\
\hline UAHealth [MSJ11] & iPhone & ANT+ & No & Athletes \\
Heart Monitoring [GL07] & Windows Mobile 5.0 Pocket PC & Bluetooth & Yes & High risk cardiac patients \\
e-Health Monitoring [CRP08] & Symbian & Bluetooth & Yes & General population \\
eCAALYX [BWTJ11] & Android & Bluetooth & Yes & Elderly w/ chronic diseases
\end{tabular}

After analysing these projects, there are a few interesting points of view that could be of use for this thesis. The researcher Sarasohn-Kahn [SK10], is concerned that too much application development is carried out by specialists without the involvement of patients. She believes that the challenges to the smart phone growth include finding the right business model and privacy issues.

Regarding the patient's attitudes and perceptions, it should also be noticed that not all the elderly will be willing to adopt such a monitoring system. A study from Marzegalli et al. $\left[\mathrm{MLL}^{+} 08\right]$, showed that some patients embraced the use of mobile applications for remote monitoring, although they were not willing to replace the personal contact with their health workers and older patients with disabilities will find it difficult to adapt to such systems. However, the elderly of tomorrow will be the middle aged of today, who are familiar with the technology involved in this type of health monitoring. Nowadays generation use these technologies on a daily basis for working, studying and leisure, so, hopefully, some of the usability issues regarding the current generation of the elderly might be, at least partially, solved.

It is true that the willingness of chronically ill adults to use mobile phones as a health device is something out of control for researchers and software engineers. But one implicit conclusion of these papers is that what developers can, indeed control, is what applications are delivered to the end-user; and only that can influence the will of our target audience.

The research on automatic detection of anomalies 2.2 was also relevant in order to find accredited and reliable threshold values used for the majority of the population, for each sensor data. However, this research became no longer subject to further studies, once both patient and physician requirements were elicited. The motives for this choice are described later, on chapter 3. Finally, section 2.3 has demonstrated the main features and advantages of the technology in use, hopefully proving that their choice was appropriate and beneficial to the end product. 


\section{Chapter 3}

\section{System Requirements and Architecture}

\subsection{System Requirements}

This section presents the system requirements specification, as a result of the first phase of the prototype development. The following subsections begin with a description on the requirements elicitation process, followed by a context description, actors classification, use-case diagrams, non-functional requirements and the system's assumptions and dependencies.

\subsubsection{Requirements Elicitation}

This specification process can be divided in three main parts. A first one, where the system's main goals were evaluated, helping to define its scope, that is, the system boundaries. The next part was an investigation on the state-of-the-art, looking for projects, studies and technologies similar to the one being developed in this dissertation. This research improved the system requirements firstly, by discovering the latest and most innovative works around this area; and secondly, by understanding what went right and wrong in those works, hopefully this system will gather the best of them.

At last, several informal interviews were made with medical specialists, including doctors and nurses. This gave insights on what the system should do (or not do) and also some directions regarding the health monitoring. During these interviews and based on the opinion of those specialists, important decisions were made on the features to be developed. It should be noticed that although the interviewed clinicians had a different technical background, the sample was not as diverse as it could be, given the available time for these phase was short. An overview of the points-of-view appointed by the specialists are presented next: 
- Given the available devices ${ }^{1}$, the most easily detected disease would be hypertension. Regarding hypertension, specialists gave us a few insights, namely that the main causes of its appearance are lack of physical exercise, excess of salt and stress. Also, for a correct diagnosis, one blood pressure reading alone is not conclusive, it must always be compared with the patient's measurements history and medical background. Besides, for the blood pressure reading to be accredited, it should follow a set of guidelines [NIC11], otherwise it could be meaningless. For instance, if a patient measures himself while in stress or after a workout, the values will always be higher than a regular measurement.

- Each sensor has more or less utility, depending on its target patients or diseases. Both medication and diagnosis processes vary significantly depending on the device and desired monitoring. Also on the sensor devices, a glucose meter would be a very interesting complement the system, given that it monitors a disease - diabetes - that requires constant monitoring of its main values.

- A better knowledge of the disease by the patient himself is always beneficial. As stated by Seto et al. in [SLC ${ }^{+} 12$ ], appropriate self-care has been found to improve health outcomes. Integrating some kind of hint advisor before and/or after each measurements, would be interesting.

- Regarding the user interface, it is very important to keep things simple and not complicate processes and operations for both patients and physicians.

- From a patient point-of-view, giving constant feedback from the patient's clinician is an important feature, although it may be hard for him to handle extra workload. All doctors indicated nurses, as the ones with the most appropriate profile for managing the patients. They would filter most measurements and the doctor in charge would be contacted in emergency situations, only. In order to optimize the feedback sent by each clinician, the patient readings could have a configurable schedule, so each clinician would be able to manage his own schedule with the moment when patient readings are most abundant. The system should also be able to filter between normal values and the ones exceeding certain threshold values, for easier reading.

- Similar systems being currently used are focused on real-time monitoring, with the patient having to walk with some devices at all time. When the patient goes back to the clinic, all recorded data is exported and only later, analysed. The flexibility and mobility provided by the system being developed here would be a big advantage. One of the clinicians is confident that, despite all medical applications out there, there is still room for a mobile health monitoring system like this, not only because

\footnotetext{
${ }^{1}$ At this phase of the thesis, the available devices on Fraunhofer AICOS were a weight balance, a blood pressure monitor, an heart-rate monitor and a foot-pod.
} 
of the clear advantages it may bring, but mostly, because of the focus being given to both patients and physicians.

- One doctor referred the possibility of manually entering the measurements, if the patient has no ANT+ device. Although it does not assure he is not sending fake values - which frequently occurs -, it does not limit the system to these kind of devices and allows the system to handle any sensor that can be used by the patient, at home.

- All interviewed clinicians referred the importance of separating the information presented to patients and physicians. For instance, if an anomaly is detected perhaps it is not wise to show it to the patient right away, or even show it at all. This type of information may worry the patient in a way that is not beneficial for either patient and physician.

Given all these insights and after weighting the pros and cons, the following decisions were made. The devices to be integrated in the system would be the weight scale and the blood pressure monitor, as these are the ones with most medical relevance, easing the clinician task of monitoring hypertension. Because a blood pressure reading must follow certain guidelines to be validated, the mobile application would include a simple wizard for the patient to know how and when to take that reading.

In order to access the system, it was decided to build a web application so that physicians could access it, at any time. Patients would also be able to do so, but their main platform would be a mobile application, installed in his smart-phone, able to communicate with the sensor devices, send and receive information from the web application.

To remember the patient of each assigned measurement and also to give some flexibility to the clinician, the web application would allow the scheduling of alarms for each sensor device. Regarding the separation of information to be shown to patients and physicians, it was decided to not present any kind of warnings to the patient. The decision of when and how to warn the patient, is transferred to the physician, which in deed, is a more natural process. If the anomaly is detected, the physician will be immediately warned and then, if he wants to, he can send a message to his patient saying whatever he feels more appropriate.

Since more than one clinician can be monitoring a patient, the system should be able to associate several clinicians to the same patient. This way, a nurse could be monitoring that patient, for instance, every two days, while his doctor would only access the web application once per month.

At last, it was decided not to implement the automatic anomaly detection system as it was initially thought, at least for now. From what we were told, it is a difficult task even for clinicians and given its complexity, it would take time that is not available during 
this thesis. Instead, the web application would allow the clinician to set threshold values for each variable of each device, for each of his patients. Once a reading exceeds that threshold value, then the system would present that reading as an irregular measurement, alerting the clinician for that situation.

\subsubsection{Context Description}

This subsection presents a description on how the system is expected to be used by its different stakeholders. To begin with, a chief physician - someone in charge of the system administration inside the hospital or clinic - should register physicians (doctors and nurses) in the system. This will be an occasional operation taking no longer than a couple minutes. This chief medic should also give instructions to physicians on how to use the system, since they will be the main users of the web application and the ones who will present both web and mobile application to the patients.

Once the system is well understood and a doctor has an appointment with a patient - who could benefit from the monitoring system - he presents it to the patient. If the patient is willing to use the system, he should first register himself on the web application (this can also be done by his physician). It is then necessary to configure the mobile application with the user's credentials, so it is able to communicate with the web server. This operation can be done during the appointment or at a later moment by the patient, if he feels comfortable to do so. The last required step, is for all interested clinicians in watching over this patient to say it on the web application. They can do so with a click of a button on each patient's public page.

By the time the patient leaves the clinic, he can start interacting with the system by taking measurements from his sensors, sending them and receiving feedback from his physician, that will then access the web application whenever he receives an alarm or chooses to analyse the historical data from his patient.

This procedure assumes the patient already has all required devices: one smart-phone and one (or more) sensor devices. Acquiring the sensors will depend on the business model adopted by the medical entity. For instance, the patient could buy the devices to that medical entity or some kind of renting system could be used.

\subsubsection{Actors}

The target user for the mobile application is a senior person, whose knowledge on technology and smart-phones might be fairly different between each user. However, the interface design was designed to mitigate the low level of the user's expertise, in order to provide a seamlessness interaction with the system. The user of the web application will commonly be a physician, expected to have, at least some experience with computers and browsing 
the Internet. It is also expected the physicians are capable of making informed decisions on each patient's condition.

The levels of expertise required to seamlessly use the system are little: for the patients, although familiarity with the Android platform is an advantage, the expected knowledge required to use the mobile application is practically none, as the emphasis given on usability and interface design was great; for the physicians, as the web application experience is similar to using any regular website, anyone familiar with web browsing is skilled enough.

Given the fact this system was a developed as a proof of concept, little emphasis was given on the management of the web application. Features such as creating, editing and removing physicians, patients and health records were kept simple, although in future development these would require a clear specification, which would be different whether the system is used within a hospital or a private clinic.

The main actors are described in the following list:

- Patient: Represents the patient, having access to all of the features available on the mobile application. He can also access the web application, having mainly read permissions. This allows him to view his historical data, his physician's general information, his assigned sensors and respective measurements frequency. He can also view all received and sent feedback messages, as well as send new messages to the physician.

- Physician: User authenticated in the web server, having access to most of the web application features. These features include registering new patients, managing them and setting up general system settings. This actor is not supposed to interact with the mobile application.

- Chief medic: Entity with most authority on the system, allowed to do everything a physician is able to do and, also capable of registering and removing new physicians in the system.

\subsubsection{Use Cases}

Figure 3.1 presents the use case model of the whole system, having two main packages: the mobile application package and the web application package. They both represent the usage of the mobile and web application, respectively.

As it can be seen, a patient will use both mobile and web application, while the physician and chief medic solely interact with web application. The following subsections provide a description for each of the use cases in each package. Although there is a connection from the patient to the web application, not all use cases are available to him. These details are further detailed on the relevant use cases. 


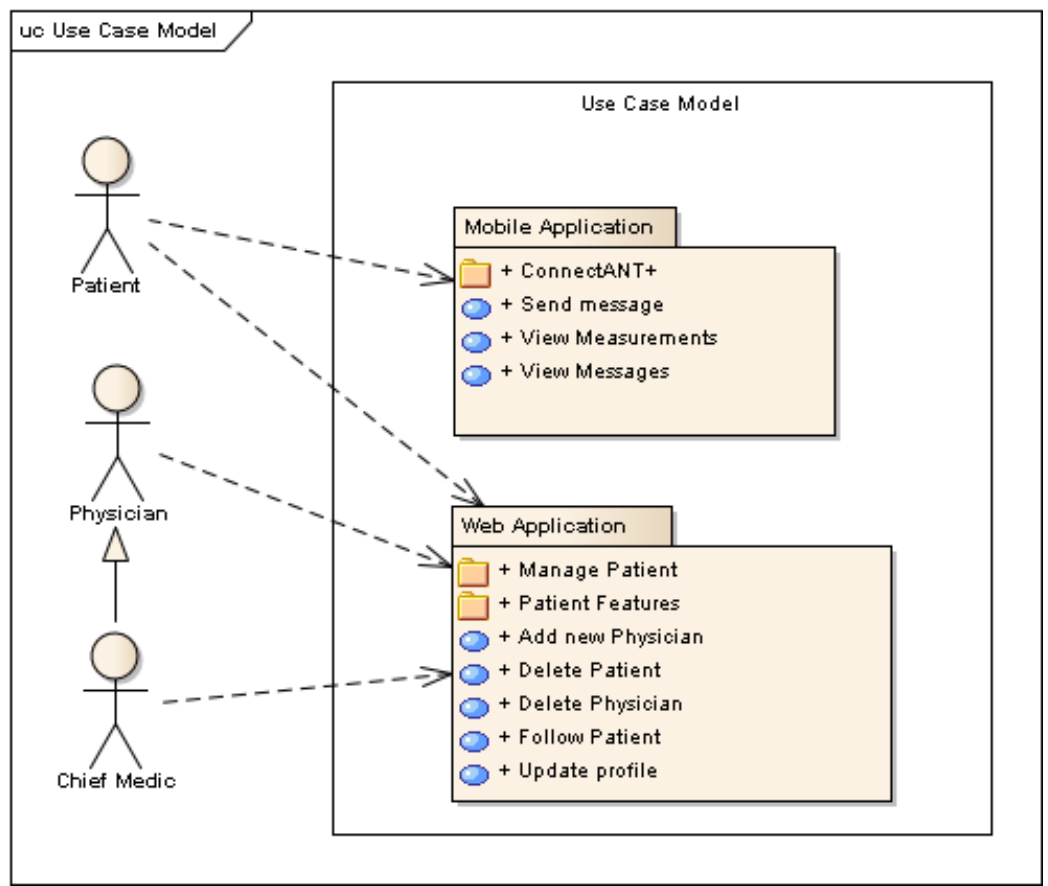

Figure 3.1: Use Case Model

\subsubsection{Mobile Application}

The mobile application use case diagram 3.2 shows the several activities the patient can perform on his smart-phone. The Connect Ant+ package (Figure 3.3) encompasses all operations involving the connection between sensors and smart-phone. The following list describes each use-case:

- View Measurements: Allows the patient to view his past measurements, grouped by sensors. It is supposed for the user to have already taken some measurements and sent them to the web server.

A measurements list will appear upon opening this view. It is possible to group this list by different sensors, selecting them from a check list.

Priority: High

- View Messages: Shows all sent and received messages, assuming there is at least, one message sent from the physician. This message list will not be updated until the patient opens the mobile application being connected to the Internet.

The list of messages appears when this view is opened. Each list item can be clicked in order to view the full content of the message.

Priority: High

- Send Message: Allows the patient to send a text message to the web server, assuming there is an Internet connection available. 


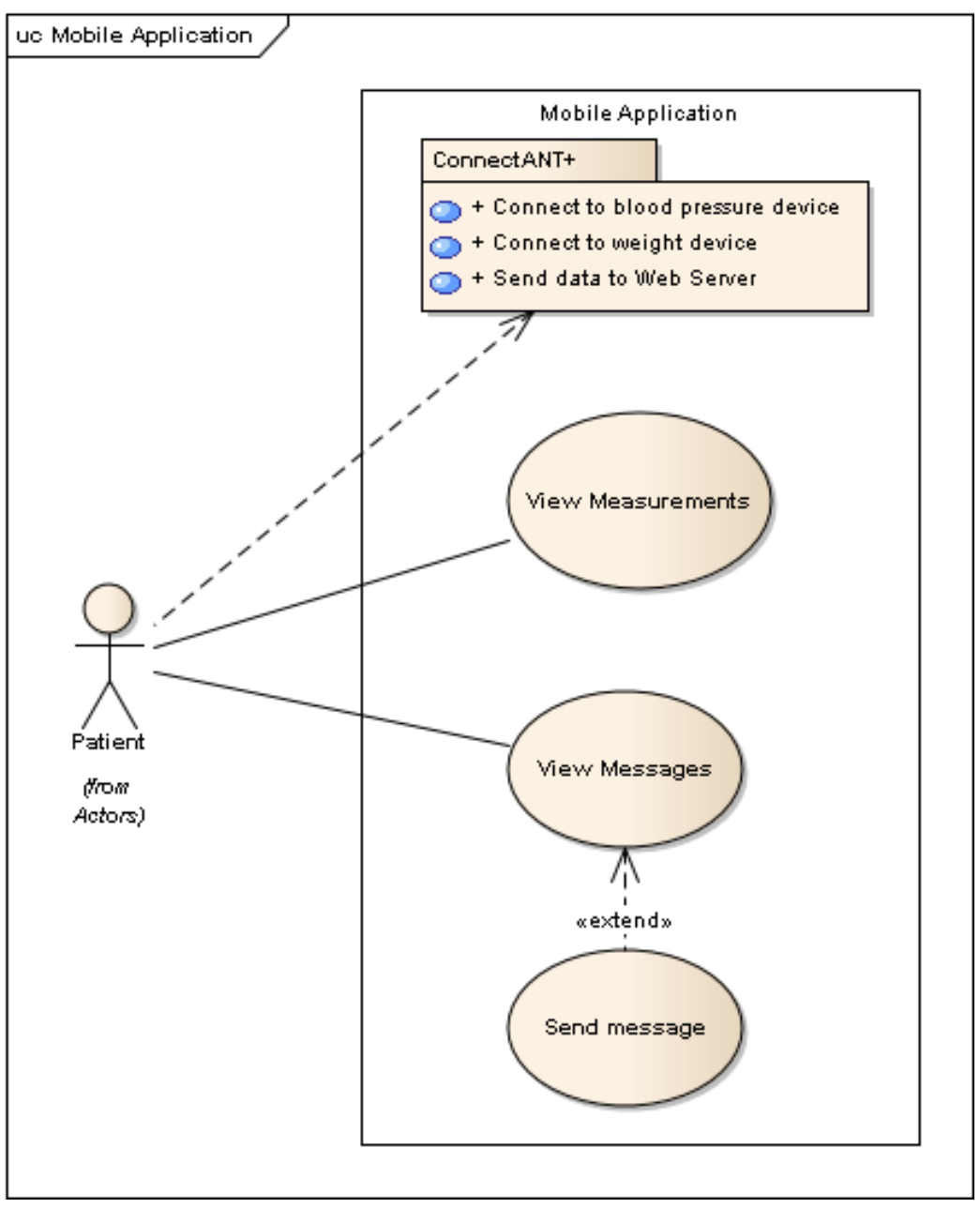

Figure 3.2: Mobile Application

This use case is available through the previous one - View Messages - having an input form to write and send the message.

Priority: High

- Connect to blood pressure device: Establishes a connection with the blood pressure device and receives the latest measured data, assuming the user has an ANT+ blood pressure device near him. Once he chooses this device, the patient's procedure is to follow the carefully designed instructions and wait until the connection is established and the values are read.

Priority: High

- Connect to weight device: Connects with the weight device and receives the latest measured data, assuming the user has an ANT+ weight scale near him. Just like the previous use case, once the patient selects this device, he simply follows the given 


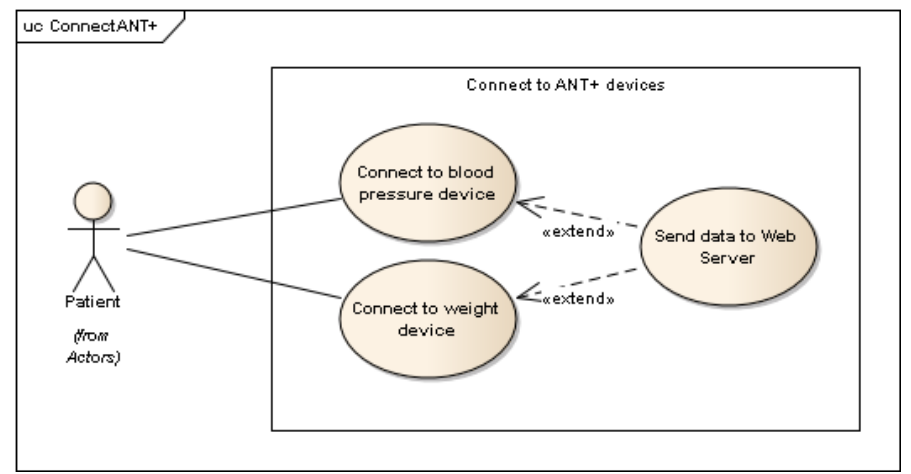

Figure 3.3: Connect to ANT+

instructions on his smart-phone and in time, the values should appear in his smartphone.

Priority: High

- Send data to Web Server: Sends the measured values to the web application through the network. It is expected the user has already performed one of the previous use cases - connect to blood pressure device or connect to weight device - and has an Internet connection available, otherwise it will not send those values. If the measurement is successfully sent, it is stored in a local database, so the patient can review his measurements whenever he wants to.

Priority: High

It is important to notice, that all ANT+ devices connected to the mobile application must operate according to their corresponding protocol or profile, as defined by the ANT+ Alliance. These profiles assure the interoperability between ANT+ devices. However, different protocols sometimes require different use cases for each device. These questions are better described later, on chapter 4, but the fact that one of the main goals in this thesis was to keep the user interface easy and concise, efforts were made in order to keep the same user interaction between each device.

\subsubsection{Web Application}

Figure 3.4 presents the use case diagram related with the web application. As it was introduced in subsection 3.1.3, several actors can access it: patients, physicians and a chief-medic. The patient only has access to reading operations; the chief medic is allowed to do everything the physician does, plus adding new physicians into the system. A detailed description on each of the use cases is presented below.

- Add New Physician: Allows the chief medic — and no one else - to register new physicians, a doctor or a nurse, into the system. This will be a seldom operation, as 


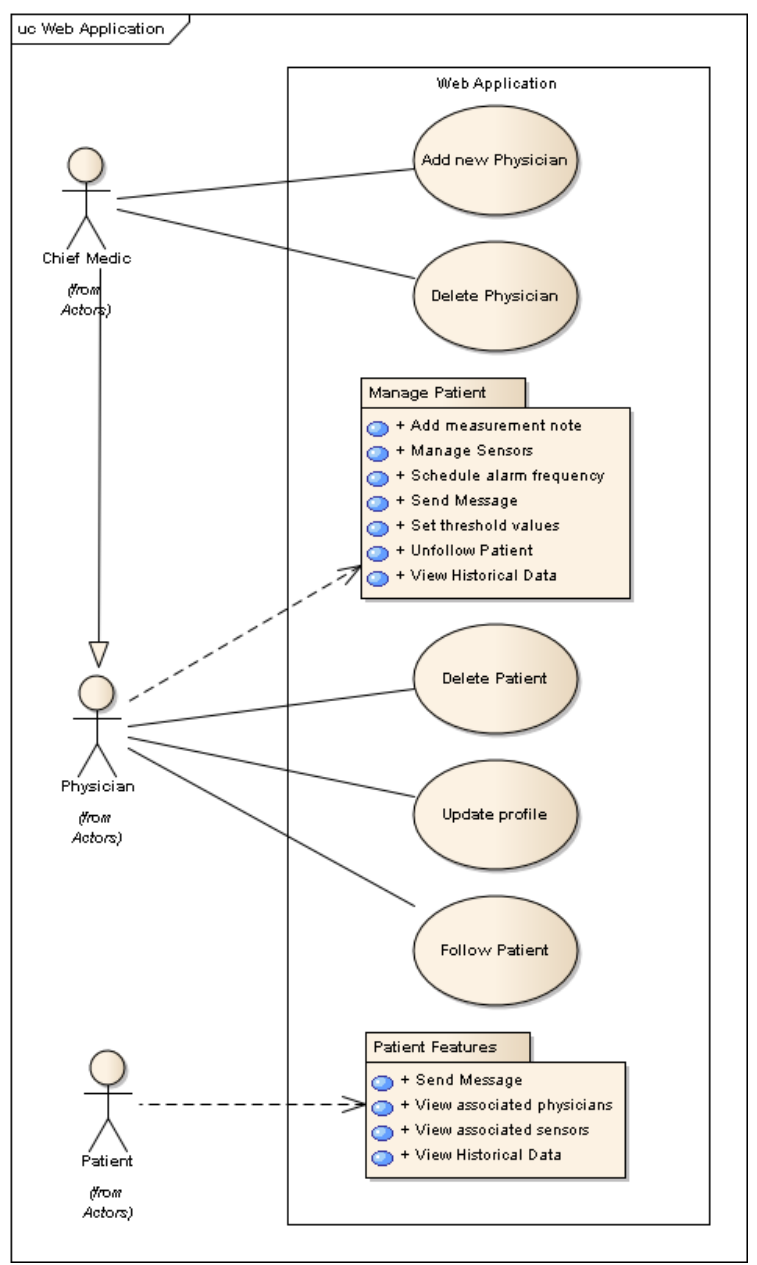

Figure 3.4: Web Application

the number of physicians in the clinic does not change very often.

The chief medic introduces the physician basic data, such as name, speciality, email contact, among others and after submitting the form, an email is sent to the newly physician with his system credentials.

Priority: Low

- Delete Physician: Opposite use case to the previous one, enabling the chief medic to remove physicians from the system.

Priority: Low

- Delete Patient: Similarly to the previous use case, allows the removal a patient from the system. It can be done by either the chief medic or a physician.

Priority: Low

- Update Profile: Use case where the user is presented with a simple form allowing him to change his personal data, such as name, contact, password, among others. 
Priority: Low

- Follow Patient: By following a patient, the physician is allowed to do all operations regarding the management of a patient, as described in Figure 3.5, allowing the physician to keep an eye on as many patients as he wants to.

Priority: High

Regarding the management of each physician's patient, Figure 3.5 presents the use case diagram that encompasses all operations available to interact with them. All the use cases on this package assume the user already selected a patient to interact with.

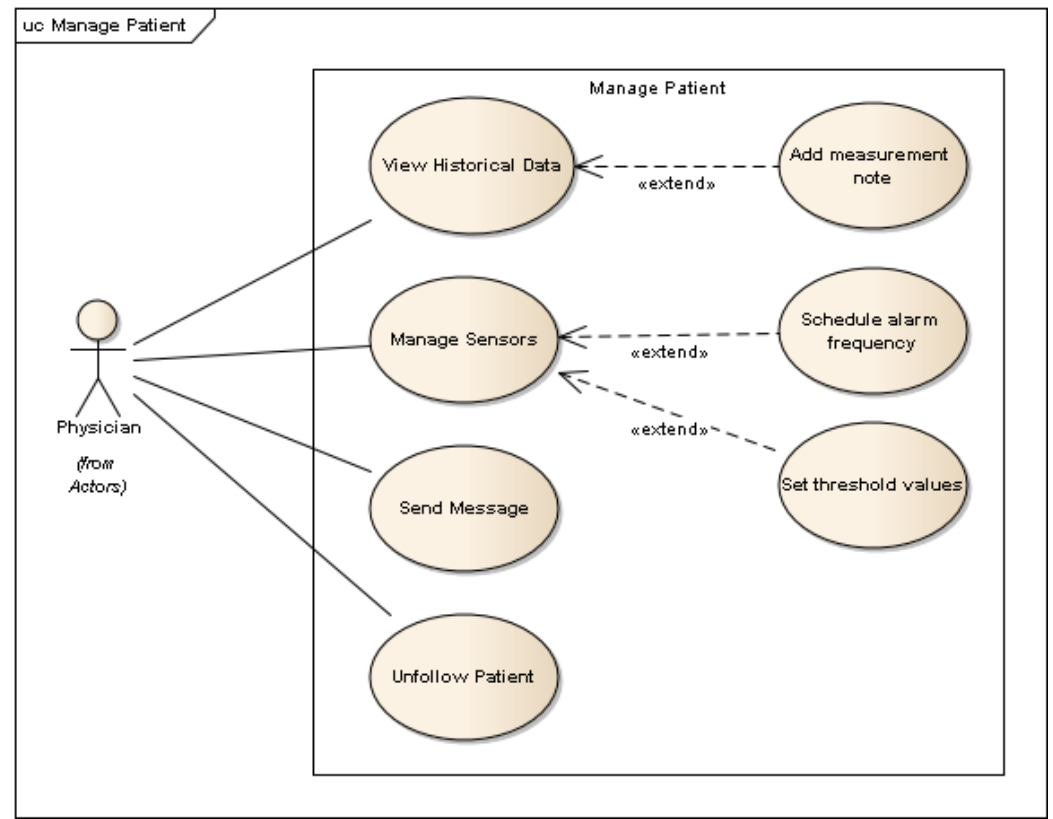

Figure 3.5: Manage Patient

- View Historical Data: Shows both measurements taken by this patient and feedback messages sent to him, or received by him, ordered by date. The measurements list can grouped by the different sensors associated with the patient. For each measurement it is also possible to do the following operation.

Priority: High

- Add Measurement's Note: Allows the physician to add a specific note for a measurement on this patient, visible for all doctors and nurses associated with this patient. Each measurement has an appended button that pops up a simple form to write the note. Once created, the note can be edited or removed at any time.

Priority: Low 
- Send Message: Allows the physician to send feedback messages to his patient. The patient will then be able to see those messages in his smart-phone or in the web application.

Priority: High

- Unfollow Patient: Allows the user to stop monitoring a patient. By choosing this option, the physician stops having access to all operations inside this use case package (Figure 3.5)

Priority: High

- Manage Sensors: Allows the physician to associate or dissociate sensors from this patient. The list of sensors of a patient, defined in this use case, has a direct impact on what measurements are taken by that patient, since the physician will need to specify both an alarm frequency for the user to take this measurement and the threshold values associated with this device. These two use cases are described below. Priority: High

- Schedule Alarm Frequency: Allows the physician to specify how frequently should this patient take a measurement with this sensor. This frequency is then reminded to the patient on his smart-phone with custom-built alarms, remembering him to measure this value.

As it was previously described, the physician has to specify how many times per day, week or month, he wants his patient to perform the measurements and when the patient's smart-phone connects with the web server, the system synchronizes itself.

Priority: High

- Set Threshold Values: Lets the physician specific threshold values, regarding this sensor. The physician can specify a lower bound and/or upper bound for each value received with this sensor.

Whenever a patient's measurement exceeds a threshold value, that measurement appears with an alarm icon, so the physician will know something wrong happened. This alarm icon will only be visible for the associated physicians. Priority: High

The Patient Views package, shown on Figure 3.6, presents all operations that a patient is allowed to do on the web application. These operations are described below.

- View Historical Data: The patient can view his measurement's history and feedback messages, ordered by date.

Priority: Low 


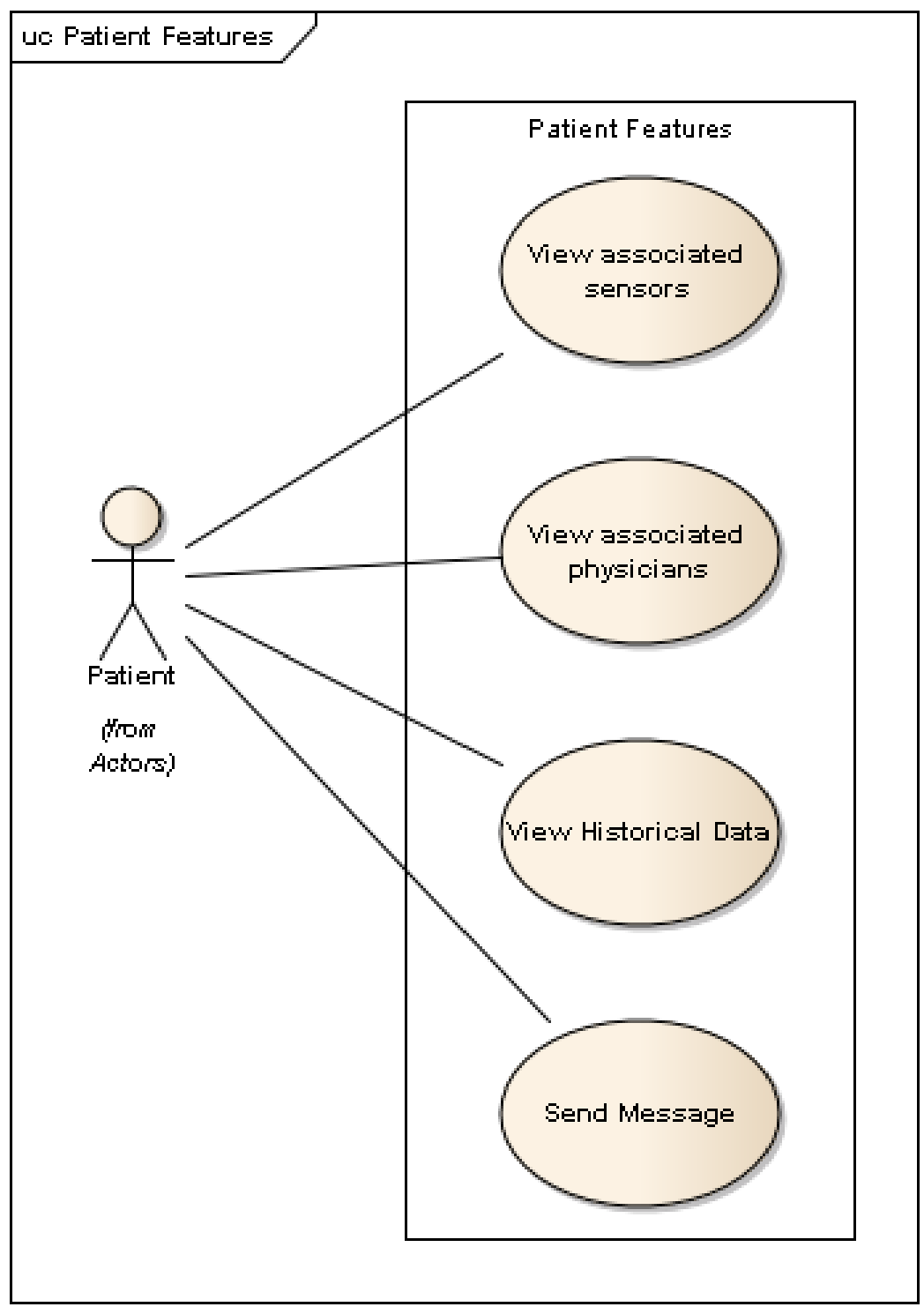

Figure 3.6: Patient Views

- View Associated Sensors: Presents the list of sensors currently associated with this patient and for each sensor, presents the alarm frequency set for this device.

Priority: Low

- View Associated Physicians: Shows the list of physicians who are associated with the patient, displaying their public details, such as name and speciality.

Priority: Low 


\subsubsection{Non-functional Requirements}

The following list presents requirements specifying non-functional requirements, i.e. a description of a property or characteristic that a software system must exhibit or a constraint that it must respect [Wie03].

- Usability: Given the characteristics of the mobile application users, it is mandatory for the application to be easy to use and learn. Usability tests and validation were made in order to comply with this property. Regarding the web application, although usability is not a major goal, its users do not have a technological background; therefore its processes should still be of easy comprehension. Priority: High

- Reliability: The simple fact that the system deals with health-related data, has a direct impact on the importance of the system to perform its required functions for a certain period of time without failing. Error-handling must be treated carefully and, in case of system error's, both the mobile and web applications should be responsive enough so the user is not led into misunderstandings and abandoning of the system. Priority: High

- Security: Also related with the fact of dealing with health-related data, comes security concerns. With a system as the one being developed, there are several points where security can be breached. The first one is inside the BAN (Body Area Network): between the sensor device and the user's mobile phone, a third-party could be listening to the measurements made by the users and send them to an unauthorized web server. Although this is plausible situation, as described in 2.1.6, at the moment of taking his measurements the user is supposed to be in a safe environment, usually at home; therefore little study is required regarding this situation. Another rising issue is about controlling the access to the web application. Patient's private data will be available on the web application and it should only be accessed by authorized entities; therefore, an authentication module should be implemented. At last and probably the biggest issue on security, is the transmission of data between the mobile application and the web server. Information will be sent through wireless networks over the TCP/IP protocol, where security can not be ensured, unless security measures are taken. The system must implement security protocols, in order to provide encrypted communication and secure identification of entities. For instance, the use of an HTTP-Secure protocol is a potential solution. Priority: High

- Interoperability: In the scope of this project, the mobile application is required to connect with pre-defined ANT+ enabled devices. However, it should implement the device protocols and profiles associated with each device. These are provided by the ANT + Alliance $^{2}$, in order to give the system the interoperability to work with

\footnotetext{
${ }^{2}$ http://www.thisisant.com/ant/ant-alliance
} 
any device whose manufacturer is part of the ANT+ Alliance. Priority: Medium

- Efficiency: The mobile application will operate on a mobile device, with limited resources, such as power, storage and battery life. These limitations are a strong motivation for focusing on saving resources. Android recommends ${ }^{3}$ a set of best practices for optimizing the system and during development these should be followed. Priority: Medium

- Portability: The physicians will access the web application through a network connection. As such, it should be accessible by different web browsers and operate in the same way for each of them. Regarding the mobile application, although it could be ported to a different platform, it will not be required within this thesis. Priority: Low

\subsubsection{Assumptions and Dependencies}

In order for the application to work as expected the following assumptions are made. To get started, the patient's mobile phone must operate on the Android operating system and support the ANT+ wireless communication technology. If this last requirement is not met, the application will not be able to connect to any device. It is also expected that each and every device supports the ANT+ technology and complies with the protocols and profiles established by the ANT+ Alliance, in order for the mobile application to set up a valid connection with them. These protocols are the link between ANT+ devices providing their interoperability. At last, it is expected the patient has an Internet connection to send his measurements to the web server. However, it is not required to have a full-time Internet connection, as the system will store the minimum necessary information until a connection is found. On the physician's side, an Internet connection will always be required so he can access the web application using a common web browser.

\subsection{System Architecture}

This section presents an overview of the system architecture, describing its domain model and underlying relationships, its physical and technological model.

\subsubsection{Domain Model}

The domain model presented on Figure 3.7 describes the various entities, roles and relationships of the system. More specifically, this was the model used for the web application. Because the mobile application deals with only one patient, the smart-phone user, its domain model is a subset of the model now being described.

\footnotetext{
${ }^{3} \mathrm{http} / / /$ developer.android.com/guide/practices/design/performance.html
} 


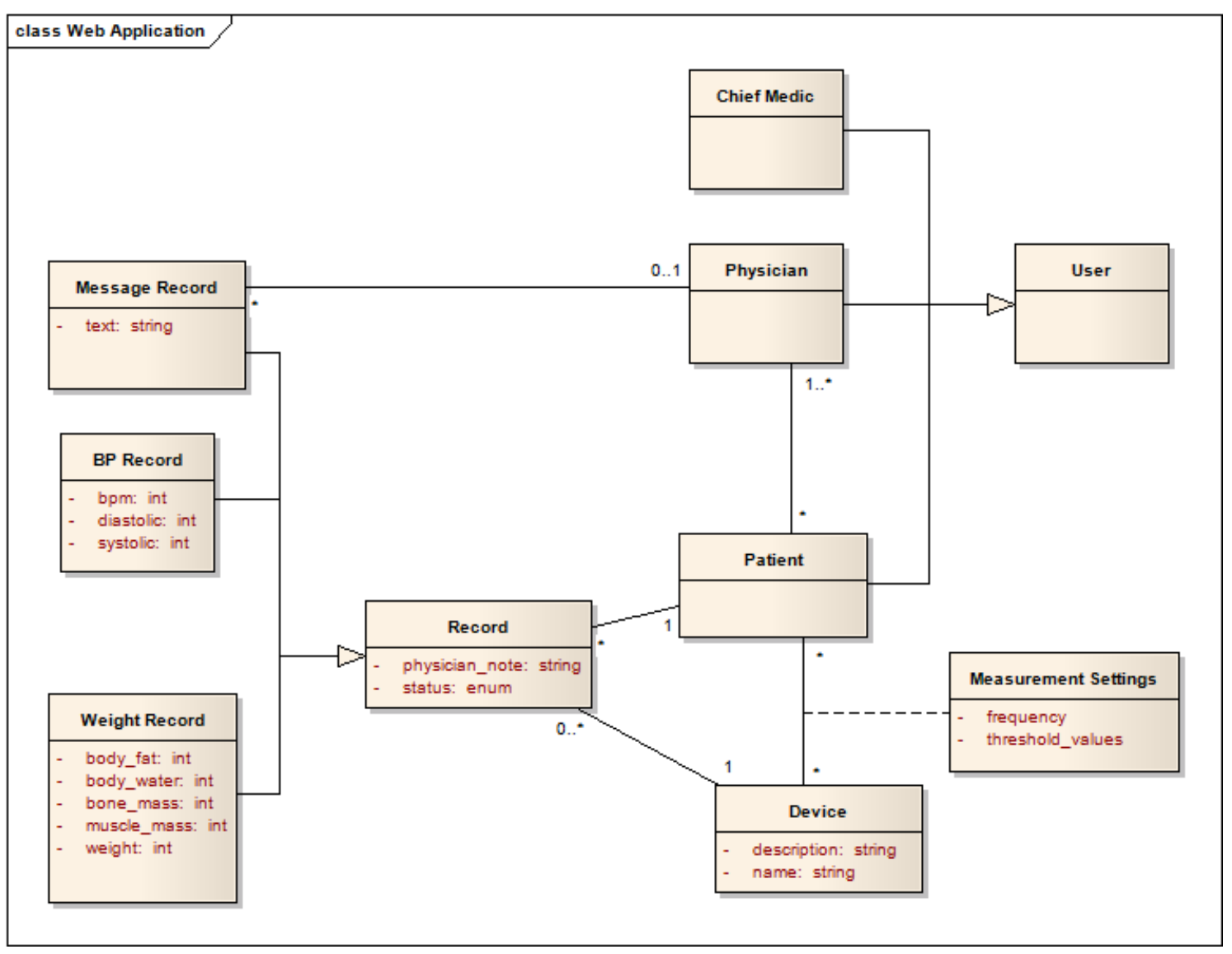

Figure 3.7: Domain Model

To begin with, there is the user entity, which then specializes in the three actors described in 3.7: patient, physician and chief medic. Then there is a record entity which can be a message record, a blood pressure record or a weight record. The message record can be a message either sent from the patient to his physician or from his physician to him. A blood pressure record and a weight record represent patient readings taken from either one of the devices.

In order to represent all relationships between patient and physician, there is a manyto-many relationship with those entities, indicating that a patient may have several physicians and vice versa. Since each patient can have many records and every record belongs to a single patient, there is a one-to-many relationship with patient and record.

Regarding record messages, it was need to assure the following: when a patient sends a message, it is sent to all his associated physicians; when a physician sends a message, it is sent to a particular patient. Therefore the one-to-many connection between physician and message record. This way it is possible to find out which messages were sent by the patient's physician. If the message was sent by the patient, a physician will reach it through all messages of his associated patients. If it was sent by the physician, the patient 
knows who sent it by this physician/message record connection.

Each patient has a set of associated sensors and associated settings. These settings include the frequency with which the patient should measure with that device and also the threshold values assigned by his physician. To accomplish this feature, the patient entity has a many-to-many relationship with the sensor entity, together with the settings association class. Given that it was decided to use only two devices - blood pressure monitor and weight scale - the relationship between patient and sensor could have been simplified. However, for the sake of future improvements it was kept this way.

\subsubsection{Physical Model}

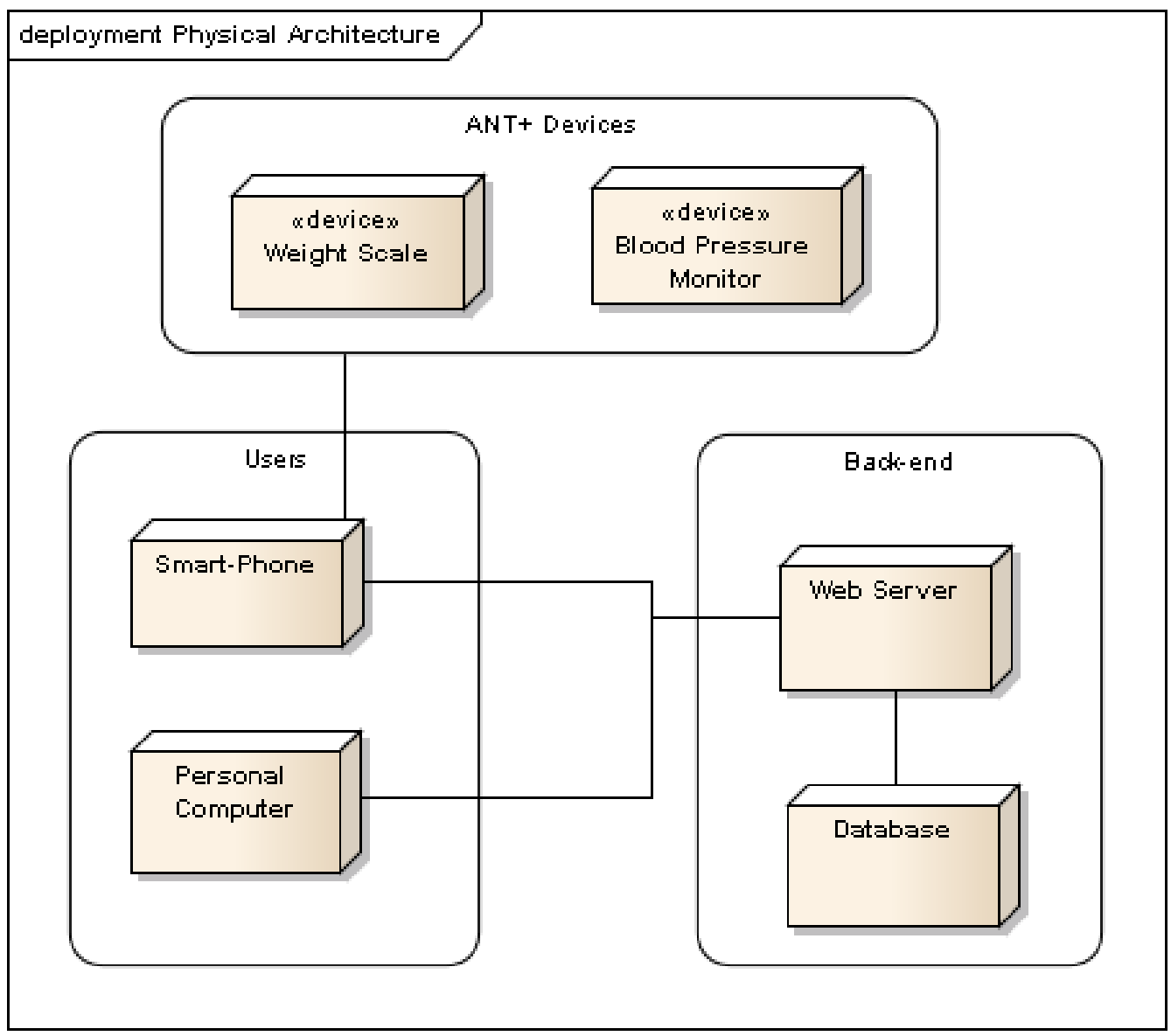

Figure 3.8: Physical Model

Figure 3.8 presents the physical architecture of the system, providing a description on how physical components will interact between each other. The diagram was grouped by: devices which solely interact with ANT+ technology, devices which remain on the back-end and devices used by patients and physicians. 
On the users devices there is the smart-phone, which is used by the elderly and interacts with all available ANT+ devices - weight scale and blood pressure monitor. The other device on this group is the personal computer, used by either patients or physicians. Both users devices interact with the web server on the back end group, serving as the connection point between the system users. At last, the web server connects with its database in order to store and retrieve the system's persistence data.

\subsubsection{Technological Model}

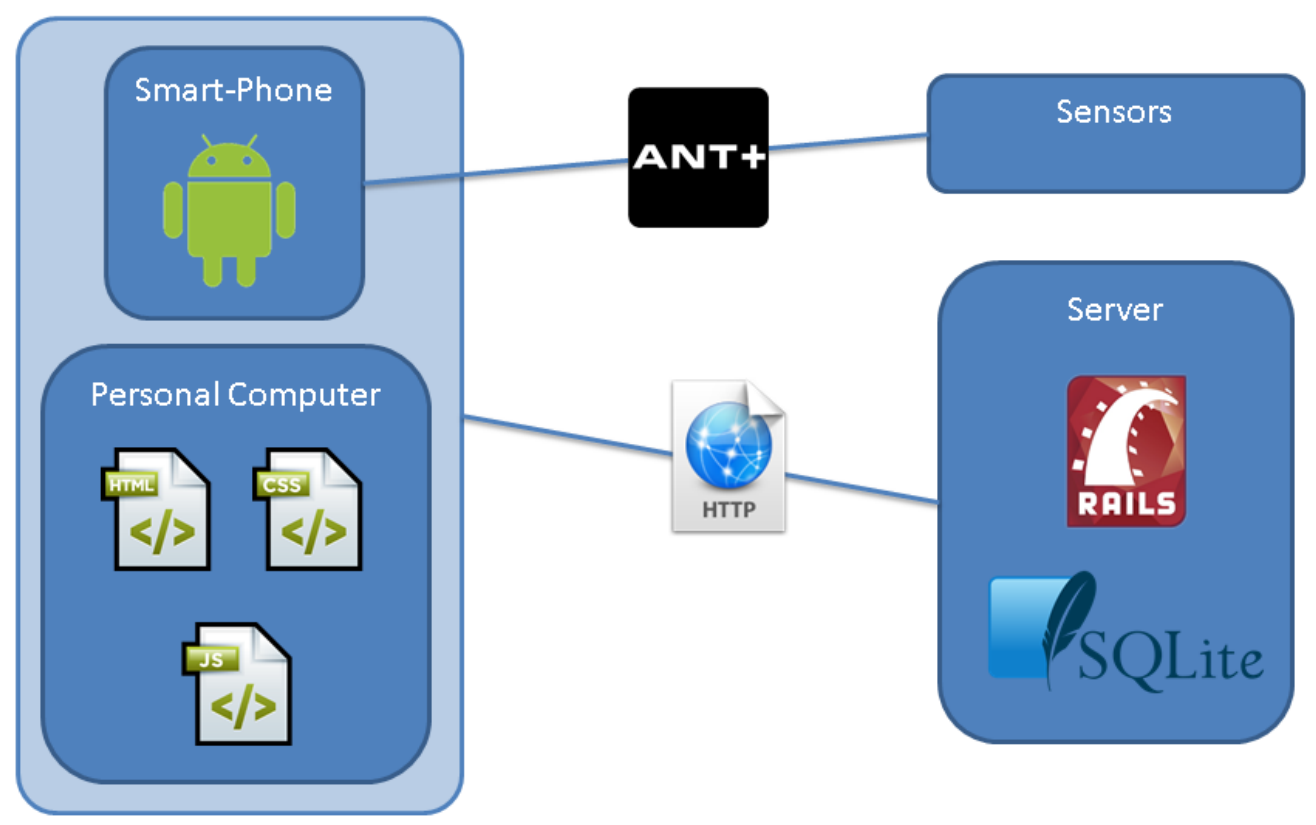

Figure 3.9: Technological Model

The technological model can be seen on Figure 3.9, giving an overview of all technologies used within the system. The smart-phone, used by each patient, operates under the Android operating system and connects with the weight scale and blood pressure monitor using ANT+ technology. Users accessing the system through the web application need a common web browser, interpreting HTML and CSS markup languages on the front-end and Javascript on the back-end. The web server operates under Ruby on Rails technology, connecting with an SQLite3 database. All users connect with the web server through the HTTP protocol - GET and POST commands were used. 
System Requirements and Architecture 


\section{Chapter 4}

\section{Implementation}

\subsection{ANT+ Protocol}

This section provides an overview on the implementation of ANT+ protocol in order to connect each device with the patient's smart-phone. It describes three main phases of development, starting with the weight scale and blood pressure device profiles, ending with the link between ANT+ and Android technology. A brief overview of this technology provided by the $A N T+$ Developer Zone is quoted below:

The ANT+ Managed Network is comprised of a group of devices that use the ANT radio protocol and ANT+ Device Profiles to determine and standardize wireless communication between individual devices. This management of device communication characteristics provides interoperability between devices in the ANT+ network.

Developed specifically for ultra low power applications, the ANT radio protocol provides an optimal balance of RF performance, data throughput and power consumption.

ANT+ Device Profiles have been developed for devices used in personal area networks and can include, but are not limited to, devices that are used in sport, fitness, wellness, and health applications. Wirelessly transferred data that adheres to a given device profile will have the ability to interoperate with different devices from different manufacturers that also adhere to the same standard. Within each device profile, a minimum standard of compliance is defined. Each device adhering to the ANT+ Device Profiles must achieve this minimum standard to ensure interoperability with other devices.

\subsubsection{Weight Scale}

ANT+ weight scales can send its weighted values to a display device in two ways: broadcast data in real-time or initiate an ANT file transfer (ANT-FS) to send all stored data 
on the display. Because the mobile application will also store each measurement of the patient, the broadcast mode is enough. The ANT-FS protocol is better described in subsection 4.1.2.2.

Each measurement usually takes a short duration ranging from 10 to 30 seconds per measurement.

The scale is able to measure the weight and, if it has access to specific user's information, such as height, age, among others, it may be able to calculate some more values, as well. This information can be set on the weight display, if it has one, or it can be sent by another device such as a watch or a mobile phone. The weight display is the screen on the weight scale, that usually shows the user's weight; however, some ANT+ weight scales are built without it. This set of user specific information is called the User Profile and it will be better described further down.

\subsubsection{Basic Use Case}

The basic use case of weighting and sending data to a mobile device is presented in Figure 4.1.

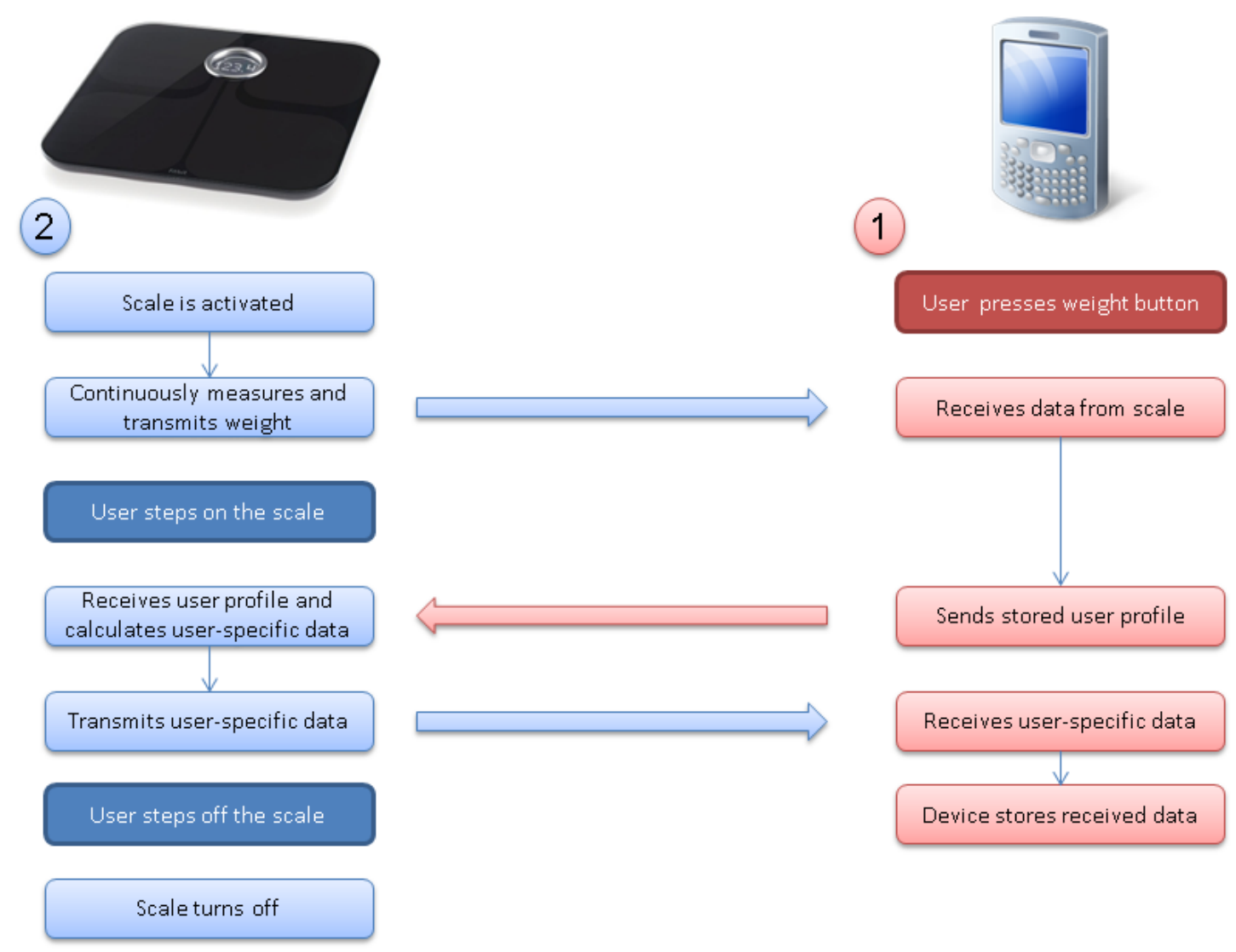

Figure 4.1: Weight Scale Use Case 
This interaction begins with the user activating the scale by pressing a button on the display device. When the scale gets activated, it starts sending data continuously, including the user's weight - which is invalid, for now - and information about the weight scale capabilities. Once activated, the user can step on the scale so the calculations begin.

If the scale is capable of user profile exchange, the user's profile can be sent in order to perform user specific measurements and computations. Once the weight scale has received the user profile and has finished its calculations, it transmits the data to the display device, which in turn can display and store those measurements. When the user sees his measurements on the display device, he can step off the scale and the device will automatically turn off.

Summing up, the user only needs to press the initial button to activate the weight scale and step on it. All other operations are seamlessly handled by both devices.

\subsubsection{Data Pages}

Before two ANT+ devices start communicating, a common channel configuration is required, including information related to the operating parameters of a channel. This information is defined by the ANT protocol and includes defining the channel type, channel period, RF frequency, among others. Once these values are set up, devices may start data exchange.

Weight scale measured data is sent from the weight scale to the display device through data pages, each one with a length of eight bytes. The first byte indicates the page number, the remaining seven bytes are sensor specific data. There are multiple supported data pages, divided into two types of data: main data and common data.

Main data pages contains the weight measurements and calculations made by the scale. Data page number one is a required data page, including the weight and user profile identification. Being a required data page, it means it must be interpreted by all ANT+ weight scales communicating devices - receivers and displays. Depending on the weight scale capabilities, other main data pages may include the following user specific measurements: user's percent body fat and percent hydration, resting metabolic rate and the recommended daily caloric intake and mass of body components including Bone and Muscle.

Common data pages contains information regarding the device itself. These pages are employed by most ANT+ devices, giving information such as the device's serial number, battery voltage or manufacturer information. In order for the weight scale to compute user specific information, the display device may send a user's profile through a specific data page number. This page includes the user's gender, age, height and activity level.

Summing up, once the users starts the weighting session, a channel is opened and configured on both sides according to the ANT protocol. Once the scale begins to send 
data, the display device checks if the weight scale supports user profile exchange. If not, the user's weight is displayed and the session is over. If it supports user profile exchange, the display device checks if the user profile is already set on the scale and if it matches the current user's profile ID. If it is not set or the ID's do not match, the user profile is sent to the weight scale and waits for the next data page, until the current user's profile ID and the user profile set on the scale, are the same; if it does match, the display device may show all available user specific calculations and the session is complete.

All these interactions were developed on the mobile application allowing it to seamlessly communicate with any ANT+ enabled weight scale. Details on the implementation of this protocol on Android are described on subsection 4.2.1.

\subsubsection{Blood Pressure Monitor}

A blood pressure monitor is designed to read the user's blood pressure. This is done by placing an inflatable cuff around the user's upper arm, which is then inflated until the flow of blood is briefly stopped, then deflated until the blood flow returns to regularity and then the blood pressure is recorded. Electronic devices are often able to display other values, such as the user's heart rate and the detection of any pulse anomaly.

ANT+ blood pressure devices are capable of storing each measurement and sending them to another device whenever required. The ANT blood pressure device profile assure the minimum capabilities to take and record blood pressure measurements. Some devices may also store multiple measurements from multiple users, allowing a collection device to receive measured data from a specific user, instead of all measured values on the device.

A collection device can be a cell phone, a personal computer or any other ANT+ enabled device, acting as a transfer device for data received from the blood pressure monitor. It may store, display or send the measured values to a data base application for further analysis. In the system being developed within this thesis, the collection device is the patient's smart-phone and it will do all those operations: store, display and transfer the measured values to a remote server.

All data is stored on the blood pressure monitor following the Flexible and Interoperable Data Transfer (FIT) protocol, defining how each measurement is saved on a file. These FIT files should be transferred from the blood pressure monitor according to the ANT File Share (ANT-FS) protocol.

\subsubsection{Basic Use Case}

Figure 4.2 presents how the blood pressure monitor is mostly used. The user takes a blood pressure reading and it is automatically stored on the device. When required, a collection device may ask the blood pressure device to transfer the stored measurements, 


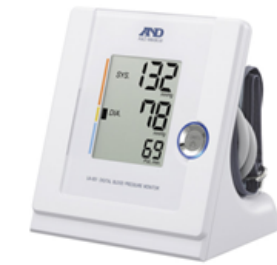

Blood Pressure Monitor

User takes reading

Data is stored in device. Data is sent to a collection device
2

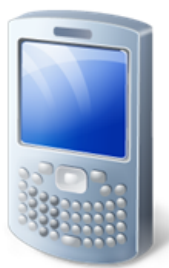

Collection Device

May store, display or send data to remote server.
3

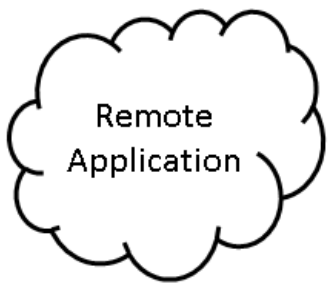

Data can be sent to clinicians or database applications over the Internet.

Figure 4.2: Blood Pressure Monitor Use Case

which in turn may store, display or send that data to a remote server over the Internet. The measurements can then be properly analysed by an healthcare professional.

\subsubsection{ANT-FS Protocol}

ANT File Transfer is a protocol implemented on top of the ANT interface, designed to enable seamless and automatic file transfer. Other file protocols like the Flexible and Interoperable Data Transfer (FIT) may be used with ANT-FS for a greater interoperability between devices. This protocol specifies three basic communication layers: link layer, authentication layer and transport layer. All layers must be fully implemented in both host and client device - an ANT-FS client is a mobile device collecting and storing sensor data that may be transferred to other devices; an ANT-FS host is a device looking to download data from an ANT-FS client. The host searches for a client beacon and may choose to initiate the ANT-FS session, if interested in receiving sensor data from the client.

An ANT-FS beacon is a message sent from the ANT-FS client, informing the host on its current data availability, capabilities and layer state. It is used to determine if a connection is desired and how it should be handled. The beacon is transmitted every channel period.

Both client and host must always be operating within a single layer at a time. Although they may not be in the same layer at the same time, it expected they progress between each layers alongside, in order to assure a seamless, secure file transfer. When a time out or error occurs, both devices return to its default layer - the link layer.

The following paragraphs describe the decisions, in each layer, required by the host device in order to download a file from the client device. 
Link Layer is the protocol's default layer, responsible for establishing the initial communication between client and host. The client starts by setting up an ANT channel and sending the beacon signal. The host starts by searching for that beacon, with its channel appropriately configured. Once the host finds the beacon, it checks its content for the client device capabilities. It accepted, it may wish to connect by sending a specific command - the link command. If this command is successfully sent, both devices move on to the Authentication layer.

The on figure 4.3 presents a link layer sequence diagram, extracted from the ANT-FS protocol document ${ }^{1}$.

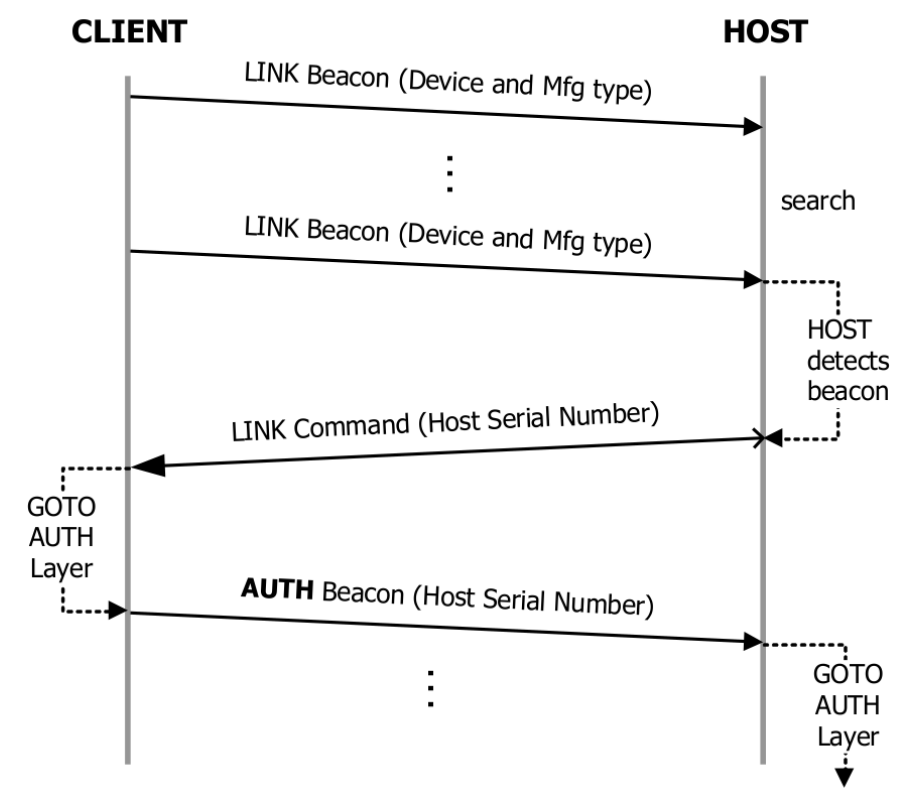

Figure 4.3: Link Layer Sequence Diagram

Authentication Layer is a state where client and host devices negotiate a trusted/authenticated relationship. It begins once the the link layer is complete and the client's beacon indicate the device being within the authentication state. There are three types of authentication:

- Pass-through: No prior knowledge of the client device is required for the host device. The client will authenticate on the host's request. It is automatically proceeds to transport layer, however, it is not secure.

- Pairing request: This type of authentication is secure, although not automatic as it requires the client device to accept a request from the host, usually involving user interaction. If accepted, the client device sends a response to the host confirming its

\footnotetext{
${ }^{1}$ ANT documentation is available on http://www.thisisant.com/
} 
acceptance. This response includes a passkey that should be stored for future authentications. The client's beacon will also update its state to transport state and both devices can proceed to its corresponding layer. If the pairing is rejected a response is sent confirming its rejection and no passkey is exchanged. Also, both devices return to the unconnected link layer. A pairing request message flow, available in the ANT-FS documentation, is presented on Figure 4.4.

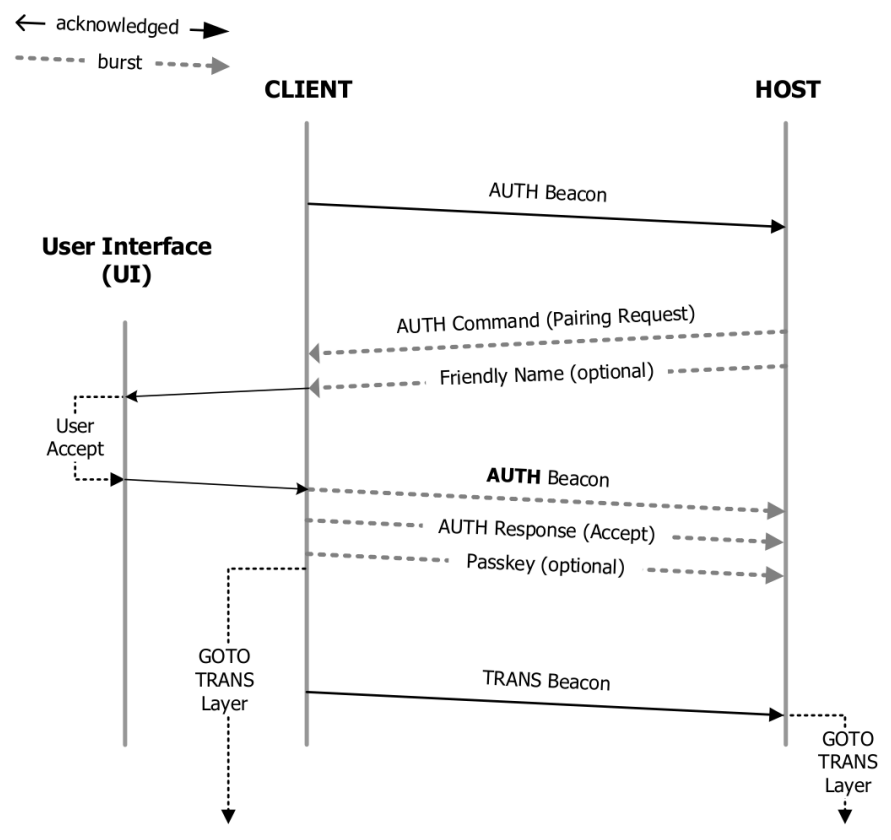

Figure 4.4: Pairing Request Message Flow

Unless pass-through mode is allowed, this authentication will only occur until the host stores the authentication passkey. Once it is done, future sessions will use the pass key exchange authentication type. If the client device has no user interface for pairing acceptance, other methods may be required. As an example, the pairing operation in the blood pressure monitor used within this thesis, requires the removal and insertion of its cell batteries and must be done within the following seconds upon its insertion; only during these moments the pairing will be accepted.

- Pass key exchange: Requires the host device to transmit his passkey, obtained from a previous pairing request, to the client. Upon receiving the passkey, the client compares it with its own and accepts or rejects it, whether the passkeys match or not. If accepted, both devices move on to the transport layer, otherwise, they shall return to the unconnected link state. This is a secure and automatic authentication method. The sequence of commands, also extracted from ANT documentation, is illustrated in Figure 4.5. 


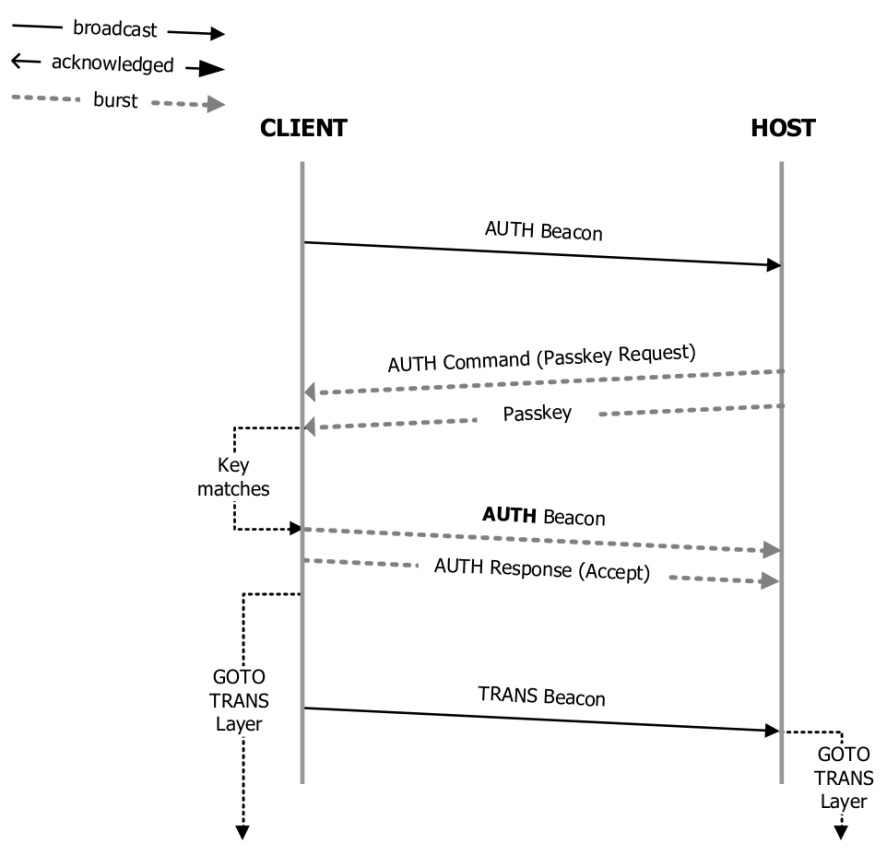

Figure 4.5: Passkey Authentication Message Flow

If the host connects with multiple clients, it may request the client's serial number in order to determine if the client has already been paired. This is done before the host chooses its authentication method. The host device can compare the received serial number with several stored clients in a database. If this client's serial number is found in the database, along with the corresponding passkey, the host may proceed to a passkey exchange; if not, a pairing request should be made.

Transport Layer is capable of a set of operations related with data content of the client device. Within this layer, the host may download, upload, erase data and query the client for data content. It can also use the command pipe for varied operations while in transport layer.

The ANT-FS client has an always available directory file, specifying the data content currently stored on the device. This file is treated has a special file and is always located at file index 0 . However, it may be download like any other file. This file include which files are stored on the client device and for each file, what is their location, its size, permissions and other details. The host device must first download the directory file in order to find out what data is available for download; the download process is the same as for any other file.

Figure 4.6 shows the several messages between both devices for a download to occur.

To begin download, the host sends a two packet download command, which, if accepted, is replied by the client with a download response including the beacon and the 


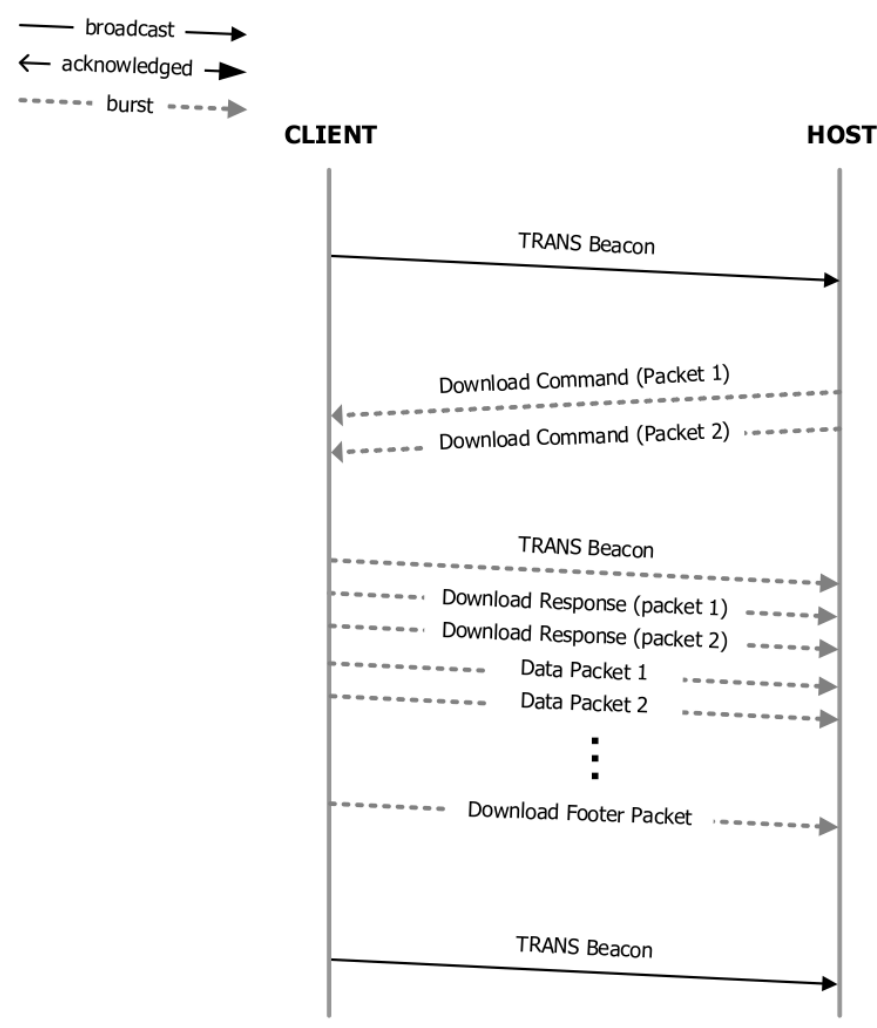

Figure 4.6: Download Message Flow

requested data. Once the data transfer is complete, both devices can return the the unconnected link state, until a next session is required.

\subsubsection{ANT+ with Android}

In order to implement ANT communication on an Android based phone and make use of the ANT wireless functionality built into the device, www.thisisant.com provides developers with an API and all required information to do so. Inside the available package, there is the ANTLib library with all required constants for ANT communication; an ANT+ demo source code, which was used for testing purposes; and android application packages (.apk) for an ANT+ demo application and the ANT radio service. Communication with the ANT hardware is established through the ANT radio service - an application service, usually pre-installed in ANT+ enabled smart-phones, acting as an interface between any application and the ANT chip inside the phone.

On a more technical level, for an Android application to run ANT applications, it should follow these steps:

1. Reference the ANTLib library on the project's build path;

2. Add ANT permissions to the Android Manifest file; 
3. Check if the device has ANT support;

4. Bind/Unbind the ANT radio service;

5. Register Android broadcast receivers ${ }^{2}$ for status and message Intents;

6. Claim/Release the interface;

7. Make calls to the ANT API for channel configuration.

Once the application has completed all these steps, it is able to communicate with other ANT+ devices by following the ANT+ device profiles. For the prototype developed within this thesis, the weight and blood pressure device profiles were implemented, as described in 4.1.1 and 4.1.2.

\subsection{Mobile Application}

This section gives a summary on the work developed for the Android based mobile application. The following subsections cover all implemented modules, describing why and how they were developed. Those modules can be seen in Figure 4.7 and consist in five main modules:

- ANT+

- Activities

- Database

- Web Adapter

- Alarms

Activities are then split into four overall operations: Blood Pressure and Weight, to take the respective measurement; Feedback Messages, in order to view clinician's messages and also send new messages; and Latest readings, to view the latest measurements taken by the patient.

Two mobile devices were used for testing purposes - Sony Xperia Active ${ }^{3}$ and Sony Xperia Arc ${ }^{4}$.

\footnotetext{
${ }^{2}$ http://developer.android.com/reference/android/content/BroadcastReceiver.html

${ }^{3}$ http://www.sonymobile.com/gb/products/phones/xperia-active/

${ }^{4}$ http://www.sonymobile.com/gb/products/phones/xperia-arc/
} 


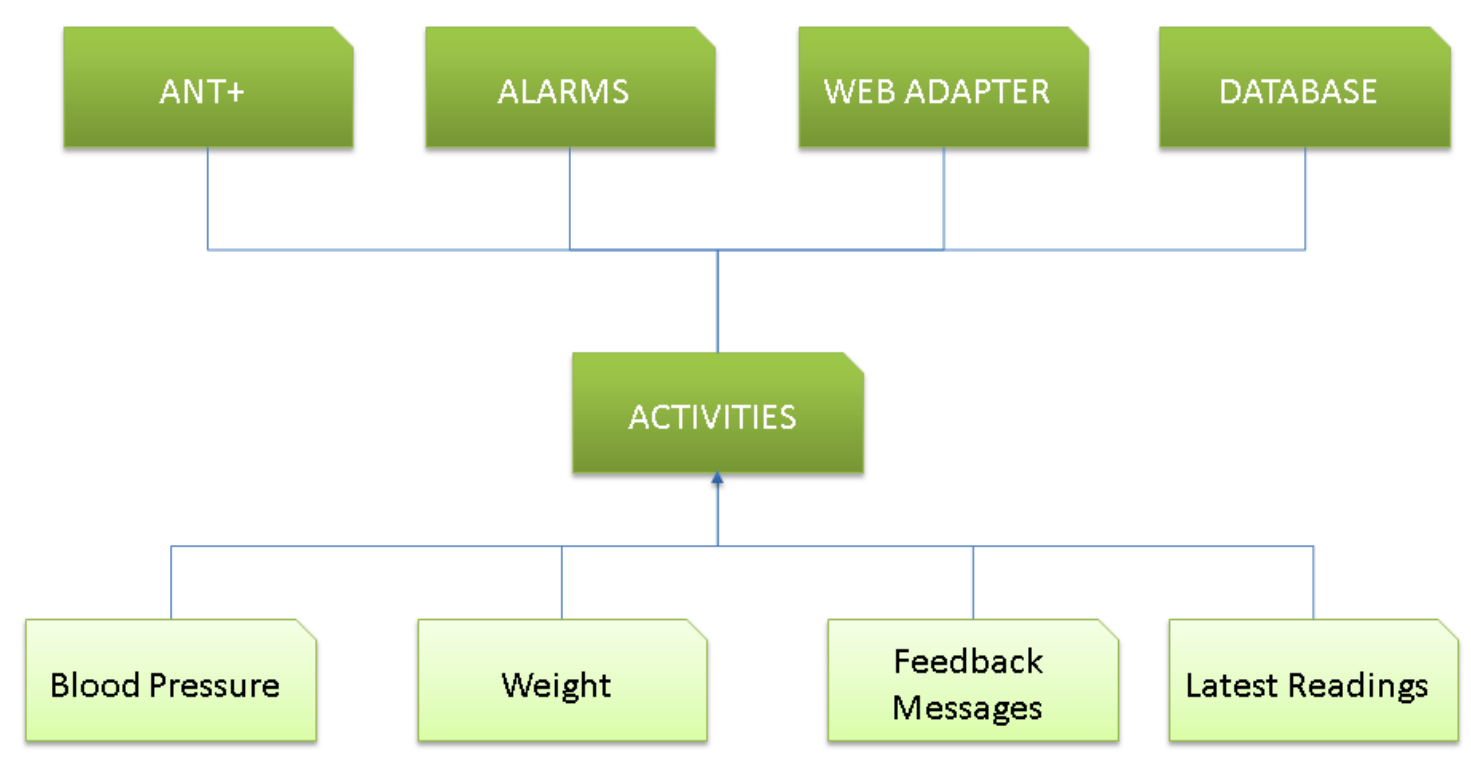

Figure 4.7: Mobile Application Architecture

\subsubsection{ANT +}

This package is responsible for dealing with all operations regarding the management of ANT+ devices. Its goal is to provide a compact and precise interface to any other package that wishes to connect with either the blood pressure device or the weight scale device. The developed code was based on the ANT+ demo application and then improved to be compatible with the ANT+ device profiles of both used devices.

Each profile involved the configuration of ANT channels and the development of several state machines, as stated in section 4.1. Also, in order to analyse ANT messages, bitwise operations were required to find out specific values. All these factors together resulted in this package to become fairly complex. Because of this, efforts were made in order to keep the access to each device data as simple as possible. To accomplish it, the callback pattern was used: the AntPlusManager class, responsible for all main ANT+ operations, provides an interface with a couple methods that are called whenever something interesting happens, such as a device was found or new data is available; any other class who wants to be notified of these events, only needs to implement that interface.

For a class to communicate with each sensor, the following are required:

1. Make a call to an AntPlusManager object to start the ANT service;

2. Notify the AntPlusManager on which class is implementing the callbacks interface;

3. Open the channel for one of the devices.

Once these three calls are made, the class implementing the callbacks starts getting notified whenever an error occurs, the ant service state changes, channel status of a given 
channel is changed or there is an update on the data fields for the specified ant channel. That class is then able specify how and when to display the received data.

To end the session, the opposite process is done: close the respective channel and make a call on the AntPlusManager object to stop communications and release the ANT radio service.

For consistency purposes, both weighing and blood pressure measurement operations was kept has similar as possible. However, it was not as straightforward as it may seem, due to the ANT+ device profiles specification. Firstly, it is not possible to activate the blood pressure monitor from the host device - the smart-phone -, the patient has to manually press the START button in it; secondly, while the weight scale broadcasts data as soon as new data is available, the blood pressure device stores each measurement after it is complete, without notifying the host device of when it happened. Specifically, it was desired for the AntPlusManager class to notify whenever a new measurement is done, in order to instantly pop up a new activity with the values read from the blood pressure device. The goal was to not require an user input, for the measurements to appear; a workaround was necessary to compose this situation.

The overall solution was to, once it is asked for the patient to press the START button on the blood pressure monitor, its respective ANT channel is opened and the mobile application starts downloading the measurements from the device until a new one is find or a time out is reached. A measurement is recognized as new, by comparing its time stamp with other past measurements, stored on the local database. If no measurement is found with the current time stamp, then it is assumed as a new measurement. Otherwise, it keeps querying the blood pressure device for new values. The time stamp is obtained from the blood pressure device, coming along with the blood pressure values.

Although it worked, this was not an elegant and/or smooth solution to this problem and because of that, a question was posted on the ANT forums, trying to find out a better one. In fact, the blood pressure device profile specifies no way of notifying the exact moment a new measurement is made, however, a better approach was recommended. Unfortunately the answer came too late to develop, given the deadline of this thesis. Nevertheless it stays as future improvements on this project.

\subsubsection{Main Activities}

An Android Activity is a component within the application, providing an user interface for its users to interact with. The layout of each activity is defined on a separated XML file, its logic on the corresponding JAVA class file. This subsection gives an overview on the several activities developed for this mobile application.

To begin with, each activity extends from a base activity class, providing methods and features available on all activities. More specifically, the base activity implements 
an options menu, an handler to periodically synchronize the local database with the web server and a method for child activities to set its title on the user interface. The options menu provides the following features:

- Force Synchronization: Immediately synchronizes the mobile application with the web server, looking for new messages or settings updates.

- Clear local database: Erases all records from the mobile application database. These records include all messages and all measurements taken by the patient.

- Update User Profile: Provides a simple form to set up the user profile to be sent to the weight scale. By selecting this option, a new activity is actually brought to the front, allowing the user to specify his gender, age, height and athletic setting.

- Server Settings: Opens up a simple dialogue, allowing the user to set up the web server URL and his web application credentials.

- Exit: Closes the application, releasing all unused content.

These options are mainly helper features and are rarely used. Their goal was to simplify those operations during development. If they were to be included in a final release, usability tests would be required to find out the best way to present them to our target users. Regarding the activity title, all activities include an header layout with its title. As all child activities will need to set up its corresponding title, an auxiliary method is defined in the base class, for code reusing purposes. The referred handler will be better described in subsection 4.2.3.

The first activity presented to the patient allows him to choose one of the four basic features of the mobile application: measure himself with the weight scale, measure himself with the blood pressure monitor, view the latest measurements or view his feedback messages. Each of those features is described in the following paragraphs.

\subsubsection{Weigh}

The weighing operation, as well as measuring the blood pressure, was one of the main goals of this thesis, as well as make the process as short and easy as possible. In order to accomplish those goals, usability tests with low fidelity prototypes were conducted, prior to the development of both mobile and web application. These tests are better described in chapter 5, with its main development advantages being that, by already having an user interface completely specified for most activities, little or none adjustments and refactoring would be required.

This operation is split into four activities, as presented in Figure 4.8: the first one is merely informative, in order to prepare the user for the measurement itself; the second 


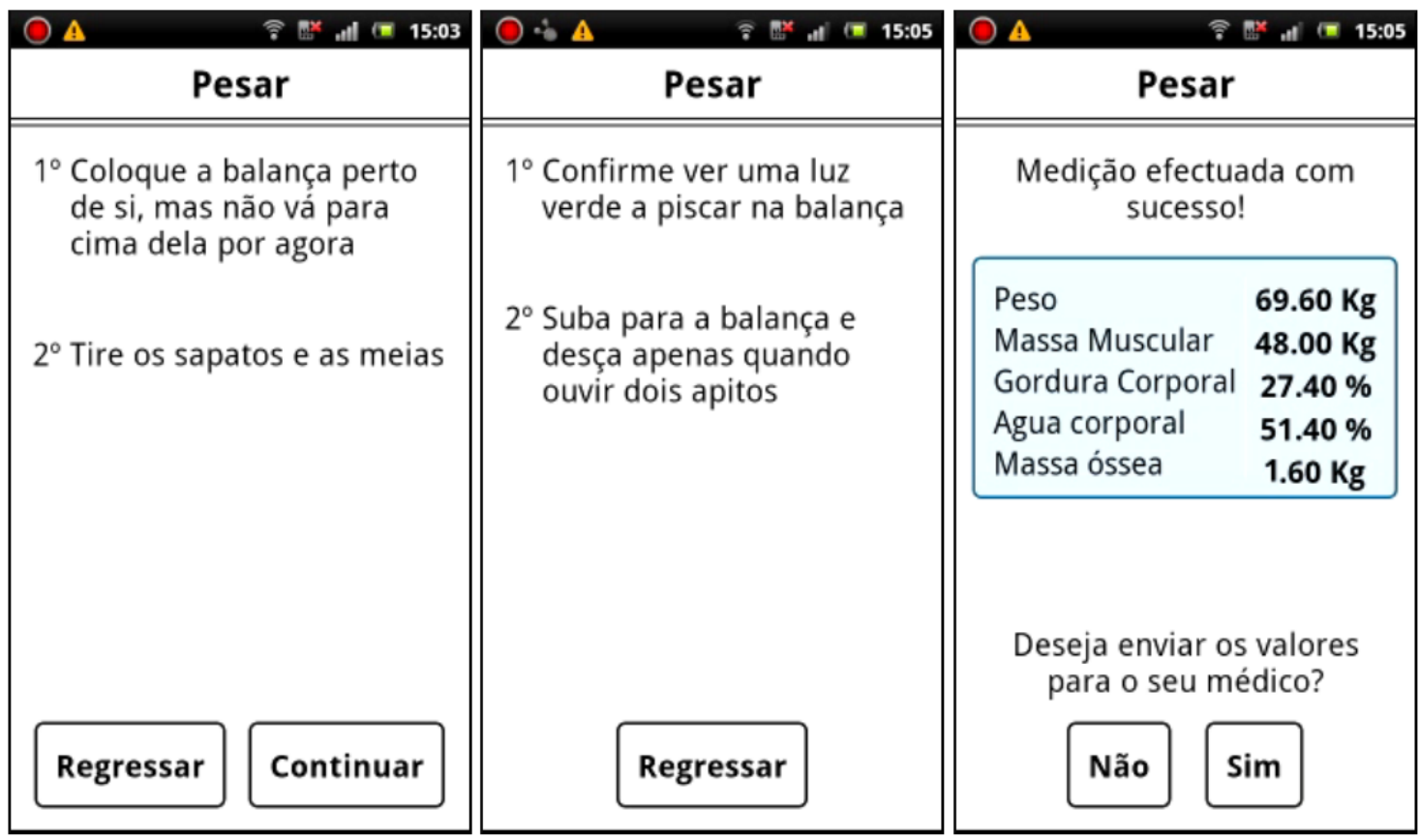

Figure 4.8: Weighing Operation

one activates the weight scale when it starts and asks the user to step on it; when the weight scale has done its calculations and the smart-phone has received all its data, the third activity instantly pops up with all the user's measurements. In this activity, the user is asked whether he wants to send the measured values to his physician; if he chooses yes, a connection to the web server is established and the values are sent. Web related operations are better described in subsection 4.2.3.

\subsubsection{Measure Blood Pressure}

Like the weighing operation, the blood pressure measurement activities were subject to usability tests. As this is a slightly more complex operation, before each measurement, the patient is presented with a simple wizard to understand or remember how to correctly perform the reading. Also a few blood pressure guidelines were included; its importance was pretty clear from the clinicians interviews, as referred in section 3.1.

Figure 4.9 shows the main activities related with this operation. The first two are there to inform the patient of some general guidelines and how to put the blood pressure cuff on his arm. The third activity, asks for the user to start his measurement by pressing the START button on the blood pressure device and wait until the reading is done. When it the blood pressure device finishes, the fourth activity should appear in a few seconds. Similarly to the last activity of the weighing operation, it presents the values received from the blood pressure device and asks for the user whether he wants to send those values to 


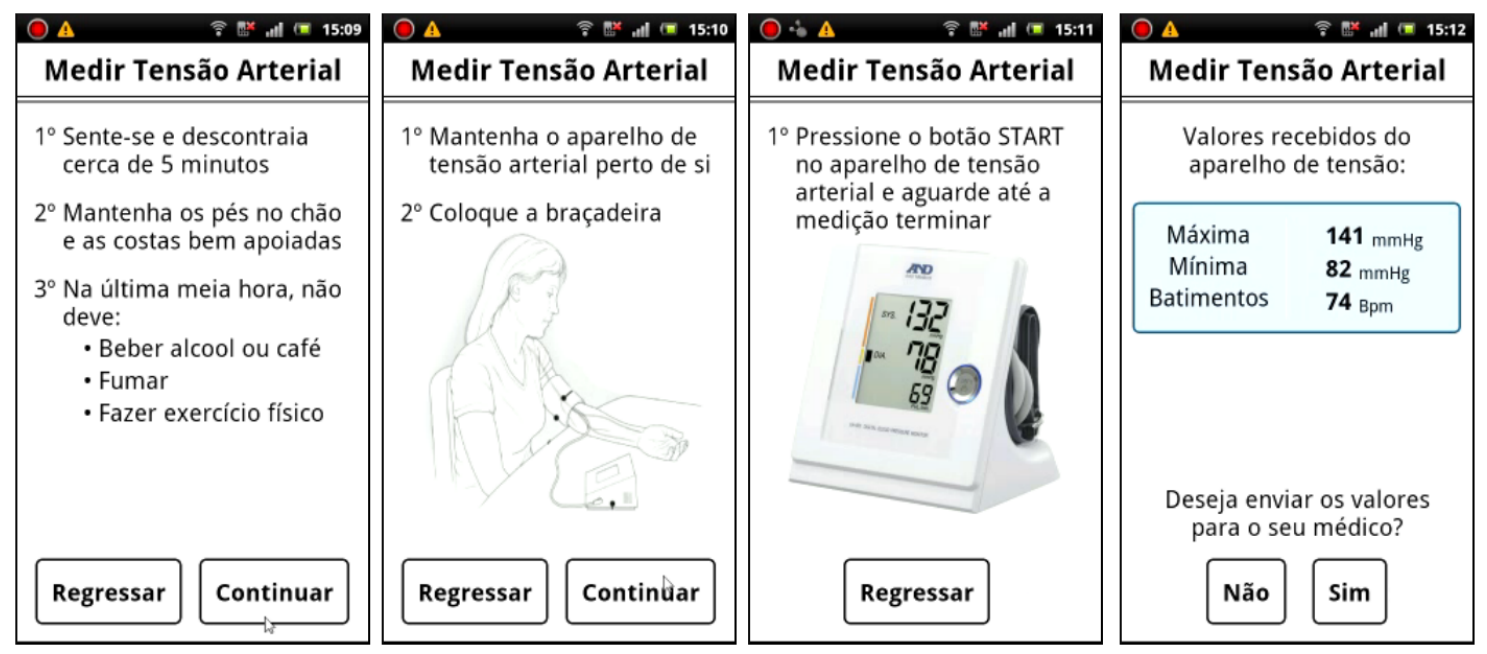

Figure 4.9: Blood Pressure Measurement Operation

his physician. At last, there is also an activity, not shown in this image, for error handling purposes in case something goes wrong.

\subsubsection{Latest Measurements \& Feedback Messages}

These activities present to the patient: the latest measurements taken on both devices that were sent to his physician, on the History activity; and the feedback messages received from the patient's physicians, on the Messages activity. This last activity also allows the patient to send instant messages to his physician through the network. Both activities access the local database to fetch all required records.

Due to the short time available for usability tests, these two activities were not tested. Nevertheless, the general layout structure was kept similar to the previously described activities, an effort to preserve the user interface as simple and easy to use as those other activities previously tested.

\subsubsection{Web Adapter}

This package is responsible of establishing the connection between the mobile application and the web server through HTTP requests and it has two main classes: WebServiceAdapter and WebServiceHelper. The first one is in charge of establishing the HTTP connection and retrieving all information related to a certain operation. The main used method simply receives an URI, establishes the connection and returns a JSON object with content computed by the web server.

The other main class, WebServiceHelper, makes the connection between all the data received from the web server and the rest of the application, returning from each operation the minimum required information, only. Because each query to the web server may 
take a while, depending on the connection quality, it is very important to not block the user interface, while it is waiting for a response. To accomplish this requirement, the WebServiceHelper extends from AsyncTask, an Android class allowing to easily perform background operations and send results to the user interface main thread. Once extended, it had to implement a couple methods: doInBackground(), to perform web service calls on the background thread; and onPostExecute(), that receives the value returned from doInBackground() and runs on the UI thread.

Every web service operation corresponds to an HTTP request, interpreted on the web server side. As each feature was being developed, both web and mobile applications suffered adjustments in order to comply with each other. These operations are described in detail on the following bullet points.

- Login: Sends the patient's credentials to the web server in order to find out if the patient is correctly authenticated. The web server returns a simple message code, saying whether the credentials are right or wrong. Because the mobile application user is a patient, only patient's credentials are accepted within this command. These command is used when the user configures the server settings, by pressing the confirm button. Not only the patient's credentials are tested, but also the connection to the web server.

- New Message Record: Whenever the patient sends a new message to clinicians, this command is used. The HTTP request includes the user credentials, message time stamp and content. If the credentials are wrong, the web server returns a message saying no record was stored.

- New Weight/Blood Pressure Record: These two operations - new weight record and new blood pressure record - are used every time the patient makes one measurement and chooses to send it to his physician. This operation is quite similar to the previous - new message record - with the exception being on the parameters being sent. The request for both of them include the patient's credentials and record time stamp, plus the specific values of each device: systolic blood pressure, diastolic blood pressure and beatings per minute, for the blood pressure monitor; weight, body fat and body water percentage, muscle mass and bone mass, for the weight scale device.

- Sync: The goal of this command is to synchronize information between mobile and web application. This type of procedures can reach a high level of complexity, taking time that is not available within this thesis. As such, only the minimum required features were implemented for the synchronization task, namely, receive any new message sent by the patient's clinician and update his alarm settings whenever necessary. 
To receive new messages, the mobile application stores the time stamp of the latest synchronization carried out. Then, in every sync operation, that time stamp is sent along with the patient's credentials. On the other hand, the web server queries its database to locate the patient with those credentials and every message that was sent to him after the time stamp received through an HTTP method. That message list is then sent back to the mobile application in the JSON format. Upon receiving all new messages, the mobile application can store them in its local database, so the patient can read them later.

In order to know when to update the alarms, the web server also returns the list of alarms associated with this patient. Therefore, this procedure also checks for changes in his currently scheduled alarms. If it detects an update, the alarm is appropriately rescheduled.

For the data interchange between web server and mobile application, the JSON standard was chosen, instead of other possibilities, such as XML or CSV. Ruby On Rails can easily export data in both JSON or XML formats by including a single line of code, so its decision came down to the ease of parsing that data on Android. After weighing the pros and cons, JSON was chosen because it already supports basic data types (integers, booleans, strings, etc.) and most of the exchanged data would be plain objects composed by those data types.

In order to keep the application synchronized with the web server, a method to keep it calling the sync operation was required. Android provides a class capable of doing so, the Handler class ${ }^{5}$. This is done by creating an Handler instance and overriding its handleMessage method. This method is called every time a message is sent to the handler. In order to accomplish these feature, the method simply calls the sync operation and sends a delayed message to itself. When the specified delay time is reached, the message is sent and the handleMessage method is called once again. This procedure keeps running until the application is stopped. Because it is pretended to keep running on every activity of this application, the handler is defined on the BaseActivity class (referred in previous subsection 4.2.2).

All HTTP requests were made through GET methods, and as mentioned before, all of them include the patient's credentials. On a security point-of-view, this is a far from optimal solution, especially when dealing with sensitive information. The relevance of this issue was already discussed in chapter 2, regarding secure mobile health systems. Unfortunately however, little time remained to improve the web adapter module and its improvements had to be left for future work.

\footnotetext{
${ }^{5}$ http://developer.android.com/reference/android/os/Handler.html
} 


\subsubsection{Alarms}

During the requirements specification it was decided that, for the sake of optimizing the moments when a clinician would be able to give feedback to his patients, the system should enable the clinician to schedule measurement alarms for each used device, of a given patient. He should be allowed to enable or disable the alarm and customize its hour, minutes and frequency. By frequency, he should be able to schedule monthly, weekly or daily alarms; or even to customize the number of days between each measurement alarm - for instance, schedule an alarm to pop up every 3 days.

In order to schedule an alarm, the Android AlarmManager ${ }^{6}$ is used. This class provides access to the system alarm services, allowing the scheduling of some code to be run in the future. Whenever a new is received from the web server sync process, the current AlarmManager instance is obtained from the system service and a pending intent ${ }^{7}$ with a specific request code is scheduled. This request code is used to identify the intent, in case the alarm is cancelled.

Once the AlarmManager triggers an alarm, an alarm receiver is called. The AlarmReceiver class extends a BroadcastReceiver ${ }^{8}$, overriding its onReceive method. This method may be called even if the mobile application is currently not running. What is does is, start a new activity to open up the mobile application, sending some extra information along the way. Then, whenever the main activity is called, it looks for that information to know if it should pop up the alarm or normally proceed.

The alarm itself is a simple AlertDialog ${ }^{9}$, together with an alarm notification sound. Once it pops up, the patient is asked to measure himself with one of the two devices. If he chooses to do so, the application redirects him to the corresponding operation, otherwise he can just go back to whatever he was doing before.

\subsection{Web Application}

The end of this chapter describes the implementation and main working features of the web application, according to the specified requirements in the previous chapter. It was developed on the Ruby On Rails technology and connected to an SQLite3 database. Although a few use cases could not be finished in time - such as allowing the physician to add a measurement note or the patient to view his scheduled alarms - all of them with high priority were accomplished.

Following the Ruby On Rails MVC principle, the main application code is separated in three main folders: models, views and controllers. The models folder contains each class

\footnotetext{
${ }^{6} \mathrm{http}: / /$ developer.android.com/reference/android/app/AlarmManager.html

${ }^{7}$ http://developer.android.com/reference/android/app/PendingIntent.html

${ }^{8} \mathrm{http} / / /$ developer.android.com/reference/android/content/BroadcastReceiver.html

${ }^{9} \mathrm{http}: / /$ developer.android.com/guide/topics/ui/dialogs.html
} 
of the domain model (Figure 3.7), all of them extending a Ruby On Rails ActiveRecord. A diagram of the used models is presented on Figure 4.10, with the user model being the parent class of Admin, Patient and Physician; and the record model being the parent class of a BP Record, Weight Record and Message Record. The SensorRelationship model represents the many-to-many relationship between Sensor and Patient, storing what sensors are associated with a patient and its associated settings (alarm frequency and threshold values); the UsersRelationship model is used to store the patients-physicians relationship.

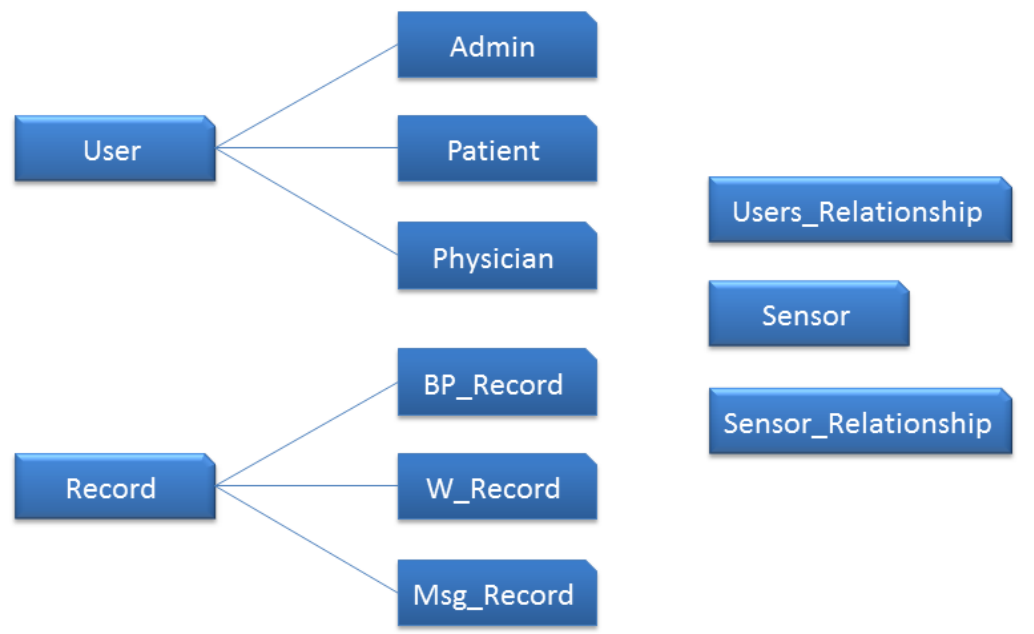

Figure 4.10: Web Application Models

Each view, specifies the user interface that is presented to the end-user through HTML and ERB (embedded Ruby) to access data from the controllers. For the user interface design, Bootstrap was used, a framework from Twitter that allows an easy mechanism to add interface elements to an HTML5 application.

The controllers specify all the logic between models and views, serving as an intermediate between the server and its end-user. Figure 4.11 shows all controllers used in the application and the defined methods (or actions) for each of them. Ruby On Rails adds by default the following actions:

- index: Display all elements of the model associated with the current controller;

- new: Display a form for creating a new object of the model;

- create: Creates and stores the object, usually with the values submitted in the form created in the new action. Typically, no view is appended to this action;

- show: Presents the current element with all visible attributes of the model;

- edit: Similar to the new action, but for editing the object; 


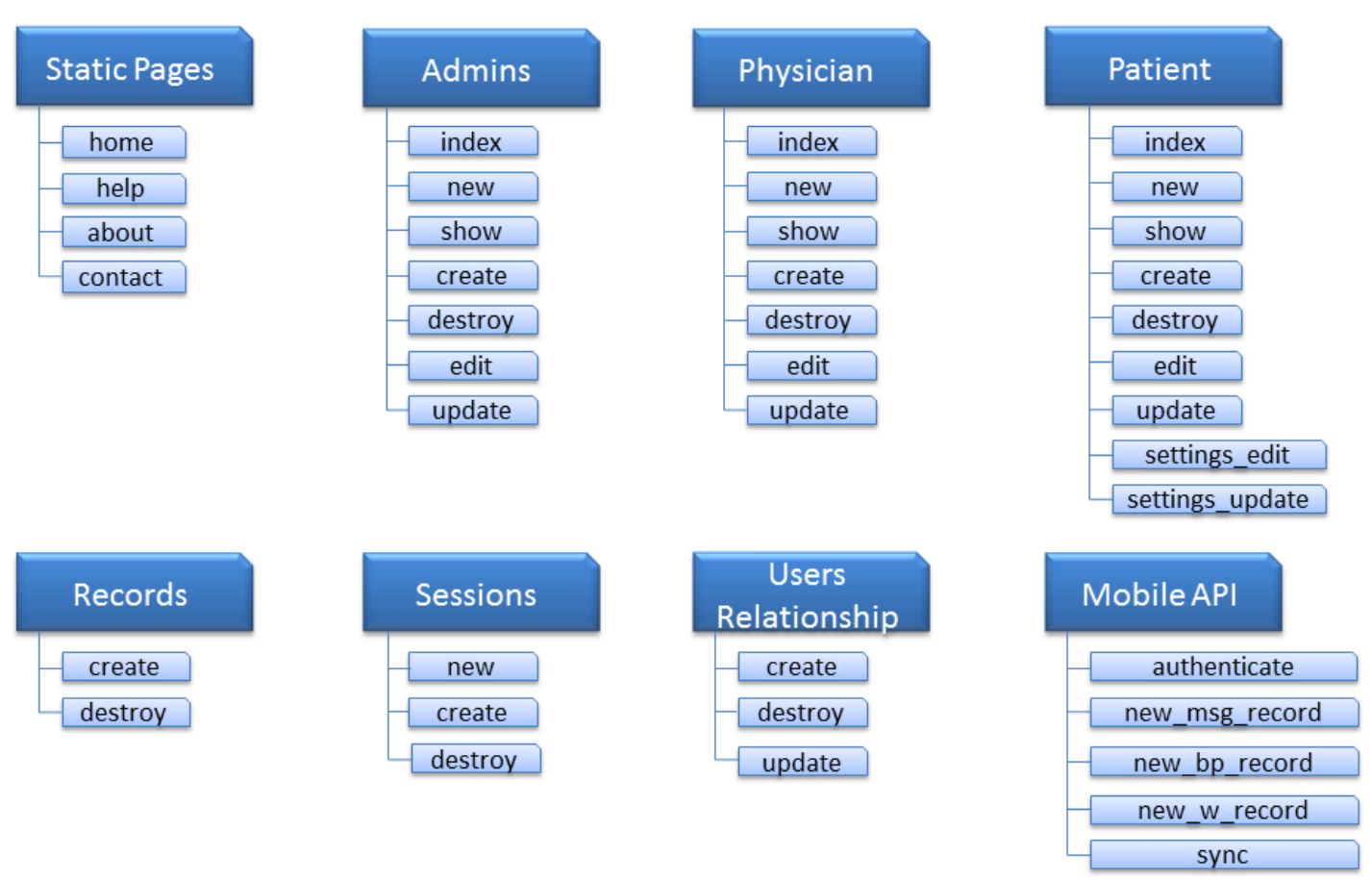

Figure 4.11: Web Application Controllers

- update: Similar to the create action, but for updating the object. Typically, no view is appended to this action;

- delete: The opposite of the create action, used to delete the current object. And again, usually no view is created for this action.

For this application, some unnecessary actions were removed while others were added; the next lines explain the main goals of each of the controllers. StaticPages controller is only used to specify static pages - home page, help page, contacts page and an about page. - where no connection with a model is required. The controller simply redirects these pages to the corresponding view. The Records controller creates and destroys record objects and has no view associated with its methods.

Both the Admins, Physicians and Patients controller provide the default methods index, new, show, create, edit, update, delete. However, its access is restricted, depending on the current user and the concerned operation. The Patients controller also has two extra actions: settings_edit and settings_update, for editing and updating the measurements settings of a patient - these settings allow the scheduling of alarms and setting the threshold values for a given device.

The Sessions controller has the new action, in order to display the sign in form; and the create and destroy actions for actually logging in and out of the application. The UsersRelationship controller defines the creation and removal of patient-physician relationships. 
At last, the Mobile_API controller specifies what operations can be used by the mobile application to connect with the web server.

The following subsections describe the main features of the web application, split up into use case modules.

\subsubsection{Authentication}

Authentication is handled on the user model, so that all subclasses - admin, physician and patient - include all operations applied to an user object. Its attributes include a user's basic data: name, email, password and the created_at and updated_at timestamps from Rails. There is also a type attribute, to determine what type of user it is: patient, physician or admin. This technique is called single-table-inheritance and is used to emulate objectoriented inheritance. To accomplish inheritance, each subclass only needs to extend its parent class and Ruby On Rails does most of the work. At last, the user model also has a remember_token, attribute for storing the user's unique cookie, composed by a random base64 string.

The actual login and logout operations are managed by the sessions controller, through both create and destroy actions, respectively. On the create action, if a user with the provided email is found and its password matches the password provided, the user becomes logged in and a cookie is saved, through the Rails syntax. Actually, for security reasons, it is the password's hash that gets compared and not the password itself. To irreversibly encrypt the password to form its hash, the state-of-the-art Bcrypt ${ }^{10}$ hash function, was used.

In order to restrict certain actions to authorized users only, Rails provides the before_filter method. It executes any method given as parameter, immediately before those actions are executed. For instance, to make sure a logout operation is only called if the user is authenticated, a before filter method is applied to the destroy action, passing as parameter a function to determine if the current used is indeed, authenticated. This procedure is used on all remaining controllers, whenever necessary.

Once authenticated, the user is redirected to his home page. Figure 4.12 shows a physician's home page. On the left of the screen it can be seen the physician's name and its associated patients. On the right of the screen, all the records of their patients are listed, ordered by date. Each icon image - as the one on the left of each patient record corresponds to a user's avatar, more specifically, a user's gravatar. Gravatar ${ }^{11}$ is a globally recognized image, allowing the user to associate one email address with a single avatar.

\footnotetext{
${ }^{10}$ http://en.wikipedia.org/wiki/Bcrypt

${ }^{11}$ http://en.gravatar.com/
} 


\section{APLICAÇÃO DE SAÚDE ANT+ Inicio}
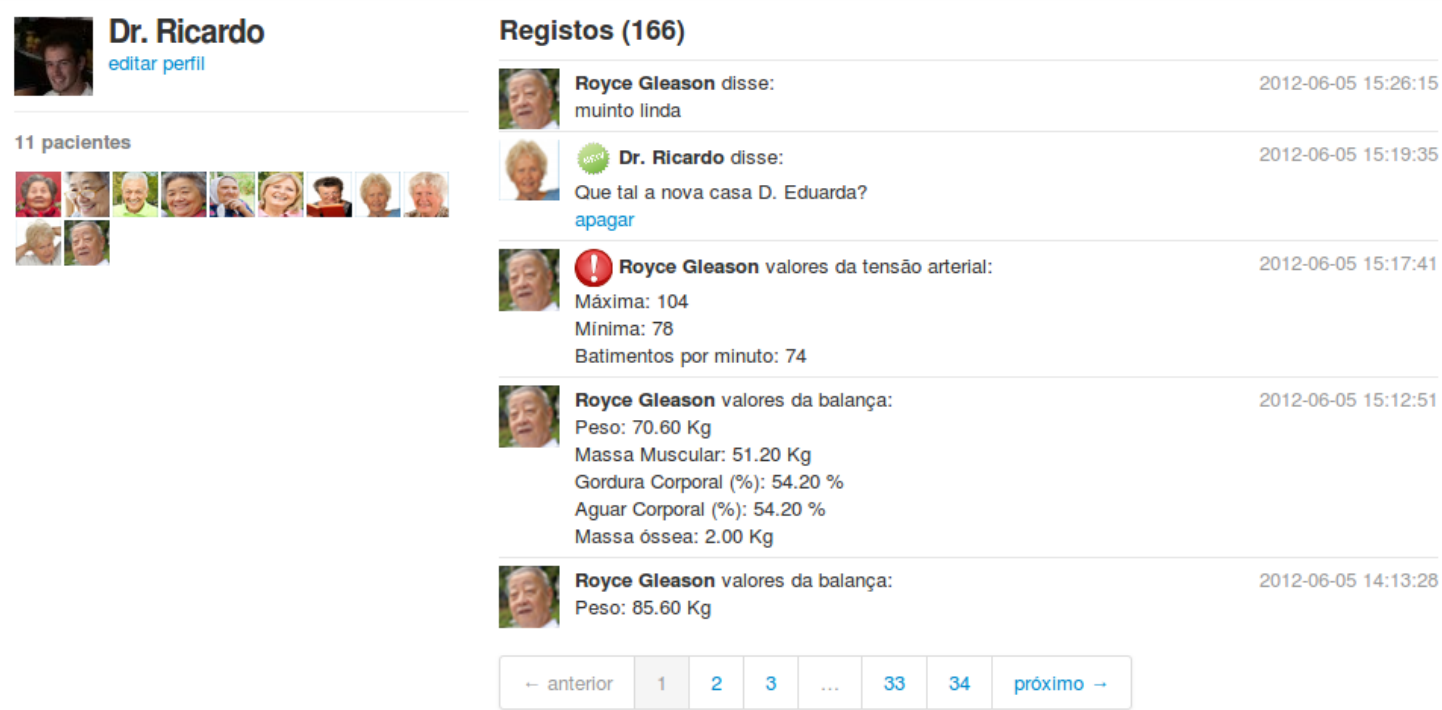

Figure 4.12: Physician Home Page

The pagination process in each list within the application is handled by a Ruby On Rails plug-in called will_paginate ${ }^{12}$. With one line of code, the records are appropriately fetched from the database and another line of code, adds to the user interface, the previous/next page form.

\subsubsection{Manage Patient}

This subsection describes what was developed from the use cases (referred on Figure 3.5) regarding the management of a patient by his physician. Whenever a physician enters the patient's profile page, he sees what is presented on Figure 4.13.

On the left, the physician is able to view the patient's profile, edit his sensors settings, view other physicians who might be associated with this patient and send him a text message. On the right side, there's a button to stop following the patient, if desired, and under it, the list of records - message records, weight records and blood pressure records - from that patient, once again, ordered by date.

Each record has a status associated with it, whose meaning is now explained. Whenever a new record is created, it is stored with its status being "new", therefore a corresponding icon appears appended to the record, on the records list. The record status becomes "read", when a patient or physician (depending on who created the record) views

\footnotetext{
${ }^{12}$ https://github.com/mislav/will_paginate
} 
APLICAÇÃO DE SAÚDE ANT+

国

Royce Gleason

ver perfil

configuraçāo dos aparelhos

2 médicos

주의

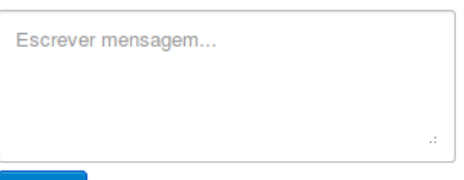

Enviar
Não acompanhar

Registos (131)

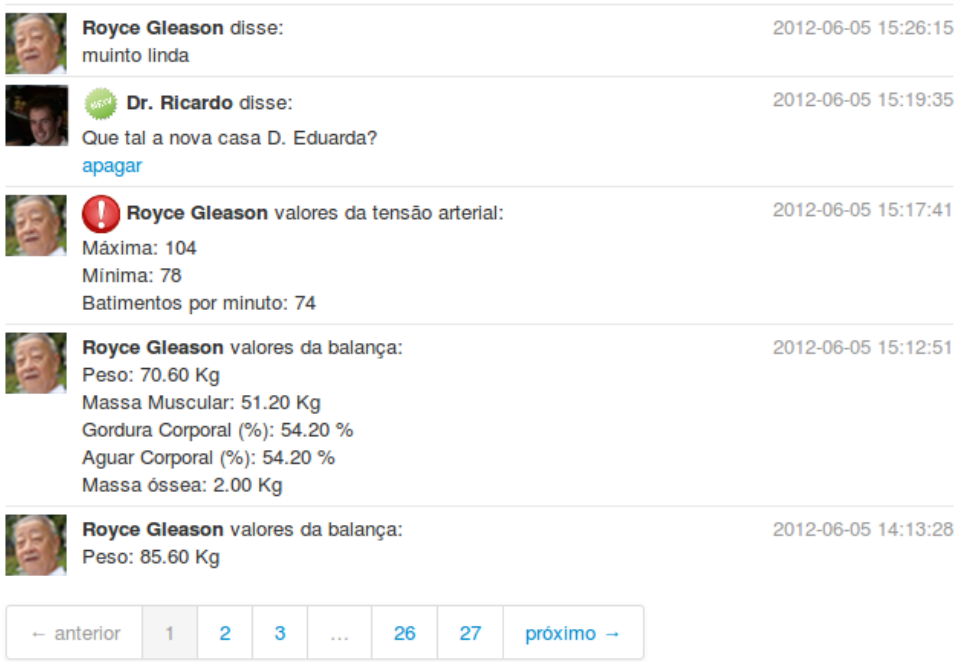

Acerca Contactos

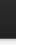




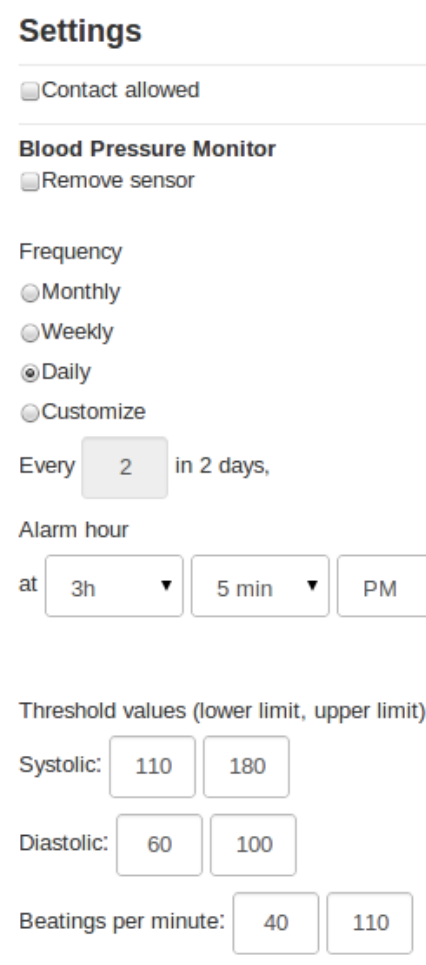

Figure 4.14: Sensors Settings Page

implemented on the user's model.

For the creation of users, anyone who enters the application is able to register as a patient. However, the creation of physicians is only available for the chief medic - the admin. Deleting either patients or physicians is also only available for the chief medic.

\subsubsection{Patient Features}

Once the physician's use cases were implemented, including support for the patient to access the web application was trivial. Firstly, because a patient is a subclass of the user model, which includes all the required logic for authentication. Secondly, because except sending messages, all patient's use cases are meant for reading purposes, only. As such, the views used for both patients and physicians are the same, however, if the signed in user is a patient, unauthorized components are removed and the he will not be able to access them.

\subsubsection{Internationalization}

Similarly to the mobile application, all the web server user interface was written in Portuguese. Rails provides an $i 18 n$ module in order to clearly separate a Portuguese version from an English version. By specifying custom variables on each view, instead of static 
strings, Rails will look for its translation on a specific file, depending on the chosen language. In order to add support for a new language, only a single file is needed to update.

\subsubsection{Mobile API}

The mobile_api controller specifies the actions to be accessed from the mobile application. These actions were previously described on subsection 4.2.3, explaining what each of them receives as parameters and retrieves, through the JSON format. In order to export the appropriate data into JSON, Rails can do so in a single line of code, with the respond_to method. With this method, rails determines the desired response format from the HTTP header submitted by the client's request, in this case, header having a JSON extension. 
Implementation 


\section{Chapter 5}

\section{Tests and Results}

It is proven that the elderly find most technological products difficult to use for several reasons, as discussed in chapter 2.1.5. Because this thesis aims for that age group, it would be a lack of consistency not to include the elderly in the development of the prototype. There was a need to find out their capabilities, their main difficulties and how they truly use the system. Only then, the prototype could have a chance of becoming an useful, usable and used product. Its usefulness was already known because of its tangible benefits; the phases described in this chapter, look forward to create an usable product, whose users find it easy and practical to interact with; and hopefully to become, an used one.

This chapter reviews the processes and results of the two test phases in this thesis usability and prototype tests - and ends by analysing the main results of the entire mobile health system developed.

\subsection{Usability Testing}

Once the general requirements were specified, it was time to start developing the mobile application. But not before getting to know better the target users and their opinions about the system. This obviously came to change those requirements and the actual vision of the system. The goal was to observe people using low fidelity prototypes, in order to discover errors and areas of improvement.

Low fidelity prototypes, also known as paper prototypes, are rough drawings of the interface to use. Its benefits is that it saves time by allowing developers to test an user interface before a single line of code is written, and it is also easy, fast and inexpensive to change them at the moment.

In order to help with the tests, each session was made with the thesis author, his supervisor at the company and a nurse working at Fraunhofer Portugal, who introduced 
us the seniors. From now on, when first person plural is used, it is referring to the test team.

\subsubsection{Sample}

With the help of a partnership between Fraunhofer Portugal and a few elderly associations, 9 usability tests were conducted. Although this number may not be very significant, the results were still very helpful. The participants were between 62 and 81 years old and in average, 71.6 years old. All of them were from Oporto. Obviously, all prototypes were written in Portuguese. Regarding their level of education, most of them finished the primary school and quitted studies after it. Only one finished secondary school and none went to the university. Although for nowadays standards, it may seem very low, this was the standard education level for the majority of the Portugal population, at their time.

Actually, it is expected the target users to be a little younger, with their cognitive capabilities well preserved and motivated to use the system. These characteristics were rarely found within the test subjects. Nevertheless, if these users succeed in using the application, it is almost certain that anyone will be capable of using it. So what at first did not seem like an ideal choice of participants, in the end, it turned out to be the best decision.

\subsubsection{Method}

Each prototype was designed with the free online application, Balsamiq Mockups ${ }^{1}$. Each image screen of the user interface was then copied to a smart-phone, simulating a real usage of the application.

The tests started with a description of what the system was, what was being done in the tests and what their goal was. The participants were told what they were going to do, as well as thoroughly explaining that, if they found some difficulty along the way, it would be a flaw in the user interface and not their fault. These indications are considered to be very important in order to let the participant feel comfortable with the both the test team and the test itself [Nie93].

Then, a few questions were made regarding what words to use in specific situations and what expressions they believed being better suited for those situations. The generation gap between typical students and the elderly is such, that the most effective way of finding a common language was by doing this questionnaire. For instance, several expressions can be used, in Portuguese, to denominate blood pressure. It was important to figure out one word or expression that could be understood by everyone.

The next part of the test, was to ask the senior to pick up the smart-phone and use it to perform the most important tasks of the system. They would tell us what option/button

\footnotetext{
${ }^{1}$ http://www.balsamiq.com/products/mockups
} 
they would choose in each interface and we would change the image in the smart-phone appropriately. Each task had a set of images, organized by folders and ordered by sequence of appearance, inside the smart-phone. The preparation of the images structure, inside the smart-phone, made it very quick and easy to change them without affecting the user's performance. The operations were:

- Use the smart-phone to measure his weight

- Use the smart-phone to read his blood pressure and send the values to your physician

Think aloud protocols involve participants thinking aloud as they are performing a set of specified tasks. Users are asked to say whatever they are looking at, thinking, doing, and feeling, as they go about their task. This enables observers to see first-hand the process of task completion (rather than only its final product). Observers at such a test are asked to objectively take notes of everything that users say, without attempting to interpret their actions and words. Test sessions are often audio and video recorded so that developers can go back and refer to what participants did, and how they reacted. The purpose of this method is to make explicit what is implicitly present in subjects who are able to perform a specific task.

During these tasks, the think aloud protocol was used. It is an usability testing method, where participants are asked to say what they are looking at, thinking at, doing, feeling, as they perform each task [Sen92]. These way we could better understand if they got stuck in some point during the task and why it happened. This part of the test was probably the most productive one, as we could see in first hand, how the elderly were using the system.

Once these tasks were completed, the test ended with a quick satisfaction survey, in an informal manner. In these questions we would listen the elderly opinions about the application, whether they liked it, whether they imagine themselves using it, what they would change or add to the system and also about some possible additions to the application, we thought they might appreciate. These thoughts will be better discussed in the next paragraphs.

\subsubsection{Results}

Regarding the terminology questionnaire, the results are posted in its original language Portuguese -, because all tests were made with Portuguese users. Although a translation is possible, in every language there are words where a direct translation does not reflect the word's actual meaning. The main results of the questionnaire are presented below.

In the following charts, each column represents the number of participants who chose each word or expression. The graph on the left in Figure 5.1, shows how many patients chose a certain word/expression for the "blood pressure" term. The right graph, shows the participants preferences, regarding the expression to use when a weighing operation 

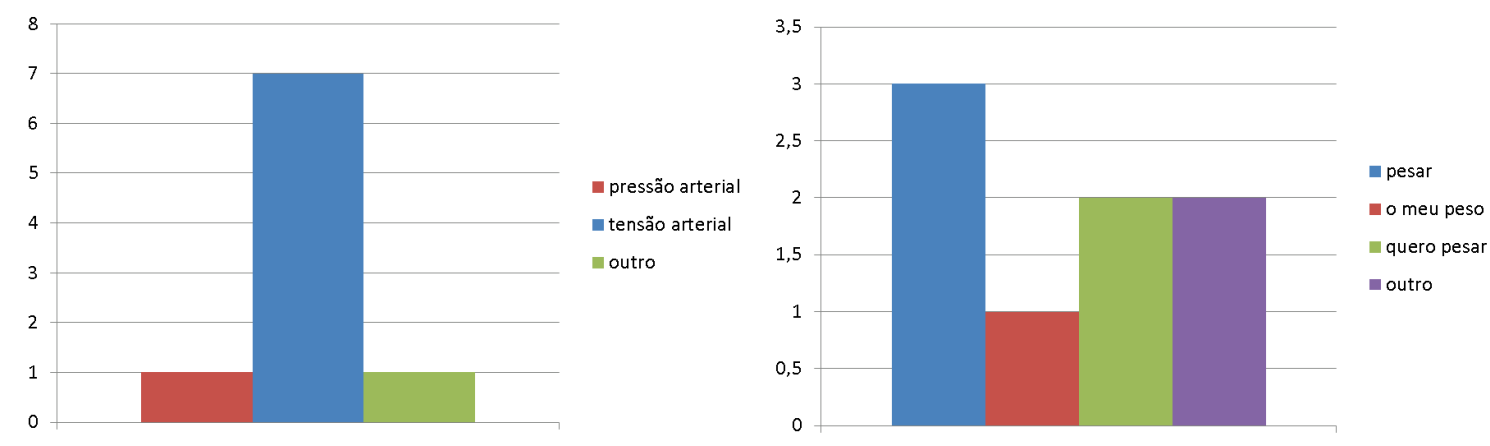

Figure 5.1: Naming Questions Number 1 and 2

is to be made. Figure 5.2 shows how many participants found more appropriate to call to the blood pressure values: systolic and diastolic.

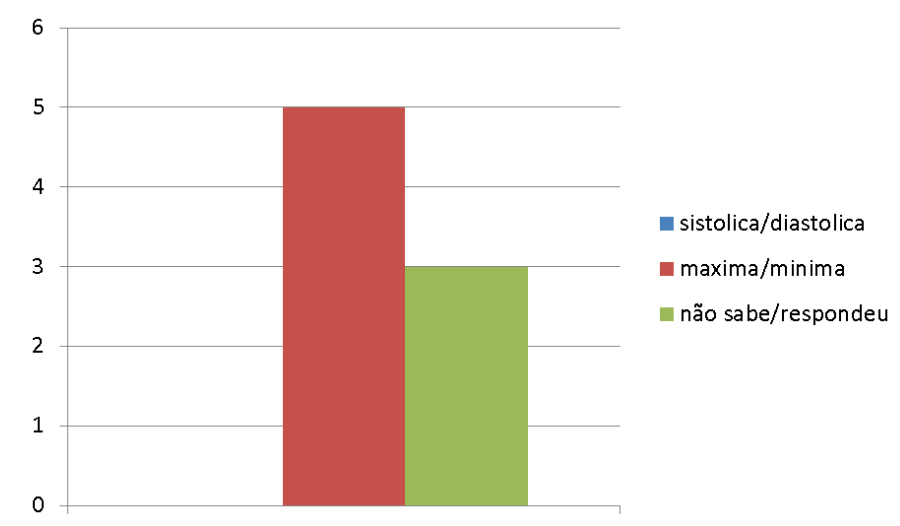

Figure 5.2: Naming Question Number 2

On the tasks results, the chart on figure 5.3 shows how much time, in minutes, each patient took to perform both measurements. In average, one weight measurement was made in 4 minutes, while one blood pressure measurement took almost 8 minutes to done. It should be noticed that, although only images were being used, the participants actually did measure themselves: a working prototype of the ANT+ communication was used in the background, in order to simulate the time spent on each measurement. During each session, two smart-phones were always used: one for the participant to interact with and another one, used only by the test team, where an ANT+ prototype was available to read each participant's measurement, right on the moment. This way, a complete measurement operation could be simulated with the maximum possible realism.

It is easy to detect that the time of measure in both devices slightly decreases on each participant. It happened for two main reasons: from one test to another, the context description given to each senior became more accurate and their better understanding on those tasks, resulted in faster measurements; also, throughout the tests the prototypes were 


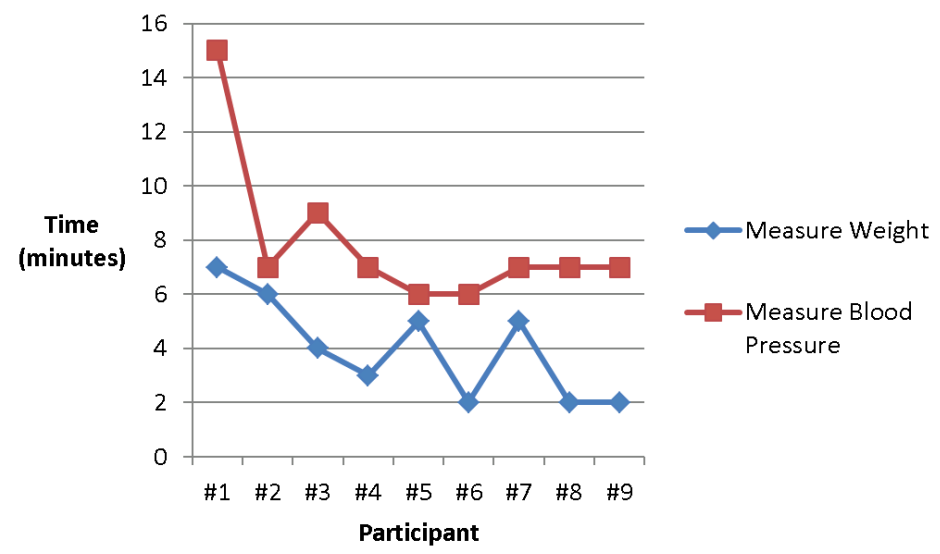

Figure 5.3: Duration of Measure on Usability Tests

evolving according to the received feedback. This chart proves that those changes were in fact, effective.

Of all the nine participants, 6 of them showed visible interest on the mobile health system as it was presented to them and only 3 did not look that motivated. Perhaps its not a coincidence, that two of them were 79 and 81 years old, being the two oldest participants. Of the six motivated ones, all would like to see the history of measurements within the application and all would like to learn more about their problems and/or diseases. For instance, one senior wanted to know why lately, he was feeling so tired; another one wanted to know the meaning of each blood pressure measurement. At last, except one participant, all of them would like to be able to receive feedback messages from their clinicians. One stated that the clinician feedback is very important, as well as the possibility to answer each feedback message. Another one recalled that it would be interesting to know whether his physician has reviewed their measurements yet.

Some common problems were found during these tests. Several participants would stuck with, at least one of these issues:

- Seniors stepped up the weight scale before it was turned on;

- Small fonts are very difficult to read;

- Instructions appearing on the bottom of the screen were usually forgotten quicker then the others;

- Frequently, instructions were confused with buttons

- Using relatively complex words is usually a bad idea, mainly because of the usual lack of memory in the elderly and, sometimes, diminished level of education or knowledge; 
- Participants with blood pressure monitors at home, often had better results in this task;

Upon realizing these difficulties and in order to mitigate them on the developed prototype, some decisions were taken. First of all, it should be noticed that all tests were made in each senior's association for the elderly. It was their own environment and too much distractions, that simply were out of our control, constantly appeared. This negative point meant, that we not always had their full attention on the tests and perhaps, that is the reason for some of the problems previously reported.

Regarding the font size, first it was found that the minimum required font size should not be under $22 d p$ - density-independent pixels ${ }^{2}$. By minimum required, it means the senior would read it without any difficulties. Once no smaller fonts than that size were used, no more problems around this issue were reported.

About the instructions being better understood when not placed at the bottom, a fairly good workaround turned out to be using images at the bottom instead of text. Although this might have been a distraction problem. One that would not happened if the senior was at home, by himself.

The issue of instructions being confused with buttons, probably happened because what they were seeing was images. In fact, on the final prototype testing, this problem did not appear. On the developed Android application, whenever a button is pressed, visual feedback is given. On the complex words, an effort was made to stop using them. The naming questionnaire also helped with this issue.

At the end of this test phase, the user interface for the blood pressure and weight operations was completely specified in each prototype. It would have been desirable to do more tests involving more participants and other operations of the mobile application, however it already took almost two weeks to perform and analyse the tests and no more time could be allocated. Still, its advantages were significant: a much better understanding of the users by the developer and the output provided - user interface prototypes - which ended up saving much of the development time, thereby accomplishing a better quality in the end result.

\subsection{Prototype Testing}

Once the development phase came to an end, it was time to test the mobile health system. The main goal was to find out if this prototype has a chance of actually becoming a real life product. Similarly to the first usability tests, the application usage needed to be observed, looking for possible flaws or areas of improvement. For a complete test, it would be desirable to test both mobile and web application with patients and clinicians,

\footnotetext{
${ }^{2} \mathrm{http}: / /$ developer.android.com/guide/practices/screens_support.html
} 
respectively. It was not possible, though, once again for the lack of time available. This testing phase was focused on the mobile application and the elderly, because they were this thesis main target users. Testing the web application must be delayed for future work in the project.

Just like in the usability tests and in order to help in each test session, both the thesis supervisor and the nurse working at the company were involved. The remaining of this section describes who were the participants involved in the tests, how each test session was conducted and, at last, the achieved results.

\subsubsection{Sample}

Similarly to the usability tests, the participants were chosen from the partnership between Fraunhofer Portugal and some elderly associations. Although more tests were scheduled, some participants cancelled at the last moment and only nine were made. The nine participants were between 59 and 74 years old and in average, 67.8 years old, a little younger than the ones from the usability tests and closer to our target users. Of these nine participants, four of them participated in the usability tests and the others never had heard of it before. Their education level was similar to the elderly involved in the usability tests.

\subsubsection{Method}

For these tests it was very important to have the participant's full attention on all tasks. A more peaceful, quiet and controlled environment than the one used on the previous test phase was preferable. Fortunately, Fraunhofer Portugal had the perfect facility for this task: a full apartment (with living room, bedroom and bathroom) meant for testing purposes, only. Within the flat, we could simulate a real situation with the maximum possibly realism.

The goal was to simulate the entire process of the system's usage: the patient goes to an appointment in the hospital or clinic, then goes home with both smart-phone and ANT+ devices and, when a scheduled alarm appears on the phone, he measures himself with the corresponding device and sends the values to his physician. Then, on the web application side, a clinician analyses the patient's measurements and sends a feedback message back to the patient. Now back to the patient, he receives that message, reads it and gives an answer to his physician. To finish the process, the patient uses the smart-phone to review his latest measurements.

Because the mobile application was stable enough, we were confident the elderly could use the smart-phone by himself, with minimum help from the test team. So, in each session we gave the smart-phone to the participant and recorded the entire session from three angles: one camera on the living room, another on the bedroom and the last one on the smart-phone itself, recording everything the elderly was doing. By registering 
all sessions, we did not have to be constantly looking after the patient to know what he was doing, resulting in a much more realistic scenario.

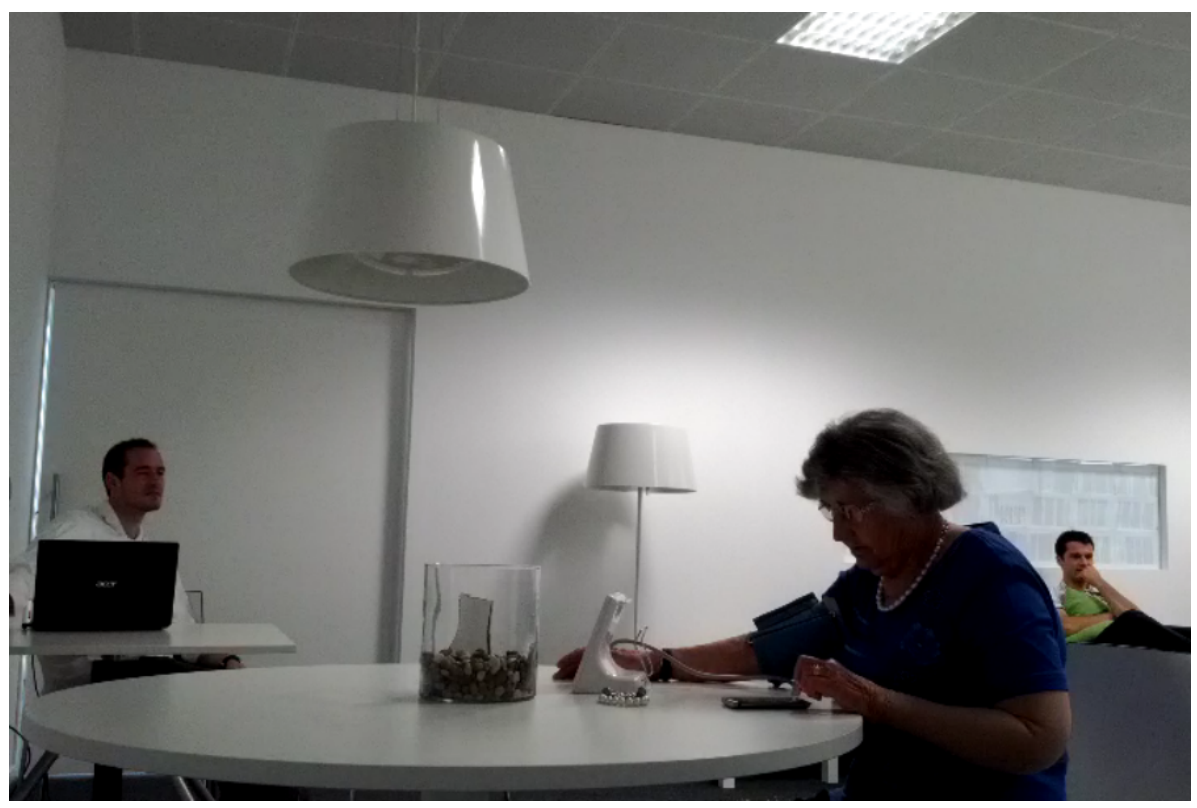

Figure 5.4: Participan Number 5

When a participant was ready to begin, he would enter the apartment and during the next 30 minutes, more or less, the thesis author and his supervisor would be with him inside the flat. The following steps, describe exactly how each session took place:

1. The participant was introduced to the thesis and the prototype system, explaining him what it was and its main advantages. The test team would describe why the test was being made and how it was going to be;

2. Then, we would start a little acting. The participant would go to an appointment held in one corner of the living room - whose physician was an element of the test team. The physician explained the participant that there was a new mobile health kit in the clinic, available for trial, ready for him to bring home and start using it. The physician also asked the patient to measure himself with both devices and send those values back to him, whenever an alarm is received on the smart-phone;

3. Once the previous step was well understood, the patient would "leave the appointment" and take the kit "back home". Go back home was simply to leave that corner of the room. The test team element playing a physician would stay in his "office" for the rest of the session and the other element accompanied the patient more closely;

4. After the patient placed each device in his bedroom (or wherever he preferred to) both the participant and the test team element would sit on the couch, watch some TV and wait for a measurement alarm to pop up; 
5. The physician, still in his "office", would now schedule through the web application, a measurement for the weight device, to be done in the following seconds;

6. Upon receiving the alarm on the smart-phone for reading his weight, the patient would go to where he put the weight scale, measure himself, send the values to his physician and then go back to the couch;

7. Once the values were sent and appeared on the web application, the physician would schedule a measurement once again, this time for the blood pressure monitor;

8. As with the previous measurement, upon receiving the alarm, the patient would pick up his blood pressure monitor, read his blood pressure using the smart-phone, send the values to the physician and go back to the couch;

9. After receiving the blood pressure values on the web application, the physician would then send a feedback message to the patient;

10. As the participant received the message, we would ask him to read it out load and try to answer the physician with the smart-phone;

11. To finish the test, we asked the participant to remind us what were his blood pressure and weight values, using the smart-phone. Most of the times, they had already forgotten what they were.

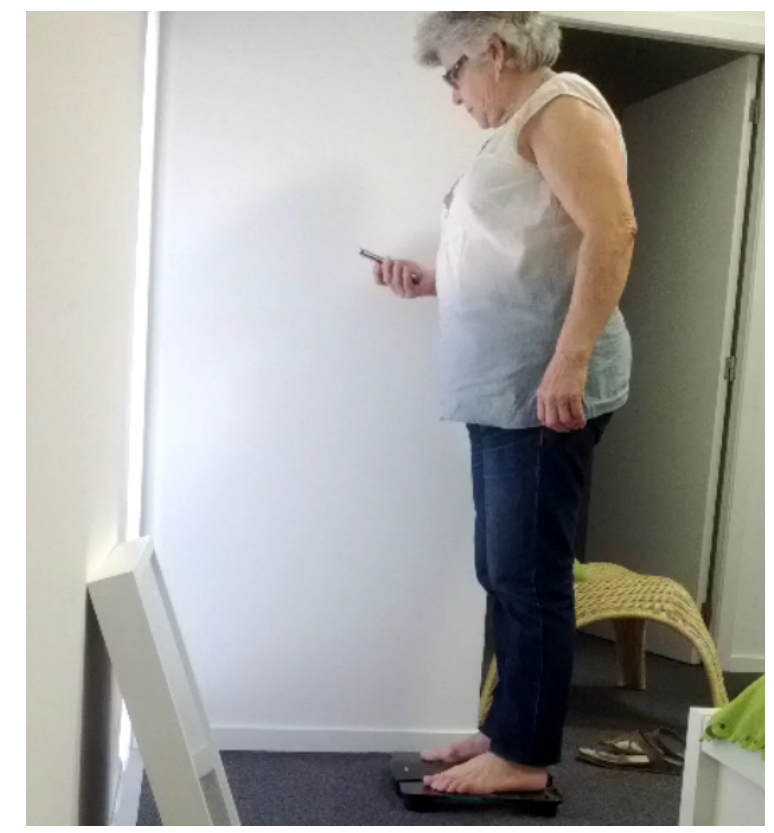

Figure 5.5: Participan Number 1

And it was over. Figure 5.5 and Figure 5.4 show participant number 1 and participant number 5 measuring their weight and blood pressure, respectively. As described before, 
no intervention from our part was required, regarding the usage of the mobile application. Although we would always help if they were getting stuck with some operation. Writing a message back to the physician was not exactly a goal of this test, but more a way to know how they felt about the possibility of writing back to the physician and to see how easy or difficult it was for them to do it. This issue is discussed on the following subsection, about the prototype testing results.

\subsubsection{Results}

Each session was expected to take around 30 minutes and we managed to do so. All testes were made in average, in 29 minutes, with a standard deviation of 5 minutes. The graph presented on Figure 5.6, shows how much time each measurement took, from the moment a participant received an alarm in the smart-phone, to the moment he sent the values to his physician.

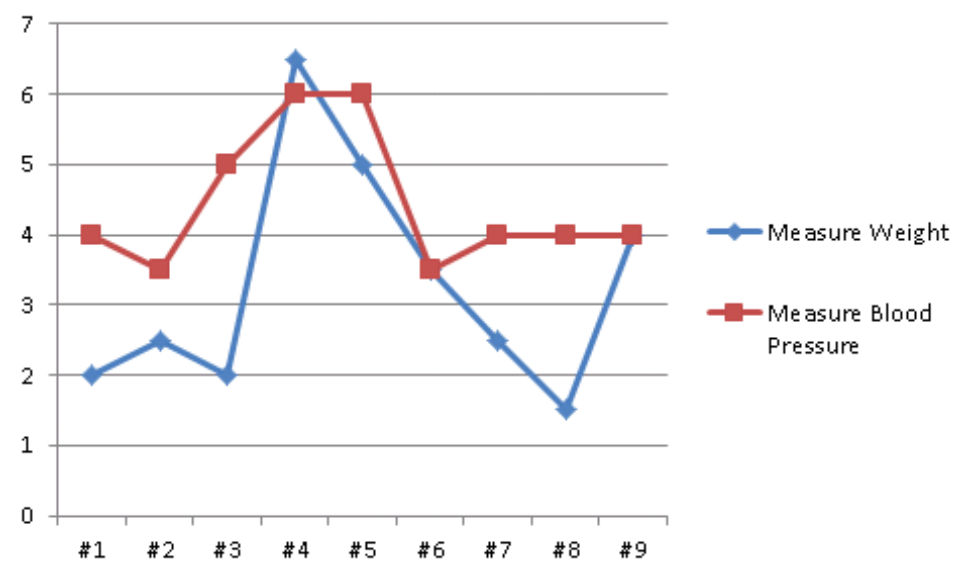

Figure 5.6: Duration of Measure on Prototype Tests

Each blood pressure measurement took in average, almost 4 minutes and 30 seconds, while the weight measurement took in average, 3 minutes and 20 seconds. Looking at the numbers and by comparing these times with the ones taken on the low fidelity usability tests, it can be seen a decrease in the duration of each measure. This proves that, not only the mobile application matched the success of the usability prototypes, but it also made both operations quicker. The slightly peak on participants number 4 and 5 can be explained by those participants clearly difficulties, when comparing to the remaining participants. One of them, was the oldest participant, while the other had a chronic injury in his fingers which ended up modifying the test itself. This last one, could not even write the message to his physician, due to this problem. Nevertheless, even with those difficulties, the participant was able to successfully measure both weight and blood pressure, with the smart-phone application. 
The fact that the weight scale had to be turned on before the participant had to step up, was slowing the weight process in almost every session. This procedure is no different than a common electronic weight scale, however, most of the participants were used to analogue devices and had no idea how it would work. Even though it is thoroughly explained on the mobile application. Nevertheless, all of them told that, these problems would only occur on first usage and if they were to make the test again, it would be much easier and much quicker.

On the remaining tests - reading the feedback message, writing it back to the physician and viewing the latest measurements - several difficulties were found and the times taken on each of them are not conclusive. Regarding reading messages and answering the physician, usually the message was read without much trouble, however the writing of a message had different opinions. Some of them thought it was much easier than their regular phones, others thought it had small buttons and therefore did not like it. It should be remembered that, they typed in the Android default keyboard and no usability tests were made on that. In fact, testing the writing of a message in a smart-phone for the elderly could be another thesis, itself. Regarding the viewing of the latest measurements, they usually had a hard time finding where they could do it. Some modifications were made on the menu item name for that option, throughout the tests. No truly successful word was found, though.

The user-interface used on these tests - reading the feedback message, writing it back to the physician and viewing the latest measurements - was not subject to prior usability tests and, although it followed some guidelines taken from those tests (font type, size, background and text colors, etc.), participants still found some obstacles. These difficulties only prove the importance of making usability tests with the end-users of a system. In fact, during development, several usability questions arose and not having an userinterface prototype to follow with, ended up being much harder than developing the other interfaces. Nevertheless, the big advantage comes to the user, as these tests have shown. 
Tests and Results 


\section{Chapter 6}

\section{Conclusions and Future Work}

\subsection{Thesis Summary}

This thesis started with a research on all areas around the subject being developed here, from similar mobile health systems to the technologies being used. This research is described on chapter 2 . It concluded that, although related projects had already been developed, none of them completely gathered the characteristics being implemented on this one. At the moment of writing this thesis, no project or study was found that combined the ANT+ technology with the Android platform, together with a web application, for health monitoring of the elderly.

Also, chapter 2 reinforced the importance of usability when aiming for the elderly. Then, for a better requirements specification, interviews were conducted with a few medical specialists, bringing a better knowledge on general health care and on the clinicians opinions regarding the system. The system's requirements and architecture were then clearly specified on chapter 3 .

Once the system was thoroughly planned, usability tests were conducted with several elderly, willing to help this thesis. This phase, documented on chapter 5, resulted in userinterface prototypes, ready to be implemented in the mobile application, which was the next phase of this thesis. The mobile application development, started by implementing the ANT+ communication between the available devices - a weight scale and a blood pressure monitor - on the Android smart-phone. Once completed, the mobile application was able to wirelessly connect with both devices. Then, all use-cases previously specified on chapter 3 were implemented. The mobile application was developed under the Android platform, while the web application through the Ruby On Rails application framework. Both implementations are described on chapter 4.

When both mobile and web applications were done, it was time to test the prototype with its end users, the elderly. Similarly to the usability tests previously conducted, several elderly were involved in the tests. These tests were made inside the Fraunhofer Portugal 
facilities and helped evaluate the success of the developed prototype. All the process was documented on chapter 5 .

\subsection{Main Results}

The research done on this thesis indicated that the system being specified in this thesis was a novelty, in terms of the components and technologies in use. ANT+ technology could provide a lighter use of the smart-phone batteries, while keeping the same features available on its competitor - Bluetooth. Also, by looking for similar studies, some features were found to be key for a successful mobile health system, such as the ease of use of the system and the motivation and involvement required from both physicians and patients.

The working prototype developed during the thesis, serves as a proof of concept for the research that was done. Its purpose was to evaluate if that research was reliable and had the potential of being applied to real scenarios.

Looking at the expected goals of this thesis and the main features provided by the working prototype, it is safe to say the main goals were accomplished. As planned, the mobile application is able to seamlessly connect with the ANT+ sensors, store the received values and present them to the patient and also, send those values to a web application. The web application allows the physicians to manage their patients by choosing who they want to monitor, or not, schedule measurement's alarms, sending messages and viewing their measurements history.

It would have been interesting to compare the prototype test results with other projects. For instance, how much time did it take to measure a patient's blood pressure and send the values to a remote server. However, since no studies were found with these type of tasks, no metrics were available for such comparisons.

Special attention to the elderly was also not forgotten and both usability tests and prototype tests were conducted, looking forward to diminish the usual reasons that keep separating older adults from mobile phones.

Regarding the automatic detection of anomalies, referred on the goals section of chapter 1 , it was left aside even before development began, after the clinicians interviews. They reminded that the consequences of warning the patient that something is wrong, without a proper explanation from his clinician, could actually be worse than the original problem itself. As such, although research had already been done on the area, this feature was immediately discarded. Possibly, it could be more useful in an automated scenario, where no measures are made and patients automatically monitor themselves; however, it will have to stay for future work on the area. 
Also, this thesis goals also referred the importance of securing information travelling wirelessly, however, this could not be accomplished, for the available time was not enough.

\subsection{Conclusions}

One of the innovating points of this thesis, was to apply ANT+ devices to health care services and, its usage was proved to be as effective as any other wireless technology, with the advantage of achieving very low costs and power, by today standards. During development, the ANT+ chip was used quite often and still, no significant changes in the battery life of the smart-phone, were noticed. Its current competitor, Bluetooth 4.0, is still integrating with current devices and it is still early to tell which of them is a better choice.

The advantages that may arise from a system like this were visible, through the developed working prototype. The tests participants were all clearly motivated on the work being made and several even asked where they could buy such a product. In the country where this thesis was developed, Portugal, no similar mobile health system has ever been implemented. Their only concern was the cost of buying such devices, which is understandable, given the current economic crisis. Although with the right partnerships and a sensible business model, it may actually become a reality in the near future.

\subsection{Future Work}

Future work on this thesis should start by refining the working prototype. As referred back in chapter 4 , the approach on getting the data from the blood pressure device could be enhanced, as well as implementing the HTTP-Secure protocol, for transferring data from the mobile device to the web server.

Also, conducting prototype tests for the web application, on the physicians point-ofview, would be very important, in order to evaluate the developed prototype. Conducting more usability tests would also be valuable, especially on the user interfaces that were not tested during this thesis.

At the moment of writing this thesis, a paper is being submitted for a conference, in an effort to share the work developed in here. There is also the possibility of integrating the prototype in S4S (Smartphones For Seniors), a Fraunhofer Portugal internal project, that aims for enabling senior users to intuitively learn and master common mobile phone's features. 
Conclusions and Future Work 


\section{References}

$\left[\mathrm{AAF}^{+} 11\right] \quad$ Ademola O. Adesina, Kehinde K. Agbele, Ronald Februarie, Ademola P. Abidoye, and Henry O. Nyongesa. Ensuring the security and privacy of information in mobile health-care communication systems. AOSIS OpenJournals, 107, 2011.

[ACIS ${ }^{+}$10] Pablo Alonso-Coello, Affan Irfan, Ivan Solà, Ignasi Gich, Mario Delgado-Noguera, David Rigau, Sera Tort, Xavier Bonfill, Jako Burgers, and Holger Schunemann. The quality of clinical practice guidelines over the last two decades: a systematic review of guideline appraisal studies. Quality and Safety in Health Care, 19(6):1-7, 2010.

[BHHS07] Erlend Bønes, Per Hasvold, Eva Henriksen, and Thomas Strandenaes. Risk analysis of information security in a mobile instant messaging and presence system for healthcare. International Journal of Medical Informatics, 76(9):677-687, 2007.

[BK07] M. Bachle and P. Kirchberg. Ruby on rails. Software, IEEE, 24(6):105 -108 , nov.-dec. 2007.

$\left[\mathrm{BRM}^{+}\right.$07] Maged N Kamel Boulos, Artur Rocha, Angelo Martins, Manuel Escriche Vicente, Armin Bolz, Robert Feld, Igor Tchoudovski, Martin Braecklein, John Nelson, Gearóid Ó Laighin, Angela Jobes8 Claudio Sdogati Francesca Cesaroni7, Marco Antomarini7, and Mark Kinirons. Caalyx: a new generation of location-based services in healthcare. International Journal of Health Geographics, 6:9, 2007.

[BWTJ11] Maged N Kamel Boulos, Steve Wheeler, Carlos Tavares, and Ray Jones. How smartphones are changing the face of mobile and participatory healthcare: an overview, with example from ecaalyx. BioMedical Engineering OnLine 2011, 2011.

[Com09] IEEE-USA Medical Technology Policy Committee. Technologies for addressing the health care needs of our aging population, November 2009.

[CRP08] V. Chan, P. Ray, and N. Parameswaran. Mobile e-health monitoring: an agent-based approach. Communications, IET, 2(2):223 -230, february 2008.

$\left[\mathrm{CZM}^{+} 11\right]$ Roberta Cozza, Annette Zimmermann, Carolina Milanesi, Hugues J. De La Vergne, Atsuro Sato, CK Lu, David Glenn, Tuong Huy Nguyen, 


\section{REFERENCES}

Sandy Shen, and Anshul Gupta. Market share: Mobile communication devices by region and country, 2q11. Technical report, Gartner, Inc., 2011.

[dKA93] de Klerk A. The right of patients to have access to their medical records: the position in south african law. Med Law, 12:77-83, 1993.

[FP10] Susannah Fox and Kristen Purcell. Chronic disease and the internet. Technical report, Pew Research Center's Internet \& American Life Project, 2010.

[GL07] Valérie Gay and Peter Leijdekkers. A health monitoring system using smart phones and wearable sensors. International Journal of ARM, 8(2), 2007.

[HSN07] Andreas Holzinger, Gig Searle, and Alexander Nischelwitzer. On some aspects of improving mobile applications for the elderly. Access, 4554:923-932, 2007.

[KCW10] A. Kailas, Chia-Chin Chong, and F. Watanabe. From mobile phones to personal wellness dashboards. Pulse, IEEE, 1(1):57 -63, july-aug. 2010.

[KMH11] S. Komatineni, D. MacLean, and S. Hashimi. Pro Android 3. Apress Series. Apress, 2011.

[KN07] R. Kliegman and W.E. Nelson. Nelson textbook of pediatrics. NELSON TEXTBOOK OF PEDIATRICS. Saunders Elsevier, 18 edition, 2007.

[LV04] Binshan Lin and John A. Vassar. Mobile healthcare computing devices for enterprise-wide patient data delivery. Int. J. Mob. Commun., 2:343353, December 2004.

[May00] L. Mayhew. Health and elderly care expenditure in an aging world. Research report (International Institute for Applied Systems Analysis). International Institute for Applied Systems Analysis, 2000.

$\left[\mathrm{MLL}^{+}\right.$08] Maurizio Marzegalli, Maurizio Lunati, Maurizio Landolina, Giovanni B. Perego, Renato P. Ricci, Giuseppe Guenzati, Milena Schirru, Chiara Belvito, Roberto Brambilla, Cristina Masella, Francesca Di Stasi, Sergio Valsecchi, and Massimo Santini. Remote monitoring of crt-icd: The multicenter italian carelink evaluation - ease of use, acceptance, and organizational implications. Pacing Clin Electrophysiol, 31, 2008.

[Mor] Rod Morris. Why ant? http://www.thisisant.com/why-ant.

[Mor93] Morton C. Creditor. Hazards of hospitalization of the elderly. Annals of Internal Medicine, 118(3):219 -223, February 1993. 
[MSJ11] Mladen Milosevic, Michael T. Shrove, and Emil Jovanov. Applications of smartphones for ubiquitous health monitoring and wellbeing management. Journal of Information Technology and Application, 2011.

[Mut09] Natalie Digate Muth. What are the guidelines for percentage of body fat loss? The American Council on Exercise, December 2009.

[Nat04] National Heart, Lung, and Blood Institute. The seventh report of the joint national committee on prevention, detection, evaluation, and treatment of high blood pressure. Technical report, U.S. Department of Health and Human Services, 2004.

[Nat12] National Heart, Lung, and Blood Institute. What are clinical practice guidelines?, February 2012.

[NIC11] Hypertension: Clinical management of primary hypertension in adults. Technical report, National Institute for Health and Clinical Excellence, 2011.

[Nie93] Jakob Nielsen. Usability Engineering. Morgan Kaufmann Publishers Inc., San Francisco, CA, USA, 1993.

[OLZ11] Alex Olwal, Dimitris Lachanas, and Ermioni Zacharouli. Oldgen: mobile phone personalization for older adults. In Proceedings of the 2011 annual conference on Human factors in computing systems, CHI '11, pages 3393-3396, New York, NY, USA, 2011. ACM.

[otDoEotUNS11] Population Division of the Department of Economic and Social Affairs of the United Nations Secretariat. World population prospects: The 2010 revision. Technical report, United Nations, 2011.

[PT85] Jiapu Pan and Willis J. Tompkins. A real-time qrs detection algorithm. Biomedical Engineering, IEEE Transactions on, BME-32(3):230 236, march 1985.

[SAL06] C.N. Scanaill, B. Ahearne, and G.M. Lyons. Long-term telemonitoring of mobility trends of elderly people using sms messaging. Information Technology in Biomedicine, IEEE Transactions on, 10(2):412 -413, april 2006.

[Sen92] C.J. Senger. Thinking Aloud Protocols: A Tool for Teaching. 1992.

[SK10] Jane Sarasohn-Kahn. How smartphones are changing health care for consumers and providers. Technical report, California HealthCare Foundation, 2010.

[SLC $\left.{ }^{+} 12\right] \quad$ Emily Seto, J. Kevin Leonard, A. Joseph Cafazzo, Jan Barnsley, Caterina Masino, and J. Heather Ross. Perceptions and experiences of heart failure patients and clinicians on the use of mobile phone-based telemonitoring. J Med Internet Res, 14(1):e25, Feb 2012. 


\section{REFERENCES}

[SLH ${ }^{+}$07] T. Scott Saponas, Jonathan Lester, Carl Hartung, Sameer Agarwal, and Tadayoshi Kohno. Devices that tell on you: privacy trends in consumer ubiquitous computing. In Proceedings of 16th USENIX Security Symposium on USENIX Security Symposium, SS'07, pages 5:1-5:16, Berkeley, CA, USA, 2007. USENIX Association.

[The12] The Socio-Economic Impact of Mobile Health. Technical report, The Boston Consulting Group and Telenor Group, April, 2012.

[Wie03] Karl Eugene Wiegers. Software Requirements. Microsoft Press, Redmond, WA, USA, 2 edition, 2003. 


\section{Appendix A}

\section{Clinicians Interviews}

\section{Resultados:}

- Hipertensāo será a doença mais facilmente detectada com os sensores disponiveis

- Medidor de glucose p/ diabéticos seria uma excelente adição ao kit!

- Indice de massa corporal (IMC) seria interessante para mostrar progressos

- Nutricionistas poderāo ajudar no diagnóstico dos valores recebidos pela balança

- Possivel integraçāo de um sistema de sugestōes/ajuda ao paciente, antes e após mediçōes.

Figure A.1: Clinician Interview Number 1

\section{Resultados:}

- Valor de pressão arterial por si só é não é conclusivo. É preciso comparar cada valor com o histórico de mediçōes e contexto médico do paciente.

- Para uma mediçāo da pressão arterial ser fiável, deve de ser medida segundo guidelines impostas e nāo em qualquer altura.

- Número de batimentos cardiacos deve ser sempre enviado em conjunto com as medidas de pressão arterial

- Hipertensão é causa de: pouco exercicio, excesso de sal e stress

- Maior conhecimento da doença pela parte dos pacientes é muito importante

- Feedback textual è mais importante que feedback "simbólico"

- Enfermeiros têm um perfil mais adequeado para a utilização deste sistema

- PDF's:

- The Hypertension Team: The Role of the Pharmacist, Nurse, and Teamwork in Hypertension Therapy

- European Society of Hypertension guidelines for blood pressure monitoring at home: a summary report of the Second International Consensus Conference on Home Blood Pressure Monitoring

- Reappraisal of European guidelines on hypertension management: a European Society of Hypertension Task Force document

- Factor segurança nāo é critico (vai pas dropeboxes e ai-cloudes...)

Figure A.2: Clinician Interview Number 2 


\section{Clinicians Interviews}

\section{Resultados:}

- Sistemas actuais focados na monitorização em tempo-real, com aparelhos que acompanham o paciente a tempo inteiro, guardando informação que só é descarregada na consulta médica.

- Possibilidade de registar manualmente as mediçōes, caso nāo haja sensores ANT+

- desvantagem: nāo garante que o paciente poe os valores correctos e obriga a mais uma operaçāo da parte do paciente

- vantagem: não limita a utilização da aplicaçāo a sensores ant+ e permite expandir o sistema a qualquer sensor que possa ser medido em casa pelo paciente

- Alarmes, só do lado da aplicação médica

- Este sistema nāo substitui visitas ao médico

- Existe espaço no mercado para um sistema deste tipo

- Horário de mediçōes configurável

- Mediçōes devem ser feitas durante o horário de trabalho de um enfermeiro - assim o paciente sabe que (em principio) terá uma resposta dentro desse horario

- cada sensor tem o seu conjunto de publico/paciente/doença - alvo. Os processos de medição/diagnostico variam consoante os valores obtidos dos sensores e tipo de monitorizaçāo pretendida

- Triagem das mediçōes efectuada por enfermeiros, medico irá apenas ver a BD/aplicaçāo web nas consultas ou em casos de emergência

- Permitir filtrar por valores normais/anormais, para facilitar a leitura do medico

- Ter graficos bonitos era interessante

- Enfermeiras que visitam os velhinhos regularmente podiam muito bem utilizar este tipo de sistema

- Muito importante nāo complicar operaçōes e processos

Figure A.3: Clinician Interview Number 3 


\section{Appendix B}

\section{Usability Test Script}

Contexto Este projecto pretende criar uma aplicação para um smartphone (um tipo de telemóveis recente, cada vez mais popular), que ajude as pessoas a monitorizar o seu estado de saúde.

O objectivo é que o paciente efectue várias medições na sua própria casa, sem ter de se deslocar a uma clinica ou hospital. Através do seu telemóvel pode enviar esses dados directamente para o médico através da internet. O médico, por seu lado poderá analisar as várias medições dos seus pacientes e contactá-lo de volta, caso seja necessário (por telefone ou enviando mensagens de texto).

Neste momento, ainda estamos a pensar de que forma o sistema vai ser desenvolvido/criado e gostariamos do seu apoio para nos ajudar a entender as necessidades e dificuldades dos utilizadores finais da aplicação - o paciente.

Nomenclatura Gostaria de ouvir a sua opinião sobre alguns termos utilizados na aplicação, para tentar perceber quais as expressões que reconhece mais facilmente e o que é que associa quando pensa nelas.

1. Quando pensa em utilizar uma balança, como diz que o vai fazer? Que expressões pensa serem mais adequadas para esta actividade?

- Pesar

- Pesar-me

- O meu peso

- Quero pesar-me

- Outras?

2. Qual dos termos lhe parece mais comum?

- Pressão arterial

- Tensão arterial

3. Sabe quais os valores normais da pressão arterial? O que é cada um deles?

4. Que nome utiliza para identificar aquilo que mede a pressão arterial?

5. Seguindo a sequência de imagens, qual dos termos lhe parece mais correcto? 
- Regressar / Continuar

- Anterior / Seguinte

- Retroceder / Avançar

- Outras?

Tarefas De seguida iremos testar a usabilidade da aplicação e para tal gostaríamos que tentasse efetuar as seguintes operações com o mínimo de ajuda da nossa parte. Gostaríamos no entanto, que pensasse em voz alta, para tentar entender o seu raciocínio e as suas dificuldades. Relembro que se não conseguir fazer alguma coisa, não se preocupe pois isso significa que a culpa é nossa. As tarefas são:

1. Utilize o telemóvel para medir o seu peso.

2. Utilize o telemóvel para medir a sua pressão arterial. No final, envie essa informação para o médico.

3. Escolhendo o botão "Regressar", qual "destas" 2 interfaces esperava encontrar?

\section{Questionário de satisfação}

- Houve alguma questão que não entendeu nesta aplicação?

- Imagina-se a utilizar este serviço?

- Se pudesse alterar ou acrescentar algo, o que faria?

- Que contactos gostaria de encontrar, nesta aplicação?

- Medicos, familiares, $\mathrm{n}^{\mathrm{o}}$ do hospital ou clínica?

- Gostaria de poder ver o historico de medições na própria aplicação?

- Gostaria de saber quando o seu médico analisou as suas medições?

- E poder ver as mensagens do médico?

- E poder responder, ao médico?

- Tem curiosidade em saber o significado dos valores da pressão arterial ou da balança?

- Gostaria de aprender mais sobre a prevenção de doenças?

- E fazê-lo nesta aplicação?

\section{FIM! Muito obrigado pela sua ajuda e participação!}




\section{Appendix C}

\section{Usability Test Results}

\begin{tabular}{|c|c|c|c|c|c|c|c|c|}
\hline \multicolumn{2}{|c|}{ Nome } & Idade & \multicolumn{2}{|c|}{ Escolaridade } & \multicolumn{2}{|l|}{ Local } & Data & \\
\hline \multicolumn{2}{|c|}{ Dona Flor } & 79 anos 4 & \multicolumn{2}{|c|}{$4^{\mathrm{a}}$ classe } & \multicolumn{2}{|c|}{ Centro Social das Antas } & 23 de Março, 2012 & \\
\hline \multicolumn{9}{|c|}{$\begin{array}{l}\text { - Tem hipertensāo } \\
\text { - Mostrou pouco interesse no teste } \\
\text { Nomenclatura }\end{array}$} \\
\hline \multicolumn{2}{|c|}{ Questāo } & \multicolumn{2}{|l|}{ Resultado } & \multicolumn{4}{|l|}{ Notas } & \\
\hline \multicolumn{2}{|l|}{1} & \multicolumn{2}{|l|}{ Pesar } & \multicolumn{4}{|l|}{-} & \\
\hline \multicolumn{2}{|l|}{2} & \multicolumn{2}{|c|}{ Tensāo Arterial } & \multicolumn{4}{|l|}{-} & \\
\hline \multicolumn{2}{|l|}{3} & \multicolumn{2}{|l|}{ Sim } & \multicolumn{4}{|c|}{ Máxima e mínima } & \\
\hline \multicolumn{2}{|l|}{4} & \multicolumn{2}{|l|}{ Sim } & \multicolumn{4}{|c|}{ Reconhece o simbolo \% mas não acha interessante } & \\
\hline \multicolumn{2}{|l|}{5} & \multicolumn{2}{|l|}{ Apito } & \multicolumn{4}{|c|}{ bip ou apito, é indiferente } & \\
\hline \multicolumn{9}{|c|}{ Tarefas } \\
\hline$\#$ & \multicolumn{2}{|l|}{ Tarefa } & \multicolumn{2}{|c|}{ Resultado } & Tempo & \multicolumn{3}{|l|}{ Notas } \\
\hline 1 & \multicolumn{2}{|c|}{$\begin{array}{l}\text { Conseguiu pesar- } \\
\text { se? }\end{array}$} & \multicolumn{2}{|c|}{ Sim } & $\begin{array}{l}7 \\
\text { minutos }\end{array}$ & \multicolumn{3}{|c|}{$\begin{array}{l}\text { "Nao se coloque na balança, por agora" está pequeno. Foi para cima da } \\
\text { balança antes do tempo! Fez alguma confusāo com os botōes } \\
\text { continuar/regressar }\end{array}$} \\
\hline 2 & \multicolumn{2}{|c|}{$\begin{array}{l}\text { Conseguiu medir } \\
\text { pressāo arterial? }\end{array}$} & \multicolumn{2}{|c|}{ Sim } & $\begin{array}{l}15 \\
\text { minutos }\end{array}$ & \multicolumn{3}{|c|}{$\begin{array}{l}\text { Letras estāo pequenas. "Ameno" é palavra confusa. Texto mais abaixo é } \\
\text { menos relevante. Falta a instruçāo "tirar a braçadeira"! }\end{array}$} \\
\hline 3 & \multicolumn{2}{|c|}{$\begin{array}{l}\text { Conseguiu } \\
\text { efectuar } \\
\text { chamada? }\end{array}$} & Sir & & - & Contactos dos fa & amiliares? Sim. Conta & actos da clinica? nāo. \\
\hline$Q$ & estōes & & & & & & & \\
\hline & gnificad & lo do botāo $\mathrm{F}$ & Regr & essar & & Voltar à pagina im & lediatamente anterior & \\
\hline & staria c & de ter o histor & orico & das med & içōes? | & Nāo & & \\
\hline
\end{tabular}

Figure C.1: Test Participant Number 1 


\section{Usability Test Results}

\begin{tabular}{|c|c|c|c|c|}
\hline \multicolumn{2}{|l|}{ Nome } & Idade & Escolaridade & Local \\
\hline \multicolumn{2}{|c|}{ Dona Celeste } & 81 anos 4 & $4^{a}$ classe & Centro de Convivio do Bo \\
\hline $\begin{array}{r}\text { - Ter } \\
\text { - Mo } \\
\text { Nomencl }\end{array}$ & $\begin{array}{l}\text { m hip } \\
\text { ostrou } \\
\text { latura }\end{array}$ & $\begin{array}{l}\text { ertensāo } \\
\text { pouco inte }\end{array}$ & eresse no teste & \\
\hline Questāo & \multicolumn{2}{|c|}{ Resultado } & \multicolumn{2}{|l|}{ Notas } \\
\hline 1 & \multicolumn{2}{|c|}{ Quero pesar } & \multicolumn{2}{|l|}{-} \\
\hline 2 & \multicolumn{2}{|c|}{ Tensāo Arterial } & \multicolumn{2}{|c|}{ Nāo sabe o que significam os valores } \\
\hline 3 & \multicolumn{2}{|l|}{ Sim } & \multicolumn{2}{|c|}{ Máxima e mínima } \\
\hline 4 & \multicolumn{2}{|l|}{ Sim } & \multicolumn{2}{|c|}{ Reconhece o simbolo \% } \\
\hline 5 & \multicolumn{2}{|c|}{ Apito } & \multicolumn{2}{|c|}{ bip nāo Ihe diz nada } \\
\hline
\end{tabular}

\section{Tarefas}

\begin{tabular}{|c|c|c|c|c|}
\hline$\#$ & Tarefa & Resultado & Tempo & Notas \\
\hline 1 & $\begin{array}{l}\text { Conseguiu } \\
\text { pesar-se? }\end{array}$ & Sim & 6 minutos & $\begin{array}{l}\text { "Nao ve o botāo continuar" - nāo percebe que tem de se pesar. Confundiu-se } \\
\text { com o "regressar" }\end{array}$ \\
\hline 2 & $\begin{array}{l}\text { Conseguiu } \\
\text { medir } \\
\text { pressāo } \\
\text { arterial? }\end{array}$ & Sim & 7 minutos & $\begin{array}{l}\text { Nāo percebeu que tinha de se medir a si propria. Conseguiu perceber que tinha } \\
\text { de carregar no start. Faltou tirar a braçadeira sozinha. Queria pressionar no } \\
\text { botāo "Regressar" depois de ter os valores da tensāo no leitor. }\end{array}$ \\
\hline 3 & $\begin{array}{l}\text { Conseguiu } \\
\text { efectuar } \\
\text { chamada? }\end{array}$ & Sim & $\begin{array}{l}5 \\
\text { segundos }\end{array}$ & Gostava de ter o contacto do médico \\
\hline
\end{tabular}

\section{Questōes}

\begin{tabular}{|l|l|}
\hline Significado do botāo Regressar & Voltar à pagina imediatamente anterior \\
\hline Gostaria de ter o historico das mediçōes? & Nāo \\
\hline Gostava de ver feedback (mensagens) do médico? & Sim \\
\hline Interesse em aprofundar doenças médicas? & Nāo \\
\hline
\end{tabular}

Figure C.2: Test Participant Number 2 


\section{Usability Test Results}

\begin{tabular}{|l|l|l|l|l|l|}
\hline Nome & Idade & Escolaridade & Local & Data & Passado Clinico \\
\hline $\begin{array}{l}\text { Sr. } \\
\text { Baptista }\end{array}$ & $\begin{array}{l}73 \\
\text { anos }\end{array}$ & $12^{\circ}$ Ano & $\begin{array}{l}\text { Centro de Convivio da Gruta da Arca } \\
\text { D'Água }\end{array}$ & $\begin{array}{l}27 \text { de Março, } \\
2012\end{array}$ & $\begin{array}{l}\text { Fez uma intervenção ao } \\
\text { coração }\end{array}$ \\
\hline
\end{tabular}

- Tem hipertensão, mas nāo sabia

- Trabalhou numa escola

- Mostrou interesse no teste

\section{Nomenclatura}

\begin{tabular}{|l|l|l|}
\hline Questão & Resultado & Notas \\
\hline 1 & Pesar ou Peso & - \\
\hline 2 & Tensāo Arterial & "Vai medir as tensōes", mas o mais correcto seria "pressāo" \\
\hline 3 & - & - \\
\hline 4 & - & - \\
\hline 5 & - & - \\
\hline
\end{tabular}

\section{Tarefas}

\begin{tabular}{|l|l|l|l|l|}
\hline$\#$ & Tarefa & Resultado & Tempo & Notas \\
\hline 1 & $\begin{array}{l}\text { Conseguiu pesar- } \\
\text { se? }\end{array}$ & Sim & $\begin{array}{l}4 \\
\text { minutos }\end{array}$ & $\begin{array}{l}\text { Pensava que tinha de clicar em cada "item" das instruçōes. Perguntou se } \\
\text { era preciso tirar as meias. Nāo percebe o "Continuar". Nāo percebeu que } \\
\text { tinha de se colocar em cima da balança para se pesar. }\end{array}$ \\
\hline 2 & $\begin{array}{l}\text { Conseguiu medir } \\
\text { pressāo arterial? }\end{array}$ & Sim & $\begin{array}{l}9 \\
\text { minutos }\end{array}$ & $\begin{array}{l}\text { Nāo colocou a braçadeira. Perguntou se tinha de ser o braço direito (como } \\
\text { indica na figura). Perguntou se podia tirar. }\end{array}$ \\
\hline 3 & $\begin{array}{l}\text { Conseguiu efectuar } \\
\text { chamada? (+ } \\
\text { escolher contacto) }\end{array}$ & Sim & $\begin{array}{l}1 \\
\text { minuto }\end{array}$ & Gostava de ter o contacto do médico de familia. \\
\hline
\end{tabular}

\section{Questōes}

\begin{tabular}{|l|l|}
\hline Significado do botāo Regressar & Voltar à pagina imediatamente anterior \\
\hline Gostaria de ter o historico das mediçōes? & Sim \\
\hline Gostava de ver feedback (mensagens) do médico? & Sim \\
\hline Interesse em aprofundar doenças médicas? & Sim \\
\hline
\end{tabular}

Figure C.3: Test Participant Number 3 


\section{Usability Test Results}

\begin{tabular}{|l|l|l|l|l|}
\hline Nome & Idade & Escolaridade & Local & Data \\
\hline Sr. Alcino & 72 anos & $12^{\circ}$ Ano & Centro de Convivio da Gruta da Arca D'Água & 27 de Março, 2012 \\
\hline
\end{tabular}

- Mostrou pouco interesse no teste

Nomenclatura

\begin{tabular}{|l|l|l|}
\hline Questāo & Resultado & Notas \\
\hline 1 & Pesar-me & Começou com "O meu peso" mas mudou de opiniao. \\
\hline 2 & Tensāo Arterial & - \\
\hline 3 & - & - \\
\hline 4 & - & - \\
\hline 5 & Apito & Bip nao diz nada \\
\hline
\end{tabular}

\section{Tarefas}

\begin{tabular}{|l|l|l|l|l|}
\hline \# & Tarefa & Resultado & Tempo & Notas \\
\hline 1 & Conseguiu pesar-se? & Sim & $\begin{array}{l}3 \\
\text { minutos }\end{array}$ & $\begin{array}{l}\text { Perguntou "Qual botāo?", mas chegou lá! Mais tarde, lembrou-se que } \\
\text { tinha de tirar os sapatos. }\end{array}$ \\
\hline 2 & $\begin{array}{l}\text { Conseguiu medir } \\
\text { pressāo arterial? }\end{array}$ & $\begin{array}{l}\text { Não quis } \\
\text { medir a } \\
\text { tensāo }\end{array}$ & $\begin{array}{l}7 \\
\text { minutos }\end{array}$ & $\begin{array}{l}\text { Teve mais dificuldade em ler as instrucçōes do que na tarefa anterior } \\
\text { (letras pequenas). Continuou as instruçōes sem pôr a braçadeira, } \\
\text { tivemos de Ihe relembrar. }\end{array}$ \\
\hline 3 & $\begin{array}{l}\text { Conseguiu efectuar } \\
\text { chamada? (+ escolher } \\
\text { contacto) }\end{array}$ & Sim & $\begin{array}{l}2 \\
\text { minuto }\end{array}$ & $\begin{array}{l}\text { Gostava de ter o contacto dos familiares e médico. Mas os familiares é } \\
\text { mais importante. }\end{array}$ \\
\hline
\end{tabular}

\section{Questōes}

\begin{tabular}{|l|l|}
\hline Significado do botāo Regressar & Voltar ao menu inicial \\
\hline $\begin{array}{l}\text { Houve alguma questāo que nāo } \\
\text { entendeu? }\end{array}$ & Sim. "Confirma enviar para o médico?" Está confuso. \\
\hline $\begin{array}{l}\text { Gostou do que viu e gostaria de } \\
\text { utilizar? }\end{array}$ & Sim \\
\hline $\begin{array}{l}\text { Gostaria de ter o historico das } \\
\text { mediçōes? }\end{array}$ & Nāo \\
\hline $\begin{array}{l}\text { Gostava de ver feedback } \\
\text { (mensagens) do médico? }\end{array}$ & $\begin{array}{l}\text { Sim, feedback é importante. Quanto às mensagens, sim, mas só em situaçōes de } \\
\text { emergência. Responder ao médico, também faz sentido. }\end{array}$ \\
\hline $\begin{array}{l}\text { Interesse em aprofundar } \\
\text { doenças médicas? }\end{array}$ & Nāo tem muito interesse. \\
\hline
\end{tabular}

Figure C.4: Test Participant Number 4 
Usability Test Results

\begin{tabular}{|c|c|c|c|c|c|c|c|c|}
\hline \multicolumn{3}{|c|}{ Nome } & Idade & Escolaridade & \multicolumn{3}{|l|}{ Local } & Data \\
\hline \multicolumn{3}{|c|}{ Dona Carmen } & 68 anos & $7^{\circ}$ Ano de liceu & \multicolumn{3}{|c|}{ Centro de Convivio do Bonfim } & 28 de Março, 2012 \\
\hline \multirow{2}{*}{\multicolumn{9}{|c|}{$\begin{array}{l}\text { - Tem hipertensāo e outro problema de saúde } \\
\text { - Trabalhou num laboratório } \\
\text { Mostrou interesse durante o teste } \\
\text { Nomenclatura }\end{array}$}} \\
\hline & & & & & & & & \\
\hline \multicolumn{2}{|c|}{ Questāo f } & \multicolumn{2}{|c|}{ Resultado } & \multicolumn{2}{|l|}{ Notas } & & & \\
\hline \multicolumn{2}{|l|}{1} & \multicolumn{2}{|c|}{ O meu peso } & \multicolumn{2}{|l|}{-} & & & \\
\hline \multicolumn{2}{|l|}{2} & \multicolumn{2}{|c|}{ Tensāo Arterial } & \multicolumn{2}{|l|}{-} & & & \\
\hline \multicolumn{2}{|l|}{3} & \multicolumn{2}{|l|}{-} & \multicolumn{2}{|l|}{-} & & & \\
\hline \multicolumn{2}{|l|}{4} & \multicolumn{2}{|l|}{-} & \multicolumn{2}{|l|}{-} & & & \\
\hline \multicolumn{2}{|c|}{5} & \multicolumn{2}{|l|}{ Bip } & \multicolumn{2}{|c|}{ "Parece mais um bip" } & & & \\
\hline \multicolumn{9}{|c|}{ Tarefas } \\
\hline \multicolumn{5}{|c|}{ \# Tarefa } & \begin{tabular}{|l|l} 
Resultado & \\
\end{tabular} & Tempo & \multicolumn{2}{|l|}{ Notas } \\
\hline 1 & \multicolumn{4}{|c|}{ Conseguiu pesar-se? } & $\operatorname{Sim}$ & $\begin{array}{l}5 \\
\text { minutos }\end{array}$ & \multicolumn{2}{|l|}{ Com ajuda } \\
\hline 2 & Conses & guiu $n$ & medir press & sāo arterial? & Sim & \begin{tabular}{l|l}
6 & \\
minutos
\end{tabular} & $\begin{array}{l}\text { Dificuldade } \\
\text { valores do le }\end{array}$ & $\begin{array}{l}\text { em colocar a braçadeira. Ficou atenta aos } \\
\text { eitor. "E agora que faço aqui?" }\end{array}$ \\
\hline 3 & $\begin{array}{l}\text { Conse } \\
\text { escolhe }\end{array}$ & $\begin{array}{l}\text { guiu e } \\
\text { ler con }\end{array}$ & $\begin{array}{l}\text { fectuar ch } \\
\text { itacto) }\end{array}$ & lamada? (+ & Sim & \begin{tabular}{l|l}
$<1$ & \\
minuto & 1
\end{tabular} & Médico e fan & milia \\
\hline Qu & Iestōes & & & & & & & \\
\hline & gnificad & do do & ootāo Regr & ressar & & Volta par & ra $o$ anterior & \\
\hline & ouve alg & guma & questāo qu & ue nāo entend & eu? & Nāo & & \\
\hline & ostou do & o que & viu e gosta & aria de utilizar & & Sim & & \\
\hline & ostaria d & de ter & o historico & das mediçōes & & Sim & & \\
\hline & ostava d & de ver & feedback ( & (mensagens) & do médico? & Sim & & \\
\hline & teresse & em ap & rofundar d & doenças médi & cas? & Sim & & \\
\hline
\end{tabular}

Figure C.5: Test Participant Number 5 


\section{Usability Test Results}

\begin{tabular}{|l|l|l|l|l|}
\hline Nome & Idade & Escolaridade & Local & Data \\
\hline Sr. Américo & 63 anos & $4^{\circ}$ Classe & Centro de Convivio do Bonfim & 28 de Março, 2012 \\
\hline
\end{tabular}

- Tem hipertensão. Jả teve vários problemas de saúde - AVC e enfartes. (Teve uma incompatiblidade ca médica)

- Mostrou interesse durante o teste. Perguntou como é que o aparelho sabia o número da médica

Nomenclatura

\begin{tabular}{|l|l|l|}
\hline Questão & Resultado & Notas \\
\hline 1 & Quero pesar & - \\
\hline 2 & Pressão Arterial & - \\
\hline 3 & - & - \\
\hline 4 & - & - \\
\hline 5 & - & Não ouviu o bip da balança. Não trouxe o aparelho \\
\hline
\end{tabular}

Tarefas

\begin{tabular}{|l|l|l|l|l|}
\hline \# & Tarefa & Resultado & Tempo & Notas \\
\hline 1 & Conseguiu pesar-se? & Sim & 2 minutos & - \\
\hline 2 & $\begin{array}{l}\text { Conseguiu medir pressāo } \\
\text { arterial? }\end{array}$ & $\operatorname{Sim}$ & - & $\begin{array}{l}\text { Colocou bem a baçadeira (tem uma em casa). Nāo } \\
\text { percebeu o que era o "leitor de pressāo arterial" }\end{array}$ \\
\hline 3 & $\begin{array}{l}\text { Conseguiu efectuar chamada? (+ } \\
\text { escolher contacto) }\end{array}$ & Sim & $\begin{array}{l}5 \\
\text { segundos }\end{array}$ & Médico e familia (para estar a par da situação) \\
\hline
\end{tabular}

\section{Questōes}

\begin{tabular}{|l|l|}
\hline Significado do botāo Regressar & Volta para o anterior \\
\hline Houve alguma questāo que nāo entendeu? & Nāo \\
\hline Gostou do que viu e gostaria de utilizar? & Sim \\
\hline Gostaria de ter o historico das mediçōes? & Sim \\
\hline Gostava de ver feedback (mensagens) do médico? & Sim \\
\hline Interesse em aprofundar doenças médicas? & Sim. Interesse em saber significado das tensōes \\
\hline
\end{tabular}

Figure C.6: Test Participant Number 6 
Usability Test Results

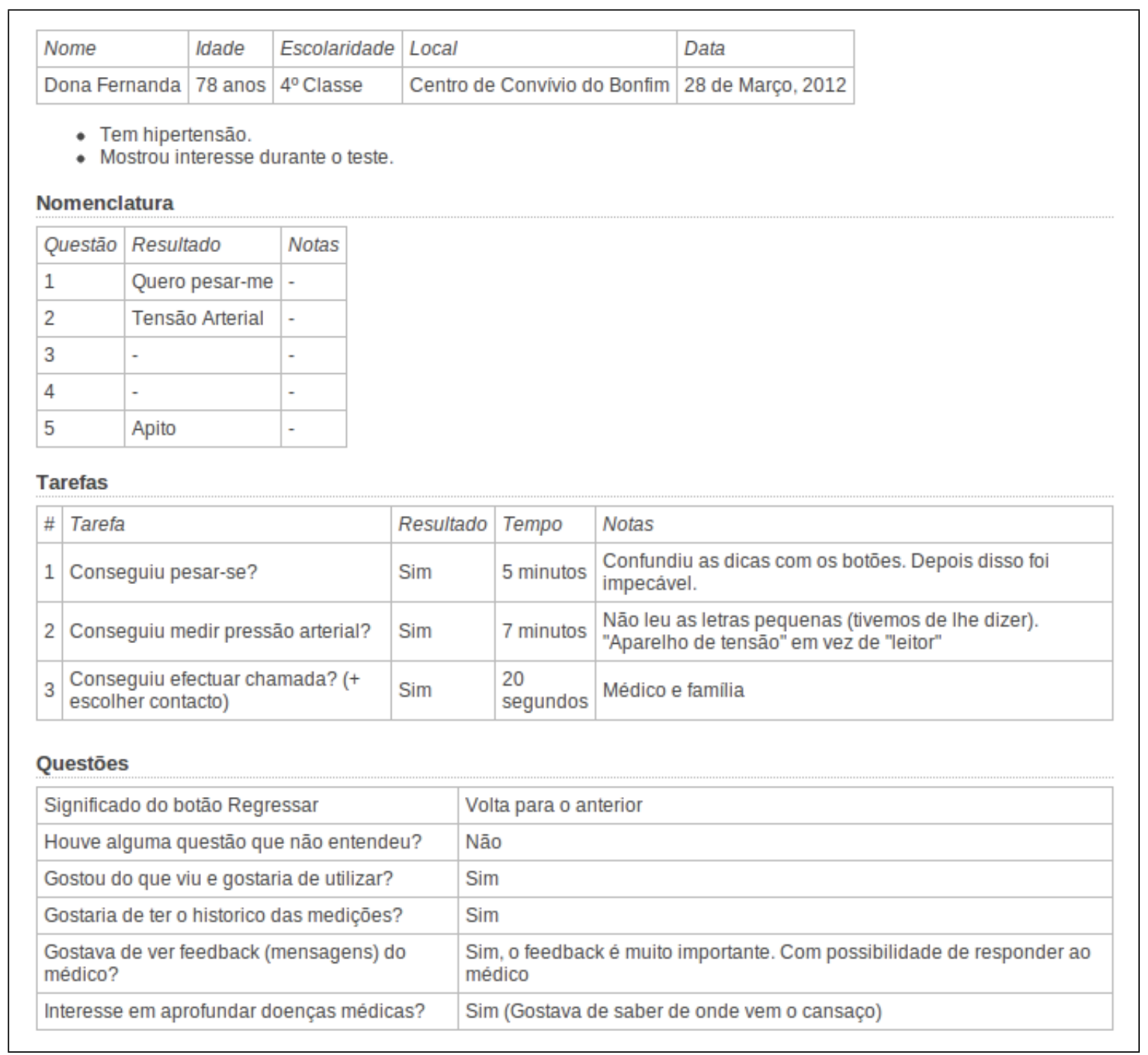

Figure C.7: Test Participant Number 7 


\section{Usability Test Results}

\begin{tabular}{|c|c|c|c|c|c|c|c|c|c|}
\hline \multicolumn{2}{|c|}{ Nome } & Idade & \multicolumn{2}{|c|}{ Escolaridade } & \multicolumn{3}{|c|}{ Local } & Data & Passado Clinico \\
\hline \multicolumn{2}{|c|}{ Sr. Jose } & 62 Anos & \multicolumn{2}{|l|}{-} & \multicolumn{3}{|c|}{ Centro de Convivio da Gruta da Arca D'Água } & 29 de Março, 2012 & - \\
\hline \multicolumn{10}{|c|}{$\begin{array}{l}\text { - Esta familiarizado com a informática } \\
\text { - Mostrou interesse no teste }\end{array}$} \\
\hline \multicolumn{10}{|c|}{ Nomenclatura } \\
\hline \multicolumn{3}{|c|}{ Questāo } & \multicolumn{3}{|c|}{ Resultado } & Notas & & & \\
\hline \multicolumn{3}{|l|}{1} & \multicolumn{3}{|l|}{ Pesar } & - & & & \\
\hline \multicolumn{3}{|l|}{2} & \multicolumn{3}{|c|}{ Tensāo Arterial } & - & & & \\
\hline \multicolumn{3}{|c|}{ Nome do aparelho } & \multicolumn{3}{|c|}{ Medidor de tensāo } & & & & \\
\hline \multicolumn{3}{|c|}{ Botōes de controlo } & \multicolumn{3}{|c|}{ Continuar / Anterior } & & & & \\
\hline \multicolumn{10}{|c|}{ Tarefas } \\
\hline$\#$ & \multicolumn{2}{|l|}{ Tarefa } & Resultado & \multicolumn{2}{|c|}{ Tempo } & \multicolumn{4}{|c|}{ Notas } \\
\hline 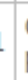 & \multicolumn{2}{|c|}{$\begin{array}{l}\text { Conseguiu } \\
\text { pesar-se? }\end{array}$} & Sim & \multicolumn{2}{|c|}{$\begin{array}{l}2 \\
\text { minutos }\end{array}$} & \multicolumn{4}{|l|}{ Sem ajuda } \\
\hline 2 & \multicolumn{2}{|c|}{$\begin{array}{l}\text { Conseguiu } \\
\text { medir } \\
\text { pressāo } \\
\text { arterial? }\end{array}$} & Sim & $\begin{array}{l}7 \\
\operatorname{mint}\end{array}$ & utos & $\begin{array}{l}\text { (quase) Sem } \\
\text { valores. Nāo } \\
\text { escolher uma }\end{array}$ & $\begin{array}{l}\text { 1 ajuda. Confundiu-se com a c } \\
\text { percebeu que tinha de clicar } \\
\text { as das } 3 \text { opçōes, que são pas }\end{array}$ & $\begin{array}{l}\text { opçāo de ligar com o } \\
\text { r no "Continuar". Pens } \\
\text { ssos. Percebeu o retir }\end{array}$ & $\begin{array}{l}\text { facto de enviar os } \\
\text { ssava que tinha de } \\
\text { irar a braçadeira. }\end{array}$ \\
\hline & lestōes & & & & & & & & \\
\hline & ontactos & & & & & & Médico de familia & & \\
\hline & ostaria c & de ter 0 & historico das & as mer & diçōes & & Sim & & \\
\hline & ostava o & de ver fe & eedback (me & ensag & gens) & do médico? & Sim (estado da mediçāo + m & nensagens do medicc & \\
\hline & teresse & em apr & ofundar doe & enças & médic & cas? & Sim & & \\
\hline
\end{tabular}

Figure C.8: Test Participant Number 8 
Usability Test Results

\begin{tabular}{|c|c|c|c|c|c|c|c|c|c|}
\hline \multicolumn{2}{|c|}{ Nome } & Idade & \multicolumn{2}{|c|}{ Escolaridade } & \multicolumn{3}{|c|}{ Local } & Data & $\begin{array}{l}\text { Passado } \\
\text { Clinico }\end{array}$ \\
\hline \multicolumn{2}{|c|}{$\begin{array}{l}\text { Sr. } \\
\text { Fernando }\end{array}$} & $\begin{array}{l}69 \\
\text { Anos }\end{array}$ & \multicolumn{2}{|c|}{$\begin{array}{l}2^{\circ} \text { Ano do } \\
\text { Liceu }\end{array}$} & \multicolumn{3}{|c|}{$\begin{array}{l}\text { Centro de Convivio da Gruta da Arca } \\
\text { D'Água }\end{array}$} & $\begin{array}{l}29 \text { de } \\
2012\end{array}$ & - \\
\hline \multicolumn{10}{|c|}{ - Mostrou interesse no teste } \\
\hline \multicolumn{3}{|c|}{ Questāo } & \multicolumn{2}{|c|}{ Resultado } & Notas & & & & \\
\hline \multicolumn{3}{|l|}{1} & \multicolumn{2}{|c|}{ O meu peso } & - & & & & \\
\hline \multicolumn{3}{|l|}{2} & \multicolumn{2}{|c|}{ Tensāo Arterial } & - & & & & \\
\hline \multicolumn{3}{|c|}{ Nome do aparelho } & \multicolumn{2}{|c|}{ Medidor de tensōes } & & & & & \\
\hline \multicolumn{3}{|c|}{ Botōes de controlo } & \multicolumn{2}{|c|}{ Seguinte / Retroceder } & & & & & \\
\hline \multicolumn{10}{|c|}{ Tarefas } \\
\hline$\#$ & \multicolumn{3}{|l|}{ Tarefa } & Resultado & \multicolumn{2}{|l|}{ Tempo } & \multicolumn{3}{|l|}{ Notas } \\
\hline 1 & \multicolumn{3}{|c|}{ Conseguiu pesar-se? } & Sim & \multicolumn{2}{|c|}{2 minutos } & \multicolumn{3}{|c|}{$\begin{array}{l}\text { Pensava que tinha de escolher umas das opçōes, que } \\
\text { sāo passos. }\end{array}$} \\
\hline 2 & \multicolumn{3}{|c|}{$\begin{array}{l}\text { Conseguiu medir pressāo } \\
\text { arterial? }\end{array}$} & Sim & \multicolumn{2}{|c|}{$\begin{array}{l}\text { (divagou sobre o } \\
\text { assunto) }\end{array}$} & \multicolumn{3}{|c|}{$\begin{array}{l}\text { Nāo percebeu que tinha de usar a máquina. Nāo viu c } \\
\text { retirar a braçadeira. }\end{array}$} \\
\hline \multicolumn{10}{|c|}{ Questōes } \\
\hline & ontactos & & & & & Médico d & amilia e hospi & & \\
\hline & gnificado & o botāc & Regressa & & & Voltar à p & gina imediatan & nterior & \\
\hline & staria de & ro his & torico das & mediçōes? & & Sim & & & \\
\hline & stava de & er feed & Iback (men & sagens) do & nédico? & Sim & & & \\
\hline & teresse e & aprofu & ndar doen & fas médicas & & Sim & & & \\
\hline
\end{tabular}

Figure C.9: Test Participant Number 9 
Usability Test Results 


\section{Appendix D}

\section{Prototype Test Script}

Contexto Antes de mais, muito obrigado por vir até às nossas instalações, a sua presença é uma grande ajuda para o nosso trabalho.

Este trabalho foi desenvolvido no contexto de uma tese de mestrado, tendo como objectivo criar uma aplicação para um smartphone - um tipo de telemóveis recente, mas cada vez mais popular - que ajude as pessoas a monitorizar de uma melhor forma o seu estado de saúde.

O objectivo é que o paciente efectue várias medições na sua própria casa, sem ter de se deslocar a uma clinica ou hospital. Através do seu telemóvel pode enviar esses dados directamente para o médico através da internet. O médico, por seu lado poderá analisar as várias medições dos seus pacientes e contactá-lo de volta, caso seja necessário.

Portanto, um caso típico de utilização deste sistema é o seguinte. O paciente visita o seu médico, que por sua vez aconselha a utilização desta aplicação. Caso o paciente escolha adoptar este sistema, poderá então levar os aparelhos para sua casa e efectuar as medições ao longo do tempo. Estas medições podem ser agendadas pelo médico, por exemplo às $14 \mathrm{~h}$ de três em três dias, e o paciente irá receber alarmes no seu telemóvel sempre que uma medição esteja agendada. Ao receber este alarme, o paciente efectua a medição e o seu resultado é enviado para o médico imediatamente, pela Internet. Por sua vez, o médico pode ver estas medições a qualquer altura e, caso queira, pode enviar uma mensagem de texto para o paciente. Sempre que receber uma mensagem do médico, o paciente é notificado, podendo também responder através do seu telemóvel.

De seguida, pretendemos testar a nossa aplicação procurando recriar ao máximo um ambiente típico de utilização da mesma.

Tarefas Imagine que está a visitar numa consulta e eu, como médico, lhe digo o seguinte:

O nosso hospital tem um novo serviço para monitorizar a sua dos nossos pacientes e o senhor (a) é o primeiro a ter a possibilidade de o experimentar. Por favor, leve estes aparelhos para casa e quando receber um alarme, efectue a respectiva medição e envie os valores para mim.

Agora imagine que já regressou a casa e tem os dois aparelhos no seu quarto. Entretanto irá receber os alarmes no telemóvel e quando isso acontecer:

- Efectue a medição que lhe é pedida

Portanto, sinta-se completamente à vontade em andar pela casa e se tiver alguma dúvida, não hesite em perguntar. No entanto, como estamos a recriar um ambiente típico, 
gostaríamos que tentasse efetuar as tarefas com o mínimo de ajuda da nossa parte. Relembro que se não conseguir fazer alguma coisa, não se preocupe nem tenha receio de o dizer. Isso significa que a a aplicação que criamos não está explicita o suficiente ou demasiado complicada e então o erro será nosso, não seu.

depois de fazer as duas medições...

Agora que já efectuou as medições, sabendo que pode revê-las no telemóvel:

- Diga-nos quanto pesa e qual a sua tensão arterial

Tal como tinha-mos referido, o médico poderá enviar-lhe mensagens depois de ver as suas medições, portanto vamos aguardar que ele as veja e lhe envie uma mensagem. Quando isso acontecer:

- Diga-nos qual a mensagem que o médico lhe enviou

- Responda ao médico

\section{Questionário de satisfação}

- Houve alguma questão que não entendeu nesta aplicação?

- Imagina-se a utilizar este serviço?

- Se pudesse alterar ou acrescentar algo, o que faria?

FIM! Muito obrigado pela sua ajuda e participação! 


\section{Appendix E}

\section{Prototype Test Results}

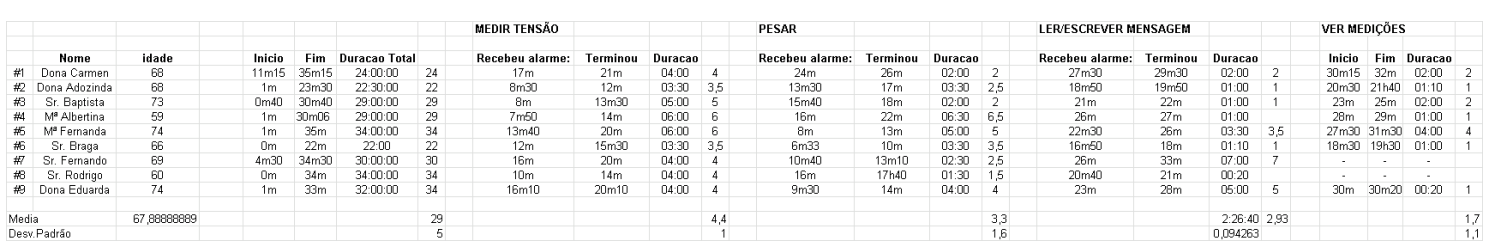

Figure E.1: Prototype Test Results

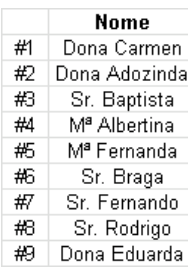

NOTAS

Erro tecnico nos alarmes do pesar, mas depois correu bem

Carregou no botẫo start antes do tempo. Precisou de ajuda na balança. Para mensagens, achou mais falcil que o telemóvel dela Foi para cima da balança cedo de mais, mas leu novamente e conseguiu fazer correctamente, sem ajuda

Não consegue escrever mensagens, problema nos dedos

Boa prestacao

Boa prestacao

Mediu a tensao 2 vezes, escreveu uma mensagem gigante e acabou por nẵo ver as ultimas mediçőes

Não enviou mensagem nem viu ultimas mediçổes. Mediu tensão 3 vezes

Começou a inventar nas mensagens

Figure E.2: Task Notes 